THE BATTLE WITHIN: A MIXED METHODS EXPLORATION INTO POLITICAL JOURNALISM AND ROLE STRAIN

A Dissertation
presented to
the Faculty of the Graduate School
at the Univeristy of Missouri-Columbia
In Partial Fulfillment
of the Requirements for the Degree
Doctor of Philosophy
by
KIMBERLY KELLING
Dr. Ryan J. Thomas, Dissertation Supervisor
MAY 2018


The undersigned, appointed by the dean of the Graduate School, have examined the dissertation entitled

\section{THE BATTLE WITHIN: A MIXED METHODS EXPLORATION INTO POLITICAL} JOURNALISM AND ROLE STRAIN

presented by Kimberly Kelling,

a candidate for the degree of doctor of philosophy,

and hereby certify that, in their opinion, it is worthy of acceptance.

Dr. Ryan J. Thomas

Dr. Tim P. Vos

Dr. Yong Volz

Dr. Ben Warner

Dr. Debbie S. Dougherty 


\section{ACKNOWLEDGEMENTS}

The road to my dissertation has been rewarding, challenging, and long, but it has certainly not been lonely. There are many people I would like to recognize and thank for their help getting me through this accomplishment. First, I could not have done this without the love and support of my gracious husband Ellis. He was always there to help me through challenges by remaining positive and confident in my work. I always will appreciate the effort he put into proofing my manuscripts, as well.

I would also like to thank my brilliant committee for helping me craft and execute a fun, yet important, dissertation. To my advisor and chair, Ryan Thomas, who has been someone that I have looked up to as a mentor, as a scholar, and as a person for the past three years. Thank you for always taking the time to talk me through concerns in my research or just chat about life, in general. To Tim Vos, for always encouraging, supporting, and challenging me. You are a master of media sociology, and your input was always greatly appreciated. To Yong Volz, who reminded me that qualitative research isn't just fun, but also rewarding. I always left your office feeling a renewed sense of purpose in my research and confidence in my work. To Ben Warner, who served as my quantitative guru. Through your classes, I learned more about quantitative analyses than I ever thought was possible! To Debbie Dougherty, for always helping me further develop my conceptions of sensemaking and emotionality. I consider myself incredibly lucky that I was able to take your course on organizational communication. Finally, even though he is not an official committee member on my dissertation, I would like to thank Brett Johnson. You served as both an academic and life coach for me over the past few years. I 
will forever be indebted to you for all of the guidance you gave me in preparing for comprehensive exams and balancing dissertating with life.

I honestly can't imagine going through this process without the support network of my amazing cohort and classmates. Rachel Grant, T.J. Thomson, Keshia Ashley, Vicki Brown, Terry Britt, and Doug Wilbur: I think we had the best cohort of all time! Samuel Tham: Although you left our cohort, I still want to thank you for keeping in touch and being an advocate of my work. I would also like to thank those who have provided feedback on a paper, suggested ideas for teaching, or shared perspectives on the program. This would include: Joy Jenkins, Marina Hendricks, David Wolfgang, Liz Bent, Carlos Cortes-Martinez, Joseph Moore, Dani LaGree, and Kellie Stanfield.

Finally, a big thank you to my family and friends who have helped me get this far. I owe a great deal to my parents who have encouraged me to follow my heart my whole life. Without their support and encouragement, I may not have had the strength to abandon one career in pursuit of another. My incredible friends, parents, and siblings always reminded me that a little fun every once in a while is beneficial in maintaining sanity (@). Last, but not least, thank you to my dog Halle, who made sure I went outside at least three times a day for some fresh air. 
TABLE OF CONTENTS

ACKNOWLEDGEMENTS .............................................................. ii

LIST OF TABLES AND FIGURES ………………………………..... ix

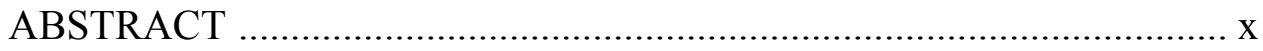

Chapters

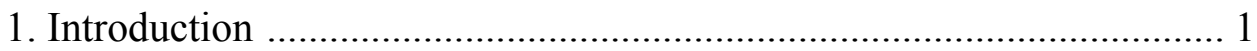

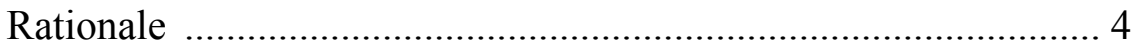

Purpose of the Current Study ........................................................... 6

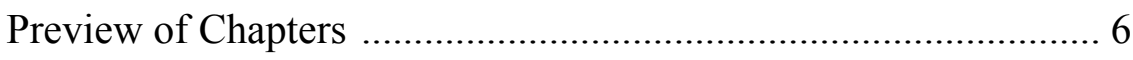

2. Journalism as an Institution ………………………......................... 8

Journalism in Democracy .......................................................... 10

Democratic requirements of the press .............................. 12

Functions of the U.S. Press System ………………………….... 15

Identification of journalistic roles .................................... 19

Internalization and Enactment of Journalistic Roles ................... 23

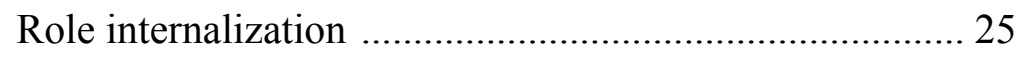

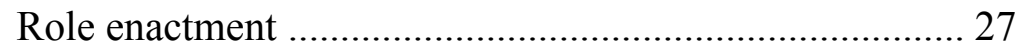

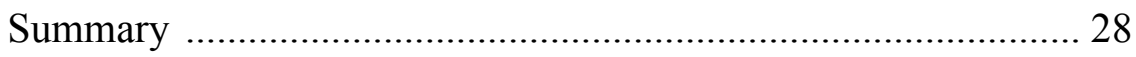

3. Factors of Influence in Role Internalization \& Role Enactment .......... 30

Factors that Challenge Cognitive Roles ....................................... 30

Micro-level factors ………………………………….. 32

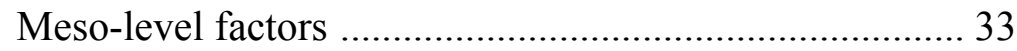

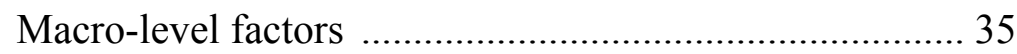


Summary 35

Role Conflict and the Sensemaking Process ................................ 36

The sensemaking process and emotionality in role internalization and enactment ................................... 37

Emotion and the American journalist ................... 38

Present Study and Research Questions ......................................... 43

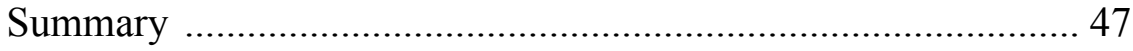

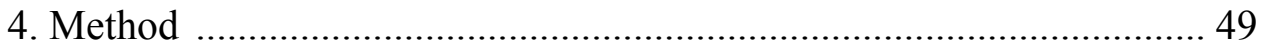

Rationale for Method Selection .................................................... 50

Use of mixed methods in the present study ...................... 53

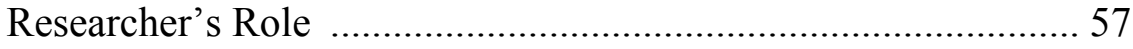

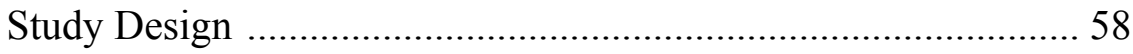

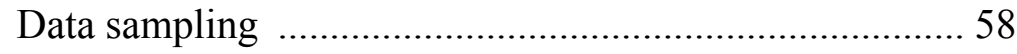

Data collection and management ……………………..... 59

Survey participants ................................................ 61

Quantitative measures ........................................ 62

Role conceptions ……………………….... 63

Influences to role enactment ..................... 63

Emotional labor ………………………..... 63

Qualitative data collection .................................... 64

Interview participants ................................ 64

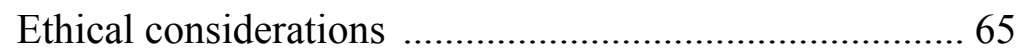

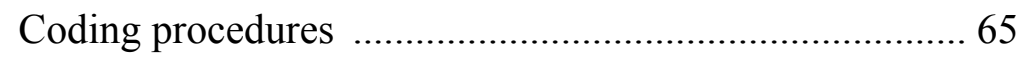

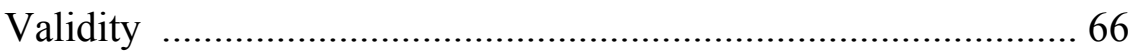


Limitations

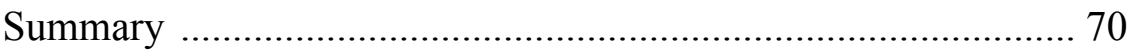

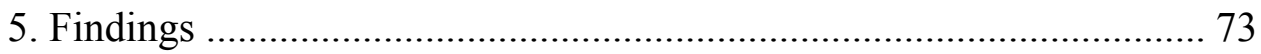

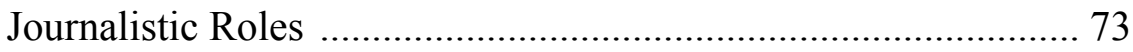

Hierarchy of journalistic roles ......................................... 76

Importance of journalistic roles ....................................... 77

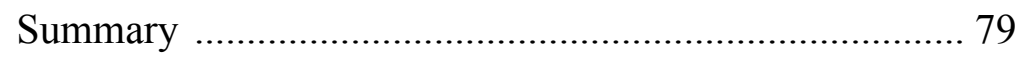

Identifying and Explaining Factors of Influence ……………..... 80

Micro-level factors ............................................................ 83

The journalist as a community member ................ 83

The journalist as a family member ........................ 86

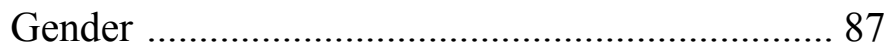

Meso-level factors …………………………………..... 89

Lack of resources ……………………………... 89

Editorial decisions ............................................... 92

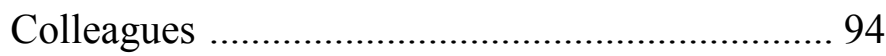

H1: Staff journalists will experience more meso-level challenges than freelance journalists ………………….... 95

Macro-level factors .......................................................... 96

External pressures and accessibility ...................... 96

Culture and technology ........................................ 99

Making Sense of Role Strain .................................................... 100

Reinforcing the real-self/fake-self dichotomy ................ 101

Establishing boundaries ...................................... 101 
A hierarchy of roles 103

Role collaboration 104

Reinforcing their cognitive role 105

Adjusting to new tasks 107

Accepting (or not) limitations 108

Summary 109

Making Sense of Emotion 109

Practicing emotional labor 110

$\mathrm{H} 2$ : Compared to freelance journalists, staff journalists will experience more surface acting and deep acting at work

H3: The longer journalists have been on the job, the less they will experience deep acting and surface acting at work

H4: Female journalists will experience more surface and deep acting than male journalists

Emotions and role strain

Emotion regulation strategies 113

Proactive strategies 114

Avoiding conflicts of interest 114

Compartmentalizing 115

A time and a place 115

Cognitive adjustments 118

Reactive strategies 118

Venting 119

Using work to mask emotion 119 
Exercise …………………………..... 121

Quality checks ........................................ 121

Reframing the situation .......................... 122

Summary ………………………………………….... 123

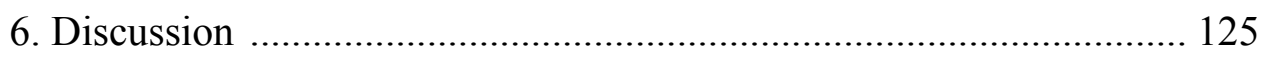

Summary of Major Findings .................................................... 125

Theoretical Implications ........................................................... 135

Practical Implications .............................................................. 143

Limitations and Directions for Future Research ……………..... 145

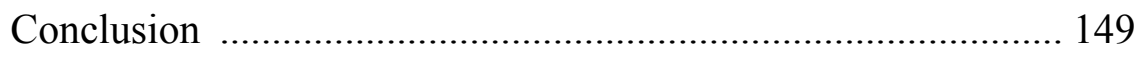

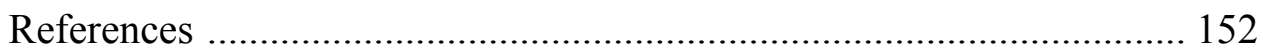

Appendices

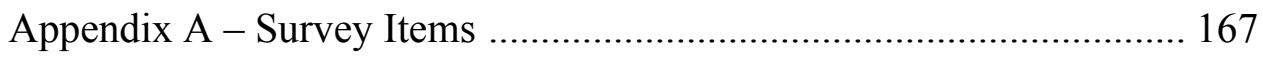

Appendix B - Interview Protocol ....................................................... 170

Appendix C - Survey Recruitment Letter ……………………………... 171

Appendix D - Survey Consent Form ……………………………...... 172

Appendix E - Description of Interview Participants ............................. 173

Appendix F - CFA Model of Journalistic Role Conceptions ................. 174

Appendix G-CFA Model of Challenges to the

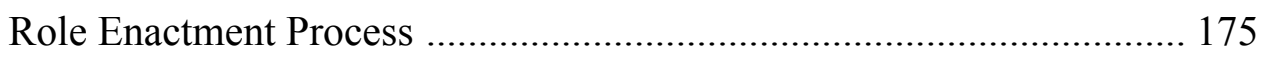

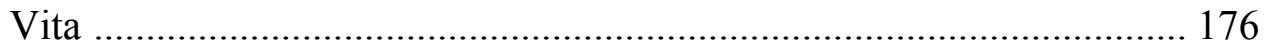




\section{LIST OF TABLES AND FIGURES}

\section{Tables}

Table 1. Functions and Roles of Journalists in Political Life ................ 23

Table 2. Exploratory Factor Analysis of Role Conceptions .................. 75

Table 3. Exploratory Factor Analysis of

Challenges to Role Enactment Process .............................................. 82

Table 4. Regression Coefficients for the

Prediction of Surface and Deep Acting ............................................. 111

Table 5. Emotion Regulation Strategies of U.S. Political Journalists ... 134

\section{Figures}

Figure 1. Qualitatively Driven Sequential

Mixed Methods Design Process .............................................................. 55

Figure 2. Journalists' Sensemaking Process of Role Strain ................. 131

Figure 3. Discursive Construction of Journalistic Roles

(Adapted from Hantizsch \& Vos, 2017) 139 


\title{
THE BATTLE WITHIN: A MIXED METHODS EXPLORATION INTO POLITICAL JOURNALISM AND ROLE STRAIN
}

\author{
Kimberly Kelling \\ Dr. Ryan J. Thomas, Dissertation Supervisor
}

\begin{abstract}
Research into journalistic roles has received world-wide attention. What tends to be underrepresented in these studies are the challenges that journalists must overcome in fulfilling their idealized roles. Therefore, this study uses a theoretical framework that accounts for influences to news production, sensemaking, and emotionality to explore how U.S. political journalists make sense of role strain. By employing a mixed methods design, this study is able to provide both generalizable findings and rich description that supports and expands on quantitative findings. Findings from the survey reveal that political journalists view an informational role as most important to their work, followed by a monitorial role. They also perceive time and money restriction as the biggest limitation to their job. Follow-up interviews with survey participants illustrate that as journalists make sense of challenges to their ideal roles, they interpret each situation by foregrounding their identity as a journalist. Based on their intepretations, they assimilate, reaffirm their ideal roles, or alter their role through a role negotiation process. Additionally, journalists try to proactively and reactively manage affiliated emotions. Findings contribute to understandings of the discursive construction of roles by examining the journalists' sensemaking process surrounding role strain. This study begins to bridge the gap between ideal roles and practice by providing an exploratory examination into the role enactment process.
\end{abstract}




\section{Chapter One: Introduction}

Normative theories of the press are often rooted in the relationship between journalism and democracy (Baker, 2002; Christians, Glasser, McQuail, Nordenstreng, \& White, 2009). In fact, Christians et al. (2009) argue that journalism and democracy are inextricably linked. Democracy denotes a social order that privileges "rule by the many" over "rule by the few" and depends on public participation in community decisions. This requires citizens be free and equal (Christians et al., 2009). It also requires a press that defends and supports the democratic process by fulfilling important functions, such as monitoring those in power, informing the public, and enabling civic discourse. To adequately accomplish these functions, press must be autonomous and capable of covering groups and leaders critically. Without a free press, democracy would cease to flourish (Carey, 1989). But journalistic functions are not just dependent on political systems. As a social institution, journalism operates alongside government, education, and other institutions in society. Every institution adopts particular functions that - in theory - preserve and support its social and political systems.

Normative ideas about press functions make assumptions about the actions journalists should take in covering those external institutions. Political journalists journalists who are assigned to cover electoral politics or local, state, or federal government - are in a privileged position to serve as a liaison between the public and government. The political function of journalism, then, is to serve as the eyes and the ears of the people and ensure that the people's representatives act in the best interests of all (Hodges, 1986). Although a primary function of political reporting is to serve as a check on government, other journalistic functions have included providing interpretation of the 
day's events and communicating the goals and values of society (Commission on Freedom of the Press, 1947). In order to fulfill certain functions in society, journalists play institutionalized roles - or "a composite of occupational tasks and purposes" (Christians et al., 2009, p. 119) - that they learn through education and training and enact in practice.

To date, literature on normative journalistic roles has been expansive (Christians et al., 2009; Hanitzsch, 2007; Hanitzsch \& Vos, 2017, 2018; Mellado, 2015). Within the context of democratic states, normative (or ideal) press roles have been conceptualized in terms of the functions the press must serve in facilitating the democratic process (Christians et al., 2009; Siebert, Peterson, \& Schramm, 1963). These are often stated as general statements about what role(s) journalists should follow. Journalists who are socialized into the institution - that is, socialized into the pattern of practices, behaviors, norms, and routines that constitute what journalism is and how to do journalism (Ryfe, 2006) - internalize specific roles that delineate what journalists ought to do. As journalists internalize some or all of these normative roles, the societal expectation of what journalists should do now becomes the journalists' understanding of what they should do (Hanitzsch \& Vos, 2017). These are referred to as cognitive roles or role conceptions.

In theory, role conceptions serve as a script for journalistic practice. However, journalists do not always practice their cognitive roles (Tandoc, Hellmueller, \& Vos, 2013). In comparing survey results to the results from a content analysis, Tandoc et al. (2013) found that the roles journalists identify with are not always enacted in their work. This is not necessarily surprising, given that journalistic content is a product of several 
levels of influence (Shoemaker \& Reese, 1996). At a macro level, long-held journalistic practices have adjusted to accommodate changes in technology and economy (Siegelbaum \& Thomas, 2016; Singer, 2004), as well as adapted to changes to government and other external fields (Ryfe, 2016). At a meso level, access to resources (Shoemaker \& Vos, 2009), routines, organizational location, profit expectations (Tandoc et al., 2013), and reporter workload (Carpenter, Boehmer, \& Fico, 2016) have been found to influence news production. Even at a micro level, a journalist's personal beliefs, values, background (Shoemaker \& Vos, 2009) and professional experience (Cassidy, 2006; Tandoc \& Takahashi, 2013) may influence the news process. Micro-level factors influence not only journalistic work, but also the perceived challenges to work. Freelancers, for example, may face similar ethical challenges as staff journalists (Jenkins, 2017), but have greater autonomy and flexibility in their job (Jenkins, 2017; Ryan, 2009) that may limit organizational influences. As journalists reflect on workplace influences, these factors shape the ways in which journalists make sense of and negotiate their cognitive roles.

Although research on journalistic roles dates back to the 1960s and 1970s (see, e.g., Cohen, 1963; Johnstone, Slawski, \& Bowman, 1972), the research on how journalists make sense of these factors in thinking about their ideal roles is limited. Recent studies into the role conceptions of journalists seem to privilege survey data (Tandoc et al., 2013; Tandoc \& Takahashi, 2013; Weaver, Beam, Brownlee, Voakes, \& Wilhoit, 2007), while research on practiced roles focuses on textual data (Carpenter et al., 2016; Mellado, 2015). Few studies have attempted to bridge the gap between role conceptions and practiced roles (Tandoc et al., 2013), and fewer studies address why 
ideal roles are not enacted. Although another strand of research has explored the factors that influence news production (Hanitzsch \& Mellado, 2011; Shoemaker \& Reese, 1996; Shoemaker \& Vos, 2009), empirical studies into how factors enable and constrain journalistic work have not been situated in a context of journalistic roles.

When factors at any level of influence inhibit a journalist from practicing in accordance with their ideal roles, or expectations at various levels conflict, journalists experience role strain or role conflict. Although role strain and role conflict have been used in organizational studies using institutional theory (Barnett \& Baruch, 1985; Coverman, 1989; Goode, 1960), studies into how journalists manage conflicting roles or regulate emotions that may come from role strain are greatly underrepresented.

Therefore, the focus of the current study is to bridge the divide between role conception and practiced roles, as well as explore how journalists perceive the competing structures challenging their work, how journalists make sense of their work in light of challenges, and how journalists manage emotions stemming from role strain.

\section{Rationale}

This study focuses on the role enactment process - the process in which a role conception becomes a practiced role (or not) - in order to build a more comprehensive theoretical model of journalistic role construction. Part of this is developing a better understanding of where journalists face challenges to fulfilling their ideal roles, as well as how journalists make sense of their role enactment process in continuously negotiating their conceived roles. This research will help fill the gap in journalistic role literature regarding why journalists feel they are unable to fulfill certain cognitive roles. Methodologically, this dissertation uses a qualitatively-driven mixed methods design that 
allows the researcher to ground the research in the lived experiences of the journalist (Hesse-Biber, Rodriguez, \& Frost, 2015) and provide insights "from the inside" (Singer, 2017, p. 218).

Through the combination of survey and interview data on the role internalization and enactment processes, this study has theoretical and practical implications. Using survey data, this study tested preconceived relationships among journalistic roles, as well as examined the cognitive roles of political journalists and assessed group differences in perceptions of workplace influences and emotional labor. The proposed model of journalistic roles developed through the survey can be beneficial to future research, as it consolidates, refines, and tests previously used survey items. Through the use of followup interviews with survey participants, this study provided a deeper dive into the decisions journalists made in constructing their cognitive roles and the factors they felt influenced the role enactment process. Additionally, findings from this study validate future research into the sensemaking process and emotion regulation strategies of journalists.

Another theoretical implication of this study rests in its contribution to institutional theory in journalism studies. Institutional theory, thus far, has been used to explain similarities across newsrooms and homogeneity in journalistic practice (Cook, 1998; Kaplan, 2006; Sparrow, 1999) or changes across journalism in response to technology and innovation (Lowrey, 2011). This study extends institutional theory in journalism studies to account for structural conflict within the journalistic institution, the influence identity has on role internalization, and the challenges journalists face when fulfilling institutional roles. 
This study also has implications for practice. Findings from this study provide a lens into understanding how journalists made sense of role conflict and emotion in their work. This included identifying the factors that journalists perceived as the greatest challenges to their work. These findings serve as a useful guide to journalism education and training programs that typically do not prepare journalists for such challenges (WahlJorgensen, 2013).

\section{Purpose of the Current Study}

The purpose of this mixed methods study is to explore how micro-, meso-, and macro-level factors conflict with role conceptions of political journalists in the United States. Although editorialists, panelists, critics, and other beat writers also serve important functions in maintaining social interests (Schudson, 2008), this study focuses solely on U.S. political journalists. Political journalism is crucial to a public understanding of, and participation in, the democratic process, but little research has been done to address why political journalists feel they cannot fulfill their ideal roles. Similarly, scholars have addressed how slow-moving causal chains or shocks to journalism's environment challenge the institution and trigger change (Ryfe, 2016), but little has been done to address the more frequent and subtle challenges journalists face when micro, meso, and macro structures conflict.

\section{Preview of Chapters}

In order to build the theoretical groundwork for this study, it is important to understand the function that journalism serves in democracy and how those functions inform journalistic roles. This study then outlines influences that have been predetermined to factor into journalistic work routines and the news production process. 
It also highlights how individuals make sense of their work and how emotions may factor into the sensemaking process. After outlining the theoretical framework for this study, the researcher justifies the selection of a mixed methods approach into research inquiry. In a time of increased complexity within the journalistic institution (Singer, 2017), mixed methods research provides more thorough examinations of complex phenomena that monomethod research cannot provide (Tashakkori \& Teddlie, 1998). Therefore, this study employed a qualitatively-driven sequential mixed methods design. Quantitative data was collected first, enabling the qualitative in-depth interviews to explain and complement quantitative results and reveal subjugated knowledges (Hesse-Biber et al., 2015). In the first phase of the research process, survey data was collected from journalists assigned to a government beat within the U.S. This phase provided generalizable insights into the role conceptions of political journalists and influences in the news production cycle, as well as assisted in defining the sample used in the followup interviews. The second, qualitative, phase helped explain and expanded on the quantitative results. In-depth, semi-structured interviews provided contextual information to journalistic role conceptions, as well as addressed how journalists made sense of role strain. Findings reveal that as journalists made sense of challenges and emotion at work, they privileged rationality and their journalistic identity. Although the journalists may have embraced and valued emotionality, it was usually leveraged as a tool to accomplish a rational end. While this study contributes to theories on journalistic roles, gatekeeping, and emotion, it also serves as the groundwork for future studies into journalism, sensemaking, and emotion. 


\section{Chapter Two: Journalism as an Institution}

The term "news production" tells us that journalism is a process and news is its product. Journalistic activity - such as the interpretation of events, construction of news, and dissemination of content - is guided by overarching normative values, beliefs, ethics, and norms that dictate how journalism should function in society. Journalism may not always be a reliable or consistent process, but understanding it as a human endeavor can help explain why news content can vary from publication to publication. The study of news processes constitutes a branch of media studies called media sociology or the sociology of news.

In media sociology, the news is viewed as a social construction of reality in which multiple actors play a role (Schudson, 2011). These actors may be endogenous or exogenous to the field, but their decisions, behaviors, and discourse help define and shape the journalistic institution (Carlson, 2016). Institutions are recurring "patterns of behavior stitched together as a series of rules" (Ryfe, 2016, p. 371) with unique social structures that cater toward specific spheres (Sewell, 1992), such as religion, education, or journalism. Rules specific to a field are institutionalized over time as resources pool around them, thus becoming routinely reproducedor normalized (Jepperson, 1991).

Within journalism studies, Cook (1998) and Sparrow (1999) pioneered institutional theory to explain the homogeneity of practices they witnessed across news organizations. They argued that routines and practices within journalism have become so ingrained in the institution that journalists at various news outlets follow, either intentionally or unintentionally, similar rules. The rules depicting what journalism is and how to do journalism are premised on normative assumptions about how journalists 
should behave during the news production process (Ryfe, 2016). One such norm, for example, was born out of the press' movement away from partisan media and toward a more socially responsible press in the early twentieth century; "objectivity" became normative operating procedure for journalists, meaning they should follow a consistent method of verifying information free from personal and cultural bias (Kovach \& Rosenstiel, 2014). Nearly fifty years later, Tuchman (1972) found objectivity to be a deep commitment for members in a newsroom. More recently, the concept is still prevalent (Kaplan, 2006) and speaks to a dominant tradition in journalistic culture (Hanitzsch, 2007); journalists across the globe have adopted an approach to journalism that requires themselves to limit their reporting to "empirically observable descriptive 'facts' about what happened, when and where" (Gans, 1972, p. 702).

But why did norms like objectivity become the standard of reporting in the early twentieth century? How did current press practices become so homogenous across news organizations? Deeper inquiry into the normative foundations of journalism is essential to understand the institutionalization of functions, roles, and press practices. After all, Siebert et al. (1963) famously asserted, "the press always takes on the form and coloration of the social and political structures within which it operates" (p. 1). Therefore, building a conception of the social and political systems that have developed alongside journalism is essential to understanding the characteristics of the journalistic institution. To begin, this chapter will explicate the journalism-democracy relationship, including democratic requirements of the press. Based on such requirements, this paper will then cover the development and advancement of theorizing on journalistic roles, how journalists internalize normative roles through socialization, and whether journalists are 
able to enact normative roles. This trajectory enables a more comprehensive understanding of why journalism operates the way it does in the U.S. (or, perhaps, elsewhere in the world), as well as articulates the ideal responsibilities, functions, and roles necessary in modern democracy.

\section{Journalism in Democracy}

Normative theories of journalism have often privileged the journalism-democracy relationship, accounting for the necessary requisites of a functioning democratic society. Journalism is a foundational and essential asset of democracy (Adam, 2009; Christians et al., 2009; Merrill, 1974; Schudson, 2008). Freedoms guaranteed under democracy are equally essential to a fully functioning press (Christians et al., 2009; McChesney, 2013). Simply put, journalism and democracy are inextricably linked (Christians et al., 2009).

This link, though, is not without its criticisms. Waisbord (2013) challenges the long-perpetuated link by noting that certain forms of journalism have no clear purpose in democracy. For example, “journalism has always churned out information with no obvious connection to any model of democracy" such as crime, entertainment, and sports journalism (Waisbord, 2013, p. 505). Although Waisbord (2013) contends that some forms of journalism have no obvious connection to democracy, even lifestyle journalism and cultural criticism serve important normative purposes such that they help expand opportunities for new knowledge and abilities, including the ability to appreciate diverse perspectives (Thomas, 2017). Civic deliberation that welcomes a multiplicity of viewpoints not only enhances public discourse (Habermas, 1989), but also opens up the possibility of social empathy, just one function of journalism in democracy (Schudson, 2008). 
Other critics are not so much challenging the tie between journalistic functions and democracy, but more-so the notion that journalism can only thrive under democratic political systems that grant press freedoms (Zelizer, 2013). Although journalism and democracy are historically linked, Josephi (2013) argues that perhaps scholars should shift away from assessing journalism based on merits dictated by any one political system. Rather, benchmarks of journalists' achievements should be grounded in journalists and their practices. Josephi (2013) contends that linking journalism to political systems limits understandings of journalistic practice and values, as journalists from different political forms still share common journalistic routines and knowledge. Although Josephi's argument is compelling, it is imperative to acknowledge the historical link between journalism and democracy to understand why certain journalistic practices have become institutionalized, especially in democratic states such as in the context of this study. The institutionalized norms and values of journalism in the U.S. reflect its nature as a social institution and a product of society. As journalism operates alongside other social institutions, its normative functions and responsibilities will depend on the functions and responsibilities of external institutions (George, 2013). For example, if the state had harsh rules against corruption that vetted out corrupt politicians, perhaps the responsibility of journalists to uncover corruption would become moot (George, 2013). As products of society, institutions reflect cultural and societal values in beliefs, norms, and values. To understand why journalism in the U.S. operates the way it does, it is important to understand what the social context is and has been in the U.S. Therefore, this study privileges the journalism/democracy link as a useful framework for understanding the influence of the social system on the institutionalization of journalistic practices. 
However, it is important to understand that variations exist in the definition and implications of democracy.

Democratic requirements of the press. Using the term "democracy" broadly does little to tell us what functions journalism should fulfill. Scholars have attempted to delineate nuanced variations of democracy in further defining the nebulous term (see Held, 1987) and have identified normative press practices in various conceptions of democracy (see Baker, 2002; Karppinen, 2013). However many variations of democracy exist across the world because there are several ways of interpreting what is meant by "rule by the people" (Held, 1987). Early forms of democracy, such as classical democracy, served as important foundations to the development of democratic traditions since 500 B.C. Although progressive for the era, classical democracy was not without its flaws, including economic dependence on slavery and a limited approach to defining who had the right to participate (Held, 1987). As philosophical traditions developed, so did models of democracy (Christians et al., 2009) and expectations of journalism (Nerone, 2013). Although the theories addressed below do not provide a comprehensive account of democratic models, they do offer a conceptualization of how journalism practices adjust to various social and political needs.

Today, democratic traditions can be evaluated along spectrums between individualism/collectivism or libertarianism/republicanism (Christians et al., 2009; Hindman, 1997). In reality, no democracy aligns perfectly with any one democratic theory (Karppinen, 2013). Yet some general typologies have been useful in understanding the relationship between mass communication and society. One such model is Baker's commonly used categorization of democracy and functions of the media 
(Karppinen, 2013). Baker (2002) articulated four models of democracy and addressed the variations in journalistic expectations for each model.

Elite democracy, also referred to by Christians et al. (2009) as administrative democracy, is a libertarian tradition that emphasizes liberty and freedom. In this form of democracy, few elites make regulatory and legislative decisions, but are put in positions of power through citizen participation in voting. It is the responsibility of those in power to advocate for the interests of the groups they represent (Baker, 2002). For elitist democracy to flourish, journalism must serve as vigilant surveillance of the elite in order to educate citizens about transgressions and misappropriations of power (Allen \& Hindman, 2014).

A second model of democracy outlined by Baker (2002) is liberal-pluralism. Although this model is also reminiscent of the libertarian philosophy, liberal-pluralism is different than elitist in that citizens do not have to rely on elites to advocate for their interests. Democracy succeeds and society functions when individuals are empowered to fulfill their own interests (Christians et al., 2009; Siebert et al., 1963). With strong roots on Milton's (1644) and Mill's (1859) pleas for freedom of expression, this model of democracy invests heavily in the marketplace of ideas metaphor (Baker, 2002). As long as citizens have the ability to express their opinions and their ideas, society will benefit. Journalism, then, must provide the forum for which citizens can express comment, criticism (Commission on Freedom of the Press, 1947), and opinions, and serve as the initiator of public deliberation (Adam, 2009).

In contrast to liberal-pluralism, republican democracy is a more collectivistic model that emphasizes the identification and fulfillment of community goods (Baker, 
2002). Through public deliberation and discourse, citizens develop an understanding of what the community needs and values. In line with this tradition, "the purpose of the press is to promote and indeed improve, and not merely report on and complain about, the quality of public or civic life" (Glasser \& Lee, 2002, p. 203). Expectations of journalism in republican democracy rests on the ability of the press to usher in public participation and discourse, listen systematically to the voices in the community, advocate for community values and goals (Lambeth, 1998), and serve as active community builders providing opportunities for citizen participation (Allen \& Hindman, 2014).

A fourth model of democracy, complex democracy, is the model Baker (2002) contends is most representative of U.S. democracy, reminiscent of both libertarian and republican traditions. Discourse democracy, an example of a complex democratic model, can largely be attributed to John Dewey (Allen \& Hindman, 2014) who contended that the goal of democracy was "to help people develop to their fullest potential" (Kovach \& Rosenstiel, 2014, p. 35). Although heavy on libertarian tradition that emphasizes individual freedoms, discourse democracy ties individual interests to the moral life of the community and asks how individual actions can benefit the common good (Allen \& Hindman, 2014). Therefore, this model has hybrid expectations for journalism that mix expectations of the liberal-pluralist model and the republican model, so that journalism both seeks to fulfill individual interests, as well as foster community building (Baker, 2002). 


\section{Functions of the U.S. Press System}

Historically, journalism has adapted to changes in political and philosophical traditions (Christians et al., 2009) and changes in the market (Nerone, 2013). Over time, this means that journalism has taken on certain functions based on what is imperative to financial and social success. In the mid-twentieth century, the Commission on Freedom of the Press was convened in response to the growing concerns of journalism's overemphasis on the market. The Commission (also known as the Hutchins Commission, after its chairman Robert Hutchins) identified three problems with press practices: the press became too inaccessible to the public, so that citizens could no longer voice opinions through media; media owners and managers no longer operated in society's best interest; and media owners and managers engaged in condemned behaviors. Based on these problems, the Hutchins Commission insisted that the time had come for media to uphold a responsibility to democracy and to society. It identified five responsibilities of the media as a system, acknowledging that they may not all be achievable by one media outlet. These five requirements included: providing an accurate account of events "in a context which gives them meaning" (Commission on Freedom of the Press, 1947, p. 21), serve as a forum for the exchange of comment and criticism; communicate the goals and values of society, serve as a platform for airing opinions and ideas from various interest groups, and be accessible to the masses.

The elements identified and proposed by the Hutchins Commission became integrated into a normative press theory called social responsibility theory (Siebert et al., 1963), arguably the dominant paradigm in modern journalism (Baker, 2002). The social responsibility theory of the press imposed normative expectations of journalistic 
performance that stressed its moral obligations to society. According to this theory, journalism's functions included: providing information and enabling debate on public affairs, educating the public in order to enable self-governing, protecting the rights of individuals by monitoring government officials, enabling the market by bringing buyers and sellers together through advertising, providing entertainment, and remaining financially self-sufficient to avoid external pressure (Siebert et al., 1963).

However, social responsibility theory is not without its criticisms. One such critic, Merrill (1974), argued that social responsibility theory imposed restrictions on journalistic autonomy, such that journalists operating under a social morality or socially defined good are under control of society. Instead, Merrill insisted that journalists practiced with absolute freedom and, in doing so, would ultimately act responsibly. Merrill's argument is in line with libertarian ideals, where staying free and autonomous "is the primary imperative of the authentic journalist" (p. 203). Under libertarian systems, press functions include: informing the public, providing entertainment, maintaining financial independence, and serving as a check on government (Siebert et al., 1963, p. 51). According to Siebert and his colleagues, the libertarian press theory assumed that the purpose of the press was to facilitate the discovery of truth. Although some information reaching the public would be false, the libertarian theory is premised on the assumption that individuals are rational consumers of media and "could be trusted to digest the whole, to discard that not in the public interest and to accept that which served the needs of the individual and of the society of which he is a part" (Siebert et al., 1963, p. 51). Journalists, then, must also produce a multiplicity of opinion and serve as a platform for 
free expression. The only way for a press to fulfill these functions responsibly is to ensure complete autonomy from government and external institutions.

Since Siebert et al.'s (1963) work on press theories, agents internal and external to the journalistic institution have attempted to make sense of and articulate journalistic functions within the U.S. Typically these debates represent a divide between collectivism and individualism, resulting in differing conceptions of First Amendment guarantees and, therefore, differing ideas of press responsibilities (Hindman, 1997). A newer tradition, citizen participation, conceptualizes media as a tool of the people that advocates for political change (Christians et al., 2009). With roots in centuries-old religious and political movements, more modern conceptions of participatory press account for radical and alternative presses that emphasize the importance of local community (Christians et al., 2009).

Some scholars have made efforts in further clarifying some of these democratic press functions (Hanitzsch \& Vos, 2018; Schudson, 2008). Schudson (2008) proposed seven functions that press assumes in democratic societies. These included (1) informing the public so that citizens can make informed political choices; (2) investigating sources of power; (3) providing analysis of complicated events or issues; (4) enabling social empathy by uncovering a multiplicity of viewpoints; (5) providing a forum for public dialogue, including serving as a carrier for diverse perspectives; (6) giving readers a cause to care about and mobilizing people to act in support of certain issues; and (7) publicizing and advancing representative democracy. Hanitzsch and Vos (2018) also identified particular functions of journalism in democracy, but distinguished between functions of political life and functions representative of capitalistic ideals. In line with 
Schudson's (2008) conceptualization, Hanitzsch and Vos (2018) proposed political functions of the press, such as informational, analytical, investigative, and advocative functions, but added two more functions. First, they outlined a developmental-educative function in which journalists are not only participants, but also promoters of "real-world change" (Hanitzsch \& Vos, 2018, p. 155). Second, they highlighted a collaborativefacilitative function that embraces a cooperation between journalism and government in order to facilitate in societal growth and well-being. Finally, they suggested that journalism should serve functions that appeal to audiences as consumers and enable the public to fulfill the needs of everyday life.

Today, debates about journalistic functions in democracy exist in literature on journalistic roles. Journalistic functions (as discussed above) are more nebulous concepts than journalistic roles and are reflections of societal needs (Christians et al., 2009). Many scholars relate journalistic roles to a broader culture (Campbell, 2004; Donsbach \& Patterson, 2004; Hanitzsch, 2007; Waisbord, 2000) or a "belief system" (Nerone, 2013). This study views a role as "a composite of occupational tasks and purposes that is widely recognizable and has a stable and enduring form" within the institution, so long as they reflect institutional practices, needs, and values (Christians et al., 2009, p. 119) and speak to a larger journalistic function. Essentially, journalistic roles are discursively constituted: "They exist because and as we talk about them" (Hanitzsch \& Vos, 2018, p. 151). They represent communicative structures of meaning that speak to journalism's identity in society and set expectations for desirable journalistic behavior in different contexts (Hanitzsch \& Vos, 2018). 
Normative roles are reflections of the values, norms, and beliefs of the institution dictated by the functions of the institution in a larger social context. The construction of normative roles is a process of ideation and discourse (Hanitzsch \& Vos, 2017) and occurs as agents negotiate an institution's boundaries, meanings, and definitions (Carlson, 2016). Normative journalistic roles, then, "are discursive articulations and enactment of journalism's identity as a social institution" (Hanitzsch \& Vos, 2017, p. 120). Thus, one way to study journalism's identity and function in society is through the study of journalistic roles.

Identification of journalistic roles. Although Siebert et al.'s (1963) primary press theories were criticized for being over-simplistic (Christians et al., 2009; Nerone, 1995) and dated (Szpunar, 2012), they were pivotal in beginning the discussion of normative expectations and roles of the press. Siebert and his colleagues conceptualized press practices in the contexts of authoritarianism, libertarianism, social reposibility, and Soviet Communism, yet Four Theories of the Press has been described as propaganda for Western models of journalism (Szpunar, 2012) and an overly simplistic explanation of authoritarianism and libertarianism with "little historical reality" (Nerone, 1995, p. 32). These shortcomings, however, do not negate the fact that, at the time, their work sparked scholarly debate on the nature of the journalism/social system relationship and the roles journalists must fulfill in certain political contexts.

Since then, early work on journalistic roles identified two roles: the reporter as participant and neutral observer (Cohen, 1963; Johnstone et al., 1972). The journalist as a neutral observer takes a more detached stance in reporting while the participatory journalist has more control over the story (Johnstone et al., 1972). Through subsequent 
survey work, Weaver and Wilhoit (1986) found the interpretive and disseminator roles that mimic the findings of Cohen (1963) and Johnstone et al. (1972). They also found a third role, the adversarial role, in which the press is an adversary of the powerful. This role, however, has consistently struggled in survey research to gain importance among U.S. journalists (Brownlee \& Beam, 2012).

In mapping journalistic roles onto democratic theory, Christians et al. (2009) identified four over-arching roles that may conceptually vary depending on the model of democracy within which they operate: monitorial, facilitative, radical, and collaborative roles. The monitorial role is often the most recognized role of the press and is the primary role in elite or administrative democracies (Allen \& Hindman, 2014). The identifying trait behind this role is the ability of journalism to function as surveillance and educate citizens on events. This role is often conflated with watchdog journalism (Bennett \& Serrin, 2005), which emphasizes vigilant surveillance of those in power. Overall, the monitorial role accounts for tasks involving monitoring public officials, being a critical observer of political conduct, and reporting on political misconduct.

The second role, the facilitative role, requires a press that facilitates, enables, and contributes to the development of the community and/or society (Christians et al., 2009). A movement in the 1990 s toward a more participatory press ushered in the idea of "public journalism" that embodied the essence of the facilitative role (Glasser \& Lee, 2002). Tenets of public journalism include the ability of the press to listen systematically to the multiplicity of voices in the community, enable public deliberation and discourse, promote the goals and values of society, and represent diverse voices in the community (Lambeth, 1998). Other characteristics of the facilitative role include press practices that 
communicate conceptions of a "common good," a term reminiscent of communitarian journalism (Borden, 2014). Although there are nuanced differences between communitarian journalism and public journalism, the facilitative role speaks to both press practices in that it represents a function of the press that depends on collectivism and public participation.

The radical role of the press accounts for a journalism that opposes dominant groups and is critical of dominant ideology (Christians et al., 2009). Usually, publications actively attempting to fulfill a radical role are smaller niche publications; however, some degree of advocacy can be found in legacy media, as well. In coverage of a G8 Summit, Atton (2002) found that The Guardian, as well as the alternative publication SchNews, both practiced some level of advocacy either through "witnessing" - where the journalist attempts to appear neutral, but exhibits advocacy through sourcing - or "native reporting." The latter was more apparent with SchNews as journalists who identified as advocates were also able to identify as journalists, ensuring them press credentials. The radical role in this case was more overt in some instances and subtler in others, particularly at The Guardian where advocacy could threaten legitimacy. In a study of an outwardly radical news outlet, Hindman (1998) found that the alternative publication The Alley struggled with balancing its advocacy with conventional practices. For the same reason that overt advocacy could threaten The Guardian, The Alley was at risk for legitimacy as a news publication in its community for not adhering to the traditional convention of neutrality. Although the radical role at times seems to challenge many long-held journalistic beliefs (such as neutrality), it is still a relevant role that journalists should practice. For example, Andersson (2012) argues that journalists failed to 
adequately challenge the dominant financial system in the U.S. and, therefore, further contributed to the market's eventual collapse in 2007-08.

The fourth role, the collaborative role, alludes to a stronger relationship between journalism and the state than any other normative role (Christians et al., 2009). This role accounts for journalism partnering with government - either coercively or voluntarily. Often, this is in response to a natural disaster, attack, or threat to national security (Christians et al., 2009), but can also be found in regularly practiced routines. In a study of media coordinators in Missouri's court system, Tandoc and Peters (2015) found that journalists often leveraged their collaborative role (their partnership and cooperation with government) as a way to further fulfill their monitorial role. Rather than seeing strain between the seemingly opposite roles, these journalists representing the court were also able to better cover the courts, thus accumulating and simultaneously enacting each role.

More recent work has expanded the list of journalistic roles substantially. Using survey data collected in 2002, Weaver and his colleagues (2007) identified 15 roles that provide the foundation for four functions - the interpretive function, adversarial function, disseminator function, and populist-mobilizer function. Hanitzsch and Vos (2018) differentiated between roles in political and everyday life. Their work expanded the list to seven roles in three areas of everyday life, as well as 18 roles within six functions of political life. Roles within the domain of everyday life speak to journalistic functions of the press that address audiences as consumers and champion capitalistic values (Hanitzsch \& Vos, 2018). These roles align with three areas of everyday life - emotion, consumption, and identity - and include mood manager, connector, inspirator, guide, friend, service provider, and marketer roles. Roles in the political domain include tasks of 
journalism that cater toward an informed citizenry and are more synonymous with the normative journalistic standards introduced by Christians et al. (2009). These 18 roles constitute six essential functions (or needs) of journalism that enable citizens to participate in political life (see Table 1) - a more relevant approach to journalistic roles in a study of political journalists.

Table 1. Functions and Roles of Journalists in Political Life (Adapted from Hanitzsch \& Vos, 2018)

\begin{tabular}{|c|c|c|}
\hline Function & Description & Roles \\
\hline Informational-instructive & $\begin{array}{l}\text { Assumes the press should provide the } \\
\text { information necessary for citizens to } \\
\text { participate in political life. }\end{array}$ & $\begin{array}{ll}\text { - } & \text { Disseminator } \\
\text { - } & \text { Curator } \\
\text { - } & \text { Storyteller }\end{array}$ \\
\hline Analytical-deliberative & $\begin{array}{l}\text { Encourages public participation and } \\
\text { provides the means for that participation }\end{array}$ & $\begin{array}{l}\text { - Analyst } \\
\text { - Access provider } \\
\text { - } \text { Mobilizer }\end{array}$ \\
\hline Critical-monitorial & $\begin{array}{l}\text { Assumes press should serve as a check on } \\
\text { powerful actors, such as government } \\
\text { officials or business elites }\end{array}$ & $\begin{array}{ll}\text { - } & \text { Monitor } \\
\text { - } & \text { Detective } \\
\text { - } & \text { Watchdog }\end{array}$ \\
\hline Advocative-radical & $\begin{array}{l}\text { Views journalists as participants in public } \\
\text { discourse who imbue their work with bias }\end{array}$ & $\begin{array}{l}\text { - Adversary } \\
\text { - Advocate } \\
\text { - Missionary }\end{array}$ \\
\hline Developmental-educative & $\begin{array}{l}\text { Models interventionist journalism in which } \\
\text { the journalist promotes social change }\end{array}$ & $\begin{array}{l}\text { - } \text { Change agent } \\
\text { - } \text { Educator } \\
\text { - } \text { Mediator }\end{array}$ \\
\hline Collaborative-facilitative & $\begin{array}{l}\text { Accounts for journalism that partners or } \\
\text { collaborates with the government on } \\
\text { initiatives involving a public good }\end{array}$ & $\begin{array}{ll}\text { - } & \text { Facilitator } \\
\text { - } & \text { Collaborator } \\
\text { - } & \text { Mouthpiece }\end{array}$ \\
\hline
\end{tabular}

\section{Internalization and Enactment of Journalistic Roles}

As demonstrated above, conceptualizations of normative roles in journalism is expansive. Understanding the normative roles of journalism elucidates not only the expectations of journalism in democracy, but also explains motivational aspects guiding journalistic decisions. Although normative roles are manifestations of institutionalized beliefs, agents internalize normative roles differently. A role conception represents a role 
that the journalist adopts and hopes to apply in practice (Donsbach, 2008). The process in which journalists adopt particular roles is referred to as "role internalization" (Hanitzsch \& Vos, 2017). Journalists may relate to any of the above roles simultaneously or depending on the situation - meaning context is important in understanding when certain roles are privileged over others (Hellmueller \& Mellado, 2015). Journalists' socialization into the journalistic institution and news organizations guide the way they internalize particular roles. Additionally, role internalization is largely based on the journalist's own values system. This values system has largely been constructed through socialization processes and reflects "institutional values, attitudes, and beliefs" (Hanitzsch \& Vos, 2017, p. 11).

The process associated with the execution of a role in practice is often referred to as the "role enactment" process (Hanitzsch \& Vos, 2018; Tandoc et al., 2013). Role performance - a term used to connect role conceptions to actual practice (Mellado, 2015) - requires a journalist enact their cognitive roles through practice. Once enacted, cognitive roles theoretically become practiced roles, which are usually identified through analyses of the journalist's content (Carpenter et al., 2016; Tandoc et al., 2013). Journalists also reflect on their work. This concept is referred to as "narrated roles" (Hanitzsch \& Vos, 2017). This aspect of role performance focuses on the journalists' perception of what they believe they did. As a cyclical process, role construction accounts for the perpetuation or alteration of cognitive roles as journalists conceive, enact, and reflect on their roles. 
Role internalization. In order for journalism to be classified as an institution, its patterns and myths must be resistant to change. Journalistic roles endure because they represent institutionalized - or deeply embedded - beliefs and are internalized by journalists. As journalists become socialized into the institution, they adopt the rational beliefs and practices associated with the institution, including these roles. Socialization into vocations can begin from an early age, as children or adolescents begin to think about their career trajectory (Myers, Jahn, Gailliard, \& Stoltzfus, 2011), or as children are born into legacy situations (Gibson \& Papa, 2000). Gibson and Papa (2000) use the term "organizational osmosis" to denote the process in which employees of an organization have been exposed to a set of beliefs, ideologies, and identities specific to one organization over a long period of time. In their study, they found that children whose family members worked at a specific organization were exposed to that organization's values and beliefs from a young age - making them ideal recruits for employment as they came of age. Although this may also be applicable to journalistic organizations, on a broader level this "osmosis" can occur over time as youth and young adults develop as news consumers - becoming cognizant of how news covers certain events and why the coverage looks the way it does - and through anticipatory socialization in journalism schools (Tandoc, 2014).

Through various phases of socialization, agents are exposed to both formal messages - messages intentionally delivered to them - and informal messages, or messages obtained through observing others in the field (Van Maanen \& Schein, 1979). As journalists move through the stages of socialization - such as vocational, anticipatory, encounter, and adjustment stages (Kramer \& Miller, 1999) - years in the field and 
extended observation of others or interaction with sources may influence role conceptions. Although agents entering a new field or organization may face similar socialization processes, each person brings in personal proclivities that lead to different interpretations of situations (Jones, 1986). In the case of journalistic roles, journalists attempt to align their professional identity with that of their organization, but must negotiate personal beliefs with organizational expectations (Tandoc \& Takahashi, 2013). Thus, the concepts of role internalization and identity are strongly linked.

It is assumed that agents of an institution have been socialized, to some degree, into institutional norms, routines, and practices. It is also assumed that journalists have been socialized into other facets of life - maybe through schooling, marriage, family, sports, or even other careers, thus producing several "identities.” For example, a journalist would probably identify as a journalist, but may also identify as a mother, a daughter, an athlete, and an atheist. To let a facet of her personal life influence her professional obligations as a journalist is somewhat taboo in U.S. journalism. Although many scholars attempt to segregate "real" and "fake" selves in conceptualizing professional identity, this segregation is irrational and never fully realized in practice (Tracy \& Trethewey, 2005) even if individuals do find ways to temporarily mask identities to see success in certain situations (see Murphy, 2013). Therefore, the conceptual distinction between personal and professional identity is not always so clean cut.

Individuals construct identity through both self-aware reflections and everyday practices of doing work and life (Wieland, 2010). Within journalism, this means constructing a professional identity involves a process of making sense of role 
expectations and aligning interests and beliefs with organizational and institutional norms. Role conceptions (i.e., the end product of role internalization) are the manifestations of the relationship between the journalist's beliefs and institutional scripts. Although influenced by assimilation into a field and organization, role conceptions "are a negotiation between an individual's personal beliefs and what that individual thinks is expected of him or her" (Tandoc \& Takahashi, 2013, p. 901) and are crucial to conceptions of one's social identity (p. 893). As journalists reflect on their role performance, they continue to negotiate their professional identity and make adjustments to role conceptions (Hanitzsch \& Vos, 2017). Over time, this feedback loop could lead to changes in how individuals conceptualize their cognitive roles.

Although journalists most likely hold more than one cognitive role, scholars have struggled to account for how journalists prioritize their cognitive roles. For example, drawing on in-depth interviews of political journalists, Vos and Wolfgang (2016) found that journalists prioritized gatekeeping and truth-telling roles over providing diverse viewpoints in reporting for both normative and practical reasons. The discovery in their work strengthens the idea that journalists not only hold more than one cognitive role, but also prioritize those roles in given contexts.

Role enactment. Regardless of the cognitive role held by a journalist, role conceptions are not always accurate predictors of role performance (Hellmueller \& Mellado, 2015). Several scholars have noted discrepancies between the roles journalists say they want to fulfill and the role that manifests through their work (Carpenter et al., 2016; Siegelbaum \& Thomas, 2016; Tandoc et al., 2013). Thus, something happens during the role enactment process that results in a difference between the cognitive role 
and the practiced role. Although journalists may identify strongly with their cognitive roles, news production is a process with several factors that influence the outcome of the final product (Shoemaker \& Reese, 1996). The finished product of newswork (e.g., the article that runs in the newspaper) undergoes several rounds of revision, such that the published work may not even represent the reporter's conceived journalistic role. In theory, cognitive roles translate into action (Hanitzsch \& Vos, 2017), but in practice this is not always the case (Tandoc et al., 2013).

\section{Summary}

Journalistic routines, norms, and values develop alongside the social and political systems within which it operates. Since journalism in the U.S. functions within a democratic system, it has adopted functions that preserve democracy and has benefitted from freedoms guaranteed under the First Amendment. In the past century, journalists shifted from sensational press practices to more objective, evidence-based reporting, as they discovered the potential impact journalism had in society. Standards of press performance began articulating the need for social responsibility. Scholars began mapping the evolution of journalistic practices and theorized that the roles journalists identified with influenced their news coverage. Today, scholarship on journalistic roles is pervasive and has a global reach.

The concept of a "role" is quite a loaded term. To unpack a role is to discover not just the tasks or practices associated with that role, but also to uncover the cognitive scripts that dictate journalistic behavior. As journalists become socialized into the field, they identify with and adopt some roles over other roles. As they internalize those normative roles, they also internalize the scripts associated with those roles. Thus, they 
become cognitive roles. In practice, these roles are enacted (or not) as journalists go through their day-to-day routines. The role enactment process describes the activity of cognitive roles manifesting in practice. In other words, they become practiced roles that are evident in journalistic work. However, as is addressed in the next chapter, journalists may face challenges during the role enactment process from factors at micro, meso, and macro levels. 


\section{Chapter Three: Factors of Influence in Role Internalization \& Role Enactment}

Several scholars have delineated the distinction between the roles journalists perceive they ought to do and the roles they actually fulfill (see Carpenter et al., 2016; Tandoc et al., 2013), but few studies empirically explored why journalists are unable to fulfill normative roles (Siegelbaum \& Thomas, 2016). Although role performance and “journalistic decisions should be conceptually linked to journalistic role conceptions and normative ideals" (Eide, 2017, p. 90), linearity does not always exist between role orientations and role performance (Tandoc et al., 2013), and several factors influence the news production process (Shoemaker \& Reese, 1996; Shoemaker \& Vos, 2009). Empirical evaluations of role performance, then, can gain explanatory power by conceptually linking role conceptions, practiced roles, and gatekeeping influences (Hellmueller \& Mellado, 2015).

As addressed in the previous chapter, role internalization is dependent on individual conceptions of identity; therefore, it is logical to assume that a journalist's identity does not also influence role enactment. However, micro-level structures are not the only influence on practiced roles. Meso- and macro-level structures also largely influence the final news product, and, in doing so, influence the practiced role. This chapter first looks at the many factors at micro, meso, and macro levels that may challenge the manifestation of ideal role conceptions, then addresses how journalists make sense of competing expectations produced by these factors.

\section{Factors that Challenge Cognitive Roles}

Since news production is a process, it is helpful to think of the many moving parts that influence its outcome when considering news content or practiced roles. Perhaps one 
of the key studies into journalistic decision-making processes was White's (1950)

assessment of one editor's reasons for selecting certain news items from a plethora of information. Although the study focused on one wire editor, a "Mr. Gates," it established a connection among an individual's value system, subjective conceptions of newsworthiness, and story selection that became influential in future gatekeeping studies (Shoemaker, Vos, \& Reese, 2009). Within gatekeeping theory, information items pass through channels on their way to becoming news items. Within these channels, information items must also pass through "gates" - decision or action points (Shoemaker \& Vos, 2009) - where forces either facilitate or restrict the continuation of items toward a finished news product (Shoemaker et al., 2009). Shoemaker and Reese (1996) identified five levels of analysis in which forces could be assessed: individual, routines, organizational, outside of media organizations, and ideology. Those five levels have been used as a framework for gatekeeping theory, identifying forces at each level that influence the journalistic decision-making process (Shoemaker \& Vos, 2009) that are both communicative and material constructions. For example, a journalist may be influenced by a communicatively constituted structure - such as religious obligations that contains a script for behavior in a given context that conflicts with the script associated with his/her journalistic role. Similarly, a journalist may also not have access to certain resources (a materially constituted structure) to fulfill his/her desired role.

Although institutional routines and practices are somewhat homogenous across news outlets in a specific medium, there are still various factors across journalists, the organizations they work for, and in institutional strucutres that affect their work differently. For the purposes of this study, routines and practices are consolidated into the 
meso level, as they are commonly dictated by organizational demands (Siegelbaum \& Thomas, 2016), the nature of the news medium, and role conceptions of the organization (Tandoc \& Takahashi, 2013). Similarly, social system factors, such as ideology and culture, are assumed to have an influence on the functions and roles that have become institutionalized. Therefore, markers of social system influence are already embedded within micro-, meso-, and macro-level expectations. In this study, the factors, then, are consolidated into three levels: micro, meso, and macro.

Micro-level factors. Micro-level influences on journalistic decisions include ways of thinking and heuristics, as well as characteristics of individuals such as personality traits, background, values, and job (Shoemaker \& Vos, 2009). Individual characteristics such as years of experience (Cassidy, 2006) or position and status within the news organization (Tandoc \& Takahashi, 2013) have been found to influence role conceptions of journalists. For example, environmental journalists who have achieved higher positions and status within an organization tend to adopt organizational role conceptions as their own (Tandoc \& Takahashi, 2013). Additionally, journalists who identify with a specific medium may also reflect role conceptions in line with that particular medium. For instance, digital journalists may differentiate themselves from journalists operating in traditional platforms, and in doing so conceive differently of their journalistic role (Ferrucci \& Vos, 2017). Education level (Schultz, 2002) and gender (Hanitzsch \& Hanusch, 2012) have not been found to influence role conceptions.

Understanding the structures that guide journalists' behavior also means understanding the factors that have exogenous roots to the journalistic institution. Journalists' personal beliefs, values, obligations, or morality may influence journalists to 
make decisions that stray from their role conception. What the journalist understands as the normative ideal for journalistic behavior can conflict with expectations of other facets of life (e.g., family). This is representative of conflict between professional and personal expectations (Coser, 1975). Thus, incorporating individual and identity factors into this study adds explanatory power to the role internalization and enactment processes.

Meso-level factors. In this study, meso-level factors refer to the practices and routines that are instilled into journalists through socialization, as well as organizational traits such as size, medium, culture, and resources (Shoemaker \& Vos, 2009). The strength of influence within organization routines, such as deadlines, supervisors, and colleagues (Tandoc et al., 2013); organizational location (Tandoc et al., 2013), and weight of the reporter's workload (Carpenter et al., 2016) have been found to positively predict role enactment. For example, Tandoc et al. (2013) found that journalists who believed routines were strongly influential to their work were more likely to enact a disseminator role, whereas those who did not perceive a strong influence from routines more likely enacted mobilizer and adversarial roles.

As a field constantly in flux, working conditions and expectations are drastically changing and leading to new conceptions of what it means to do journalism (Wiik, 2015). Organizationally speaking, newsrooms are reorganizing (Siegelbaum \& Thomas, 2016) and finding innovative ways to report the news (Singer, 2004) that alter the practices and expectations of journalists. Through these changes, cutbacks and an emphasis on deskilling can lead to a rift between journalists' ideals and their ability to fulfill those ideals in practice (Siegelbaum \& Thomas, 2016). Eventually, this rupture could lead to 
the perception of normative failure - "a growing inability to fulfill their democratic mandate" (Siegelbaum \& Thomas, 2016, p. 395).

Aside from routines and practices, journalists may experience influences from the nature or traits of the organizations. As newsrooms attempt to go "digital first," journalists must adapt to new rules of how to practice journalism on new media (Singer, 2004) and understand that different influences are inherent in different media platforms such as print, television, radio, or magazine (Shoemaker \& Vos, 2009). Not only does platform affect role conceptions (Tandoc \& Takahashi, 2013; Weaver et al., 2007), it also affects the type and focus of news stories (Singer, 2004).

Other meso-level factors in need of analysis include ownership, management, editorial supervision (Hanitzsch \& Mellado, 2011), and organizational profit expectations (Tandoc et al., 2013). When journalists perceive that management infringes on their autonomy or that the organization values profit over quality, their overall job satisfaction declines (Singer, 2004; Weaver \& Wilhoit, 1996). With news organizations cutting budgets and attempting to draw certain advertisers, journalists are faced with a lack of necessary resources to practice thorough investigative reporting - a cornerstone of the exalted watchdog role (Bennett \& Serrin, 2005; Glasser \& Gunther, 2005). Additionally, Tandoc et al. (2013) did not find that organizational factors such as market orientation influenced role enactment, but Carpenter et al. (2016) did find that nonprofit news organizations might be positioning themselves differently than for-profit news organizations resulting in different organizational role expectations. 
Macro-level factors. Macro-level factors refer to the relationship between journalism and other social institutions such as government, interest groups, businesses, and public relations (Shoemaker \& Vos, 2009). Journalism is semi-autonomous (Bourdieu, 1998) in that it regularly depends on sourcing and stories from external representatives, but is also susceptible to federal regulations and government officials. Hanitzsch and Mellado (2011) identify government officials, politicians, censorship, and business representatives to be the premier political influencers. In their cross-national survey, Hanitzsch and Mellado found that within the U.S., political groups are very influential to journalists' day-to-day activities. Similarly, public relations initiatives are often interpreted as news items and affect media content directly (Shoemaker \& Vos, 2009). Press releases, one source of information from public relations practitioners, are adopted and adapted by journalists based on standards of newsworthiness. Conceptually, news selection criteria would be linked to the journalist's role conception; however, pressure from exogenous agents to adopt the story may override the journalist's ideal role. Finally, journalists must also operate within the realm of federal regulations and court mandates (Hindman, 1997), as well as shield, libel, and slander laws (Shoemaker \& Vos, 2009).

Summary. Although scholars make the case that role conceptions and role performance should be conceptually linked (Eide, 2017; Hanitzsch \& Vos, 2017; Mellado, 2015), it would be naïve to do so without also accounting for the influences throughout the news production process. As addressed above, factors at micro, meso, and macro levels affect the decisions journalists make and the finished product of their work. Occasionally, these factors negate the journalist's role conceptions and instead lead to 
work that may reflect very different roles in practice (Hellmueller \& Mellado, 2015; Tandoc et al., 2013). Within the cyclical nature of role construction and reconfiguration, journalists reflect on their practiced roles to reconceive and adjust their cognitive roles, thus perpetuating the cycle (Hanitzsch \& Vos, 2017). If cognitive roles encounter challenges in the role enactment process, journalists must make some sort of sense of the inability to fulfill their ideal role. The next section addresses what happens when structures at micro, meso, and macro levels conflict with role conceptions, as well as how journalists make sense of role conflict.

\section{Role Conflict and the Sensemaking Process}

Institutional theory assumes institutions represent a social system where certain unobservable structures operate at various levels that affect the decisions people make (Nicotera \& Clinkscales, 2010). These structures are communicatively constituted and can operate alongside material factors (such as organizational size) at micro, meso, or macro levels as addressed in the previous section. When these structures align (for example, when role conceptions align with an editor's expectations), communicative goals are met. Occasionally, however, structures may not align. For example, journalists may identify strongly with the disseminator role, but feel pressure not to air opinions from one side of a story when those opinions are "obviously wrong" (Hellmueller \& Mellado, 2015, p. 5).

When journalists are exposed to diverse expectations, they experience "role strain" as they make sense of this diversity (Goode, 1960). "Role conflict" occurs as these diverse structures emerge simultaneously causing "dissonance" for the journalist trying to combine competing roles (Lynch, 2007). In most situations, individuals can manage 
dissimilar commands without becoming incapacitated (Lynch, 2007). However, in extreme cases, conflicting structures can result in structurational divergence where agents are unable to fulfill certain tasks without compromising other tasks (Nicotera \& Clinkscales, 2010). Regardless of the degree to which a journalist feels role conflict or role strain, this unexpected event triggers the journalist to attempt to prioritize and make sense of appropriate directions for immediate action.

\section{The sensemaking process and emotionality in role internalization and}

enactment. In journalistic practice, journalists must make sense of micro-, meso-, and macro-level challenges to their cognitive roles. Sensemaking, put simply, means making sense of a situation (Weick, 1995). It is a process individuals undergo while trying to understand unusual, unexpected, or confusing events (Maitlis, Vogus, \& Lawrence, 2013). Interruptions in daily routine and arousal play a part in triggering sensemaking. There are two types of interruptions that trigger sensemaking: unexpected events that disrupt expectations and expected events that do not happen (Mandler, 1984). Under each of these circumstances, individuals and organizations will employ sensemaking strategies until a basic understanding emerges. Sensemaking is also focused on and by extracted cues (Weick, 1995). These are the seeds that plant the sensemaking process and are identified by the sensemaker as the root of the disruption or arousal. Because role conflict, failure to fulfill role conceptions, and emotion are unexpected and confusing situations, they serve as triggers to a journalist's sensemaking process.

Although certain events may trigger the sensemaking process, sensemaking is constant and cyclical, dynamic and interactional, and inclusive of individual and organizational experiences, expectations, and norms (Tracy, Myers, \& Scott, 2006). 
Sensemaking is a life-long process of individuals placing events, interactions, and surprises in a framework that helps them interpret their identity and the world around them. It is retrospective in the sense that individuals connect past experiences with current contexts to understand the best course of action (Weick, 1995). The way journalists construct their role conceptions, then, depends on how they make sense of past experiences enacting certain roles.

Since the focus of this study is on the individual journalists' sensemaking process, it is important to understand that every journalist has emotional ties to facets of their identity - be it journalistic role conceptions, familial roles, or obligations to social groups - that vary in their strength. When micro-level expectations conflict, or when meso- or macro-level factors impinge upon the journalists' identity, individuals must make tough choices that result in some degree of sacrifice (Nicotera \& Clinkscales, 2010). With the stress of role conflict or role strain comes some degree of negative emotion on the part of the individual. As an essential element in sensemaking, emotion also serves as a cue that triggers the sensemaking process (Maitlis et al., 2013; Weick, 1995). Although emotions are understudied in journalism research (Pantti, 2010; Soronen, 2018; Wahl-Jorgensen, 2013), understanding how journalists manage their emotions can further enlighten work in role internalization and role enactment. Applying a sensemaking framework may help further explicate how emotive dissonance and emotional labor factor into a journalist's work routine and inform role enactments.

Emotion and the American journalist. In 1994, Kevin Carter received a Pulitzer Prize for his harrowing coverage of famine in Sudan. In capturing shots of the devastating scenes of starvation, he had to make a decision between upholding his role as 
a neutral disseminator of information or intervening and providing humanitarian aid. He decided to privilege his journalistic role and deliver a pivotal message to Western audiences through the heart-wrenching image of a starving Sudanese toddler with an ominous vulture by her side. Although Carter did not help the child, the image was massproduced and became a symbol for famine, as well as earning him that Pulitzer Prize. Unfortunately, he seemed to have regretted his decision not to intervene, telling a friend, “I'm really, really sorry I didn’t pick the child up" (quoted in Moeller, 1999, p. 40). Although not all conflictions are this heart wrenching, this example illustrates the complexities journalists must face among competing expectations. From experiences much like Carter's have come calls for a journalism of attachment (Bell, 1998) and empathy (McGoldrick, 2011) that challenge institutionalized norms and practices. After years of covering war and violence, for example, objectivity may wane as journalists develop an understanding that they are a part of the world they cover (Bell, 1998). These journalists, then, may further rely on unofficial sources and use frames that elicit social empathy - straying from a model of journalism that privileges shock value (Lynch \& McGoldrick, 2005).

The idea that emotionality conflicts with objective reporting methods, however, further perpetuates the notion that emotionality and rationality are dichotomous. In western cultures, there is a pervasive myth that privileges rationality over emotionality (Putnam \& Mumby, 1993). The tendency to frame rationality and emotionality as a dichotomy is problematic, as it inaccurately captures the interconnectivity between emotion and rationality (Dougherty \& Drumheller, 2006; Fineman, 1996). In journalism, for example, where many journalists embrace a watchdog role and serve as a check on 
powerful actors, they identify with and fulfill this role even in a highly rationalized context because of a feeling of "righteous indignation" (Glasser \& Ettema, 1989, p. 1).

Overall, several scholars have theorized about the relationship between emotionality and rationality and have suggested frameworks to assess this dualism. According to Fineman (1996), there are three primary approaches to the myth of rationality, two of which support the myth and one that resists the notion of a dichotomy. The first approach reinforces the idea that emotions interfere with rationality (e.g., emotions cloud judgment). The second approach views emotions as a service toward rationality, such that emotion is the means to the end goal of rationality. This approach also further subjugates emotionality to rationality. The third approach contends that emotionality and rationality are entwined and coexist. A fourth approach, added by Dougherty and Drumheller (2006), privileges emotionality over rationality. However, through in-depth interviews, Dougherty and Drumheller found that participants overwhelmingly perpetuated the myth of rationality by subordinating emotion to maintain the appearance of rationality. Although participants recognized several organizational factors that served as emotional cues (i.e., wasted time at work, unfair business practices, improper work, and process disruption), they also identified several strategies that help them control emotionality (i.e., denial, reframing the situation so emotion is not the appropriate response, rational recitation of emotional events, and stipulating a "time and place" for emotions).

In journalism, emotional cues are prevalent in many domains of the journalistic process. Journalists, like any working professional, often grapple with complex circumstances in which they must either mask emotion to succeed at work - called 
surface acting - or actually internalize "fake" emotions to better align behavior with work expectations - called deep acting (Hochschild, 1983). Arlie Russell Hochschild is often credited with pioneering the study of emotion in the workplace. Through an ethnographic study of Delta airlines, she found that the organization encouraged its stewardesses to put on a smile to sell the company. In this regard, emotionality became a commodity that was bought and sold similar to physical labor. According to Hochschild (1983), emotional labor requires individuals to suppress feelings in order to relay certain countenances that produce the ideal state of mind for coworkers and customers. Depending on the occupation and organization, individuals manipulate their emotions according to emotion display rules that are socialized within the organization and reinforced through rewards, punishment, and other socialization activities (Kramer \& Hess, 2002).

When clashes exist between journalists' real emotions and their emotional displays, they experience some degree of cognitive discomfort or emotive dissonance (Hochschild, 1983). Within the journalistic institution, the norm of objectivity is often conceptualized as a fact-based reporting method (Kovach \& Rosenstiel, 2014) devoid of emotionality (Bas \& Grabe, 2015; Pantti, 2010) and can be considered the root of a journalist's emotive dissonance. Although the conceptual wall between objectivity and emotionality may be crumbling in American journalism, enabling their coexistence (Wahl-Jorgensen, 2013, 2016), the two concepts are usually at odds as they pertain to the decisions journalists make while on the job (Pantti, 2010; Soronen, 2018). As journalists cover conflict, such as in the example of Kevin Carter, it is expected that individual feelings of empathy may conflict with the institutional norm of objectivity - thus, resulting in emotive dissonance. Additionally, certain journalistic roles have more room 
for emotionality in the news production process than other roles (Wahl-Jorgensen, 2013). For example, emotions are more acceptable in adversarial role conceptions, where journalists identify with a cause and inject themselves into reporting.

So far, few empirical studies have acknowledged the emotionality of newswork. Wahl-Jorgensen (2013) conducted an analysis of Pulitzer Prize-winning work and found that journalists employ "emotional outsourcing" as a way to manage emotions while on the job. Rather than producing work that reflects the journalist's own emotions, narrative story-telling in the Pulitzer works relied "on the outsourcing of emotional labor to nonjournalists" (Wahl-Jorgensen, 2013, p. 130) who serve as sources capable of demonstrating their own emotions. What is not known is how those journalists made sense of their enacted role or whether their practiced roles contrasted with role conceptions. Other studies into emotionality and journalistic routines have focused on television (Pantti, 2010) and magazine (Soronen, 2018) platforms. Pantti (2010) found that although journalists acknowledged the prevalence and importance of emotion in television news, they rejected the idea that they, themselves, were a locus of emotion. In her study, journalists believed that they "should not take in emotions from the events and people they are reporting on" (p. 176). In contrast with Bell's (1998) journalism of attachment, journalists in Pantti's (2010) study believed that the journalists' personal feelings and individual morality should not influence reporting. Rather, they referred to the values of objectivity and detachment that dictate journalists ignore personal feelings. In ethnographic research at a Finnish fashion magazine, Soronen (2018) found that emotional labor was necessary at three levels: (1) in relation to its ideal audience, (2) in relation to collaboration, and (3) in relation to the subjects' identity as a professional in 
the magazine field. In her study, emotion was a positive stimulant that enabled editors to better relate to their model readers, facilitated organizational processes, and enabled better teamwork. Work was also found to be a stimulant of positive emotion, as workers enjoyed their work and found it "motivational and rewarding" (Soronen, 2018, p. 302).

The current study attempts to add explanatory power to journalistic roles and practice by integrating theories of emotion and sensemaking. Not only can individuals' sacrifices result in negative emotion, but also the pressure and subsequent action of individuals suppressing unpleasant emotion can result in role strain (Brotheridge \& Grandey, 2002; Côté \& Morgan, 2002). Understanding how journalists manage emotions and experience emotive dissonance can greatly inform scholars and practitioners of the journalist's struggle to balance micro-, meso-, and macro-level expectations.

\section{Present Study and Research Questions}

Several scholars call for more analysis into the factors that impede role enactment (Carpenter et al., 2016; Hellmueller \& Mellado, 2015; Tandoc et al., 2013). Additionally, little is known about how journalists manage conflicting expectations (Hellmueller \& Mellado, 2015) and regulate emotions (Pantti, 2010; Soronen, 2018; Wahl-Jorgensen, 2013). This dissertation does not see these two opportunities as mutually exclusive. This study addresses the role internalization and role enactment processes of political journalists in the U.S., including analysis into the influence of micro-, meso-, and macrolevel factors.

To better understand what factors inhibit role enactment, it is important to first understand what roles political journalists believe are most important to their job. Although several scholars have identified the roles that journalists internalize, little is 
known about how journalists prioritize or rank their cognitive roles (Vos \& Wolfgang, 2016). Therefore, this study's first research question asks:

RQ1: Which journalistic roles do U.S. political journalists believe are the most important to their work and why?

RQ1a: What is the hierarchy of journalistic role conceptions for journalists?

RQ1b: Why do journalists believe these roles are important?

As research has shown, just because a journalist understands a role to be important to their work does not mean that they will be able to practice that role (Tandoc et al., 2013). Journalists often have to deal with external and internal factors that influence their work (Shoemaker \& Vos, 2009) and occur at micro, meso, and macro levels. To gain a better understanding of how political journalists perceive complications to their work, this study's second research question asks:

RQ2: How do journalists identify and explain the factors that challenge the role enactment process?

RQ2a: What micro-level factors impede on journalists' ability to practice cognitive roles?

RQ2b: What meso-level factors impede on journalists' ability to practice cognitive roles?

RQ2c: What macro-level factors impede on journalists' ability to practice cognitive roles?

Journalists who are employed as staff writers, editors, or content managers at an organization may experience different workplace influences than freelance journalists. In 
general, freelancers maintain greater autonomy and flexibility in their work. They have the ability to not only be selective in the stories they cover (Jenkins, 2017), but also "to walk away from questionable jobs and get other jobs which more closely hone to their conscience" (Ryan, 2009, p. 658). Therefore, the first hypothesis of this study posits:

H1: Staff journalists will experience more meso-level challenges than freelance journalists.

As these factors influence the journalists' decision-making process, they may either support the behavioral scripts associated with the journalists' cognitive role, or they could pose as a contradiction to the type of behavior needed to fulfill a cognitive role. When expectations associated with a journalist's cognitive role conflict with expectations or limitations imposed upon the journalist, they may experience a "pulledapart feeling" (Barnett \& Baruch, 1985, p. 138). This feeling is indicative of role strain, or the phenomenon that occurs as journalists attempt to make sense of the diverse expectations (Goode, 1960). Role conflict occurs as the strain causes dissonance for the journalist (Lynch, 2007). Since role strain and role conflict are unexpected, they serve as interruptions to the journalist's work routine and trigger the sensemaking process in which journalists reflect on their experiences, behaviors, and actions to make sense of a situation. Thus, the third research question of this study asks:

RQ3: How do journalists make sense of role strain at work?

Emotion also plays a role in how journalists make sense of their cognitive and practiced roles. Emotion is not only an effect of role conflict, but also can be experienced, managed, and leveraged as part of the journalistic routine. Several scholars have identified how emotion and emotional labor are relevant to journalism (Pantti, 2010; 
Soronen, 2018; Wahl-Jorgensen, 2013), but emotional labor, emotion regulation, and sensemaking in the context of role conflict or journalistic roles have been underrepresented in the literature. With the understanding that emotion plays a role in the journalists' sensemaking processes, the final research question for this study asks:

RQ4: How do journalists make sense of emotional experiences at work?

RQ4a: To what extent do journalists practice emotional labor (surface and deep acting) at work?

Naturally, the type of job may influence the way emotional labor is experienced at work. Positions that are afforded more autonomy may translate into more emotional control and flexibility (Tunguz, 2016), and less frustration and anxiety (Spector \& Jex, 1991). Since freelance journalists in general have more autonomy than staff journalists (Jenkins, 2017; Ryan, 2009), it makes sense to assume that freelancers experience emotional labor differently than staff journalists. Thus, the second hypothesis supposes:

H2: Compared to freelance journalists, staff journalists will experience more surface acting and deep acting at work.

Years of experience in journalism can also result in autonomy and flexibility in work routines, but may also represent socialization implications on emotional labor. As journalists gain experience in the field, they are further socialized into the display rules of journalism that dictate acceptable/unacceptable behaviors (Kramer \& Hess, 2002). Longer-tenured journalists, or journalists who are well-established in the field, may also maintain more autonomy and flexibility in their work routines. This autonomy, as illustrated in the case of freelancers, could mean less emotional dissonance. Finally, as journalists renogiate their professional identity to become more aligned with experience, 
expectations, and display rules, they would be less likely to feel role strain at work and more likely to experience greater consistency between felt emotion and emotional display.

H3: The longer journalists have been on the job, the less they will experience deep acting and surface acting at work.

Additionally, scholars assume that socialization into gender display rules explains the tendency for women to suppress emotion more than men (Grandey, 2000; Hochschild, 1983; Kruml \& Geddes, 2000). One perception of gender influences on emotion is that women are more susceptible to emotions that embody nurturance and warmth (Hochschild, 1983). Even though empathy is often an acceptable - even valued asset in journalism (Bell, 1998; McGoldrick, 2011), neutrality and impartiality are longheld tenets of the field that require journalists to set aside personal beliefs and feelings. Therefore, this study proposes that female journalists will experience greater emotional dissonance than male journalists.

H4: Female journalists will experience more surface acting and deep acting than male journalists.

RQ4b: What emotions do journalists associate with role strain?

RQ4c: How do journalists regulate emotion associated with role strain?

\section{Summary}

News production is a process that involves individuals within and outside of journalism, organizations, technology, and various other moving parts that can often influence the way content is created. Even though journalists internalize certain roles and view them as important markers of their professional identity, their work may not reflect 
characteristics of those roles by the time their content makes it through that process. So what happens when journalists face challenges on the job that cause them to perform contradictory to their cognitive role? How do they stay motivated to do their job? This study attempts to fill a gap in role research by incorporating sensemaking and emotionality into the role enactment process to explain how journalists interpret competing expctations at work. In order to address the sensemaking process, this study must also identify the roles journalists view as important to their work and some of the challenges they face, as well as provide in-depth information into the journalists' sensemaking process. 


\section{Chapter Four: Method}

This study employed a qualitatively-driven sequential mixed methods design using a nested sample to explore role conceptions and role enactment. Therefore, it involved collecting quantitative data first and then explaining and expanding on those results with in-depth qualitative data that revealed subjugated knowledges (Hesse-Biber et al., 2015). In the quantitative phase of the study, survey data was collected from U.S. political journalists to understand their role conceptions, perceived influences on their work, and role reflections to assess whether micro-, meso-, or macro-level factors related to their perceived role performance. The second phase of the study was conducted as a follow-up to the quantitative results to help explain and expand on the quantitative data. In this exploratory follow-up, this phase explored the sensemaking process of U.S. political journalists as they discussed role strain and emotion through in-depth semistructured interviews. Overall, results from this study contribute first and foremost to journalistic role literature, as well as sensemaking and emotion research in the journalistic field.

This chapter provides an examination of the approach used to study how political journalists made sense of their role conceptions and the role enactment process. First, this chapter will address why a mixed methods study is an appropriate approach for this exploratory study. Next, this chapter focuses on the role of the researcher in each phase of the research project. Finally, this chapter outlines the research design including sampling, data collection, and data analysis procedures, as well as ethical and validity considerations. 


\section{Rationale for Method Selection}

Although researchers have somewhat converged over the past few decades on definitions, philosophies, and approaches of mixed methods research (Creswell, 2015), several varying conceptions of what mixed methods means and how it should be used still exist (Small, 2011). Historically, mixed methods research was perceived as quantitatively-driven research projects that included qualitative research as a supplemental tool in confirming or triangulating quantitative results (Small, 2011). Although some scholars still argue that mixed methods research should privilege postpositivism (Sale, Lohfeld, \& Brazil, 2002), others see value in grounding mixed methods studies in constructivist (Hesse-Biber et al., 2015), transformative emancipation, or critical realism paradigms (Shannon-Baker, 2016). What is commonly agreed on is the idea that mixed methods research requires components of qualitative and quantitative research - often referred to as strands (Creswell, 2015; Creswell \& Plano Clark, 2011; Hesse-Biber et al., 2015) - that are integrated at various phases of the research process (Collins, 2015). In order to be a mixed methods study, rather than just a series of multiple studies, qualitative and quantitative strands must be integrated in at least one of five areas: (1) research questions, (2) units of analysis, (3) sampling, (4) data collection, and (5) data analysis (Yin, 2006). Additionally, the benefit of mixed methods research is the combination and complementarity of quantitative and qualitative data (Creswell, 2015; Creswell \& Plano Clark, 2011). Therefore, qualitizing (conducting qualitative analyses on quantitative data) and quantitizing (conducting quantative analyses on qualitative data) data are not enough to consider a study mixed methods (Creswell \& Plano Clark, 2011). 
Definitions of mixed methods research also vary in the conceptualized relationship between qualitative and quantitative strands. To some, mixed methods studies require one core methodology and one subordinate methodology, but can be either qualitatively- or quantitatively-driven (Morse, 2015). Others agree that mixed methods research can embrace a dominant-less dominant relationship between the strands, but also contend that the strands can be equivalent within a single study (Creswell \& Plano Clark, 2011; Tashakkori \& Teddlie, 1998). In sum, mixed methods research refers to a single study (Yin, 2006, 2011) that uses both quantitative and qualitative data in either dominant-less dominant or equivalent designs.

In the 1970s and 1980s, scholars uselessly debated incompatibility of integrating qualitative and quantitative methods (Creswell \& Plano Clark, 2011). Qualitative and quantitative approaches differ at their very core of epistemological and philosophical assumptions about the nature of truth and reality. Many believe that researchers cannot be both constructivists and postpositivists (Sale et al., 2002). The incompatibility thesis was so prevalent and contested that this period of time was known as the paradigm wars (Creswell \& Plano Clark, 2011; Tashakkori \& Teddlie, 1998). Over the past few decades, researchers have adopted a pragmatist approach in order to assuage the concerns of epistemological purists. Pragmatism embraces a "whatever works" mentality (Tashakkori \& Teddlie, 1998) that grounds methodological considerations on the research problem or research questions (Creswell, 2015). It is outcome oriented (Shannon-Baker, 2016) and enables researchers to embrace a constructivist paradigm in one phase of a research project and a postpositivist paradigm in the next phase, or vice versa (Creswell \& Plano Clark, 2011). 
Even though pragmatism has been increasingly accepted as an approach over the past few decades (Small, 2011), mixed methods scholars still must prepare for criticism specific to their methodological choices. Often, these critiques concern commensurability of the two seemingly opposite methodologies (Small, 2011). However, most of the critics often overestimate how tightly coupled epistemology and everyday practice really are (Sale et al., 2002; Small, 2011). Delli Carpini (2013) even calls on researchers to decouple positivism from quantitative research in mixed methods studies of entertainment and politics. Despite the criticism, there are still benefits to mixing the strands, including complementarity and triangulation. As research problems become more complex, qualitative and quantitative strands enable collaboration between worldviews that can help address complex issues (Creswell \& Plano Clark, 2011). Complementarity between the strands makes mixed methods approaches more salient in addressing the research problems that monomethod research cannot address (Singer, 2017). Researchers have also used mixed methods to triangulate data (Creswell \& Plano Clark, 2011) and build confidence in their conclusions (Small, 2011).

Grounding mixed method research in pragmatism means that the research problem, purpose, and questions will guide the design. Therefore, it is important for guiding research questions to inquire about phenomena that can only be addressed through both qualitative and quantitative methods. Although subordinate research questions may be posed specifically addressing each method, the guiding questions should require insight from both strands. For the purposes of this study, survey and interview methods provided an adequate amount of data to address each guiding research question. 
Additionally, the research problem serves as a guide to the research design. Scholars have differentiated between qualitatively-driven and quantitatively-driven mixed methods designs (Creswell \& Plano Clark, 2011; Hesse-Biber et al., 2015; Sale et al., 2002; Tashakkori \& Teddlie, 1998). Quantitatively-driven mixed methods research adopts a deductive theoretical drive, where the qualitative component is secondary and used for elaboration or illustration (Morse, 2015). Qualitatively-driven mixed methods research has an overall emphasis on inductive reasoning (Morse, 2015) and lived experiences of the subjects (Hesse-Biber et al., 2015). Although researchers may identify as pragmatists, certain complexities in research problems and research goals may require them to privilege either postpositivist or constructivist philosophies.

Use of mixed methods in the present study. The value of mixed methods research is in its ability to more comprehensively address complex phenomena in a way that monomethod research could not (Tashakkori \& Teddlie, 1998). Since news practices are "changing with unrelenting speed, unprecedented scope, and unforeseeable consequences," the complexity of journalistic practice makes it an area ideal for mixed methods research (Singer, 2017, p. 206). Over the past two decades, journalism's boundaries have increasingly blurred. Definitions of who a journalist is and what journalism have become more and more complex as publishing platforms are increasingly accessible (Schudson, 2011). Since journalism is multimodal and ubiquitous, research inquiry into the field should also become more complex (Singer, 2017). Within journalism studies, researchers have used mixed methods approaches to explore the relationship between audience click metrics and editorial decisions on story selection (Welbers, Van Atteveldt, Kleinnijenhuis, Ruigrok, \& Schaper, 2016), the subjective 
interpretations of online news habits (Zeller, O’Kane, Godo, \& Goodrum, 2014), the physiological responses to online news content (O’Brien \& Lebow, 2013), and mobile news consumption habits (Van Damme, Courtois, Verbrugge, \& De Marez, 2015).

One area of journalism research that could benefit substantially from mixed methods inquiry is journalistic role performance (Singer, 2017). So far, research on journalistic roles has been overwhelmingly monomethod (see Carpenter et al., 2016; Tandoc, 2014; Tandoc \& Takahashi, 2013), with few exceptions (see, e.g., Ryfe, 2012; Tandoc et al., 2013). Since content analytic approaches are appropriate for understanding the manifestation of journalistic roles in news content (Hanitzsch \& Vos, 2017), many scholars employ text-based analyses to study practiced roles. Carpenter, Boehmer, and Fico (2016) attempted to bridge the gap between role conception and role enactment using a content analysis - the approach they argued is best in understanding the correlation between role conception and observed journalistic behavior. Similarly, Mellado (2015) proposed an operationalization of journalistic roles for use in content analytic research. However, a shortcoming of content analysis in studies of journalistic role performance is its limitation to serve as only an observation of whether certain roles are enacted, rather than addressing why journalists enact particular roles (George, 2013). Tandoc and his colleagues (2013) took content analytic research into journalistic role performance one step further by partnering their content analysis with survey research. This enabled the researchers to understand the discrepancy between role conceptions and role enactment. But the questions still remain: Why are certain roles able to be fulfilled in some situations and not in others? What influences the role enactment process such that journalists fall short of fulfilling their ideal roles? 
Since research into the role enactment process in the context of sensemaking is understudied in journalism studies, this study takes an exploratory approach and foregrounds the lived experiences of the research participants. The quantitative strand in this study was useful for identifying the specific sample necessary for the qualitative follow-up, as well as further validating the qualitative strand (Hesse-Biber et al., 2015). Figure 1 shows the methodological model used in this study.

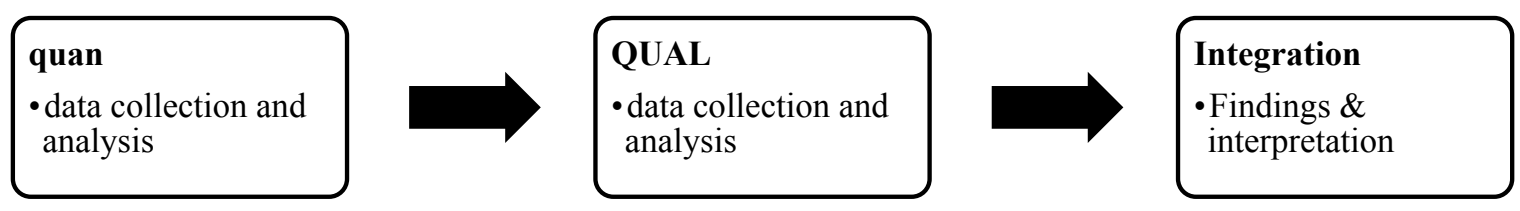

Figure 1. Qualitatively Driven Sequential Mixed Methods Design Process.

Combining surveys with interviews has been a popular approach to mixed methods research (Creswell \& Plano Clark, 2011; Hesse-Biber et al., 2015; Tashakkori \& Teddlie, 1998). According to Singer (2017), this methodological partnership can be beneficial to the study of journalistic roles. Although sequential qualitatively-driven mixed methods designs are usually conceptualized as a qualitative strand followed by a quantitative strand (Creswell \& Plano Clark, 2011; Tashakkori \& Teddlie, 1998), exploratory sequential mixed methods research can also feature a quantitative strand that precludes the qualitative strand (Hesse-Biber et al., 2015). In this design, the questionnaire will foreground the interviews, but sampling for the qualitative interviews will be based on respondents to the survey. Nested samples such as this provide the opportunity for researchers to triangulate quantitative results with qualitative follow-up, go into more depth on responses from the questionnaire, and provide complementary insights from each strand (Hesse-Biber et al., 2015). The survey provided generalizable 
findings regarding the hierarchy of journalistic role conceptions, as well as perceptions of challenges journalists faced in role enactment. The interviews provided rich description of those challenges and captured the nuanced differences existing in the lived experiences of political journalists.

For the purposes of this study, a survey was a useful instrument for making generalizations about attitudes, opinions, and beliefs (Frey, Botan, \& Kreps, 2000) of U.S. political journalists, including measuring role conceptions (Tandoc et al., 2013) and influences to journalistic work (Hanitzsch \& Mellado, 2011). Additionally, surveys are a relatively low-cost method to reach a large and dispersed audience - such as political journalists - in a way that can ensure anonymity (Frey et al., 2000). Surveys enable participants to respond at their own convenience (Frey et al., 2000), making it ideal for journalists who are concerned with deadlines and other routine pressures.

Based on survey responses, follow-up interviews were useful in expanding on the experiences of the political journalists (Hesse-Biber et al., 2015) and explaining how things happen (Baran, 2016). Earlier work into journalistic roles involved interviews with journalists (Cohen, 1963). Since then, interviews have been useful in understanding how news production practices are evolving (Boczkowski, 2010), how digitization influences role ideals (Ryfe, 2012), and how news editors make story selection decisions (Welbers et al., 2016). This study used semi-structured interviews to help explore the phenomena with flexibility built into its design (Marshall \& Rossman, 1995). As one of the "most powerful methods in the qualitative armory" (McCracken, 1988, p. 9), interviews are useful for understanding the rationale of journalists. Additionally, semi-structured interviews allow for researchers to adapt to the ebb-and-flow of the conversation and 
have been useful in studies asking participants to reflect on emotional situations (Gross, Richard, \& Johns, 2006).

\section{Researcher's Role}

Although both quantitative and qualitative approaches involve value-laden inquiry (Sale et al., 2002), they differ on the role of the researcher throughout the research process. Since mixed methods research integrates both strands, the researcher must take different roles depending on the strand. For the quantitative strand, the researcher and the phenomenon are "independent entities" (Sale et al., 2002, p. 44) and the researcher is able to investigate without influencing the study (Guba \& Lincoln, 1994). Conversely, qualitative inquiry is value-bound (Tashakkori \& Teddlie, 1998) and the researcher is more engaged with research participants and data analysis. For example, the success or failure of an interview could depend on the researcher's ability to build rapport with interviewees (Roulston, 2010). In this view, the researcher interacted with participants by guiding the conversation during in-depth interviews, but did not influence participants' responses to interview questions. Therefore, the researcher took an observer-participant role (message gathering), as well as an interviewer role in recording narratives (Tedlock, 2003).

With permission from the participants, interviews were recorded and transcribed for analysis. The researcher also took notes throughout the interview to acknowledge nonverbal communication - such as heightened emotion or hesitancy - that could further inform the analysis. Finally, since the researcher does not have a background in political reporting, let alone in news production, she verified her interpretations of subjects' answers throughout the course of the interview. By practicing member checks throughout 
the course of data collection, the interviewer was able to ensure valid interpretations of the data (Kvale, 1996).

\section{Study Design}

This qualitatively-driven mixed methods study used survey and interview methods to develop a more comprehensive understanding of political journalists' sensemaking process throughout role enactment. This study used survey data to make generalizations about the role conceptions of political journalists and the factors that influence role enactment. Follow-up interviews provided more thorough descriptions of those factors and uncovered how journalists made sense of structural conflict and emotion. Since this study used a mixed methods approach that combined qualitative and quantitative strands of inquiry, there are two components of sampling and data collection procedures. Also, mixed methods research offers additional complexities to concerns of research ethics (Preissle, Glover-Kudon, Rohan, Boehm, \& DeGroff, 2015) and validity (Collins, 2015).

Data sampling. Traditionally, political reporters serve to uphold the canons of democracy by serving as stand-ins for the public in political events, interpreters of political discourse, and surveillance of political conduct. However, when micro-, meso-, or macro-level factors inhibit them from fulfilling their normative roles, this conflict in turn influences the type of content reaching the public. This study focuses on experiences and role conceptions of political journalists within the U.S. Although journalists who represent other beats are also subjected to structural conflict during the news production process, the current rift in the relationship between U.S. government officials and political journalists makes this particular focus timely and relevant. As journalists grapple 
with the aftermath of an unexpected election and challenges inherent in covering a president who has been outwardly critical of the press, they represent a population of journalists who are currently evaluating and making sense of press practices. By accessing this particular group of journalists, the researcher is able to tap into a segment of the greater journalism population that has experienced challenges, influences, and emotion on the job.

Since this study focuses on one niche area of journalism, the population in question can realistically serve as the sampling frame. Journalism databases such as CisionPoint and Leadership Media are useful tools in identifying a wide range of journalists across the U.S. Using these tools, the researcher identified journalists belonging to the "government" beat or who covered politics. The combined list from Leadership Media and CisionPoint served as the sampling frame for this study and represented 5,461 journalists. Since the databases are not perfect representations of the population, additional vetting of survey participants was required to ensure that responses were collected only from those who primarily cover politics or government. Therefore, the first question of the survey was a "yes/no" question that stated: "I consider myself a political journalist and primarily cover electoral politics and/or local, state, regional, or national government." Respondents who indicated "no" were then vetted by the researcher. If the researcher deemed that the respondent predominantly reported on government or politics, the responses were kept for analysis. For example, one participant indicated "no" to the question, but upon evaluation of the participant, the researcher found that the respondent primarily covered city council and local commissions. Therefore, this participant was included in the sample. 
Follow-up interviews were conducted on some of the survey participants, which provided in-depth information (Creswell \& Plano Clark, 2011) on journalists' lived experiences. Because of the complex nature of the relationship between role internalization, role enactment, identity, and sensemaking, the researcher used a maximal variation sampling procedure "in which diverse individuals are chosen who are expected to hold different perspectives on the central phenomenon" (Creswell \& Plano Clark, 2011, p. 174). Characteristics used to identify the sample included gender, age, years of experience, medium, and race/ethnicity. The central idea behind this sampling approach is to reflect differences in respondents' views and provide "a complex picture of the phenomenon" (Creswell \& Plano Clark, 2011, p. 174). At the end of the survey, participants had the option to follow a link to an online form where they could then opt-in to the follow up interview.

Data collection and management. The survey was administered using Qualtrics - an online survey management software that enables survey tracking, design, notifications, and reminders. In order to increase the response rate of the survey, two follow-up emails were scheduled through Qualtrics to remind the recipients of the opportunity to help in research. The first invitation to participate in the survey was sent to all 5,461 journalists in the sampling frame in December 2017. Of those 5,461 emails, 401 bounced and 70 recipients notified the researcher that they no longer practiced journalism. Additionally, several recipients indicated that it was either against organizational policy to participate in academic research or did not participate due to personal convictions. The two follow-up reminders were administered two-to-three weeks apart. Overall, 434 respondents opened the survey: 422 journalists consented and 
began the survey and 12 journalists did not consent. Of the 422 journalists who consented to the survey, 24 dropped out before reaching the qualifying question. 97 journalists indicated they were not a political journalist from the qualifying question and were not considered political journalists based on the researcher's evaluation. An additional 52 journalists dropped out of the survey after the qualifying question and before any meaningful data could be collected. In total, 249 partial responses were collected resulting in 204 completed responses.

Survey participants. Of the 204 completed surveys, $70.6 \%$ of respondents were male $(n=144), 27.9 \%$ were female $(n=57)$ and $1.5 \%$ declined to answer $(n=3)$. Only 6 journalists were between the ages of 18 and 24 (2.9\%), but 57 journalists were between 25 and 34 years old (27.9\%), 31 were between 35 and 44 years old (15.2\%), 38 were between 45 and 54 years old (18.6\%), 50 were between 55 and 64 years old (24.5\%), 14 were between 65 and 74 years old (6.9\%), five were over 75 years old $(2.5 \%)$ and three declined to answer (1.5\%). Respondents were overwhelmingly white/Caucasian $(n=175$, 85.8\%). Only 10 participants identified as black or African American (4.9\%) and four identified as Hispanic or Latino (2.0\%). American Indian or Alaska Native, Asian or Asian American, and Native Hawaiian or Other Pacific Islander each accounted for one person $(n=3,1.5 \%)$. Five respondents indentified with a race/ethnicity not listed $(2.5 \%)$ and seven declined to answer (3.4\%). The majority of participants indicated having a bachelor's degree or equivalent $(n=120,58.8 \%) .68$ participants had a master's degree or equivalent $(33.3 \%)$, followed by those who had a doctorate $(n=12,5.9 \%)$. Two participants undertook some university studies, but did not earn a degree (1.0\%), and only 
one participant's highest level of education was high school (0.5\%). One journalist declined to answer $(0.5 \%)$.

In regards to aspects of the professional landscape of the participants, the survey also asked about total years of experience in the field, their primary medium, and whether they were primarily a freelance reporter. $35.8 \%$ of the journalists had been in the field more than 25 years $(n=73), 22.1 \%$ had five to nine years of experience $(n=45), 16.7 \%$ had 10 to 14 years of experience $(n=34), 11.8 \%$ had 20 to 24 years of experience $(n=$ 24), $7.4 \%$ had 15 to 19 years of experience $(n=15)$, and $6.4 \%$ had less than four years of experience $(n=13)$. When it came to medium served, $41.7 \%$ of journalists indicated they worked primarily for an online publication $(n=85)$, this was followed by newspaper $(n=$ $72,35.3 \%)$, radio $(n=15,7.4 \%)$, television $(n=10,4.9 \%)$, a news service or bureau $(n=$ $9,4.4 \%)$, and magazine $(n=3,1.5 \%) .4 .9 \%$ of respondents indicated working for a medium not listed (such as podcast) or as splitting their time evenly across multiple platforms $(n=10)$. Finally, only 28 respondents considered themselves primarily freelance journalists $(13.7 \%)$.

Quantitative measures. The purpose of the survey is to collect generalizable data pertaining to role conceptions of political reporters and factors influencing their work. This includes understanding the roles the journalists consider ideal and demographic information (i.e., age, years of experience, medium, status in the newsroom, and education level) that could correlate to role conceptions and provide insight into the role internalization process. This also includes insight into the journalists' perceptions of micro-, meso-, and macro-level factors that impede role enactment. 
Role conceptions. This study adapted items from previous studies measuring journalistic role conceptions (Tandoc, 2014; Tandoc \& Takahashi, 2013), as well as Hanitzsch \& Vos' (2018) operationalization of journalistic roles, resulting in a list of 18 statements (see Appendix A). Respondents were asked to rate on a 5-point Likert scale how much they agreed to each of the 18 items in describing their role as a journalist. Items were shuffled in the execution of the survey to account for respondent fatigue or sequencing error.

Influences to role enactment. Based on a compilation of factors identified by previous studies on the news production process and journalistic routines (Hanitzsch \& Mellado, 2011; Shoemaker \& Vos, 2009; Tandoc \& Takahashi, 2013), this study identified 21 items among micro-level, meso-level, and macro-level factors influential in the news cycle (see Appendix A). Micro-level structures that could inhibit role enactment included individuals' value systems and morality (Shoemaker \& Vos, 2009), as well as social reference groups such as family, friends, or colleagues (Hanitzsch \& Mellado, 2011). Meso-level factors were operationalized as medium, size of the organization, and profit orientation (Shoemaker \& Vos, 2009), as well as management structure (Hanitzsch \& Mellado, 2011) and routines. Macro-level factors included inter-institutional relationships as they influence sourcing, law and regulation (Hindman, 1997), and pressure from external groups such as public relations, politicians, and interest groups (Hanitzsch \& Mellado, 2011).

Emotional labor. In order to assess the extent to which journalists experience emotional labor, this study adapted previously developed scales used in organizational and educational research (Kruml \& Geddes, 2000; Naqvi, 2014). Using a 5-point Likert 
scale, this survey asked respondents to indicate how often they experience each of the six items. Three items are reflective of surface-level acting, such as "I put on a mask in order to express the right emotions for the job." This scale was reliable (Cronbach's $\alpha=.67$ ). The other three items were reflective of deep acting, such as "I really try to feel the emotions I have to show as part of my job" (see Appendix A). This scale was also reliable (Cronbach's $\alpha=.70)$.

Qualitative data collection. Upon completion of the questionnaire, survey participants were asked whether or not they wanted to opt in to follow-up interviews. Since in-person interviews can be expensive and timely, all interviews were conducted over the phone and ran anywhere from 25 to 45 minutes long. Although the researcher followed a specific interview protocol (see Appendix B), interviews were semi-structured to allow for flexibility within the conversation (Marshall \& Rossman, 1995). The interview protocol was designed to elaborate on the circumstances surrounding role strain, the sensemaking process, and emotion regulation strategies.

Although the interviews were recorded and transcribed, the researcher took notes during the interview to notate any significant pauses, changes in intonation, or other nonverbal cues that were not captured in the transcript. All interviewer notes were kept in a journal, as well as transposed onto the transcription in the proper context in order for the researcher to better assess those cues within their original context. After all interviews were completed, half of the recordings were transcribed by the researcher and half were transcribed by a third-party.

Interview participants. Out of the 204 completed surveys, 87 respondents opted in to follow-up interviews. Due to time and financial limitations, not every journalist could 
be interviewed. Using a maximal variation sampling procedure, interviewees were selected based on age, gender, race/ethnicity, primary medium, and years in journalism. Ten women and 11 men were interviewed. Participants ranged in age from 18-24 years to 74-85 years. Years of experience averaged 15.1 years and ranged from 2 to 50 years. Participants represented various media outlets, including newspaper $(n=7)$; online, including online-only newspapers and magazines $(n=6)$; audio/radio, including podcasting $(n=3)$; television $(n=3)$; and news service/bureau $(n=2)$. Two interview participants were primarily freelance reporters.

Ethical considerations. Mixed methods research introduces additional complexities to ethical considerations than monomethod approaches. In general, research projects are determined to be ethical based on compliance and integrity, where compliance stipulates that researchers treat participants fairly and integrity requires that the research purpose and research process match (Preissle et al., 2015). Researchers should pay particular attention to ethical considerations in the research design phase, recruiting participants, researcher relationships with participants and other researchers, data collection and analysis, and representation of research participants (Preissle et al., 2015). Since the survey used in this study ensured confidentiality, the researcher did not share any personal identifying information with another party. Research conducted using the survey and interviews was in line with the requirements of the campus Institutional Review Board. Finally, all participants were briefed up-front on the nature and intention of the research.

Coding procedures. After data were adequately collected, the researcher conducted counterpart analyses in which qualitative data and quantitative data were 
intertwined to tell a story (Yin, 2006). This type of analysis is commonly found in research that uses qualitative interviews to supplement quantitative findings (Yin, 2006). First, confirmatory factor analyses using structural equation modeling provided insight into the structures of journalistic roles and challenges to the role enactment process, serving as a foundation for scale development for future studies (Hoyle, 2000). Second, inferential analyses examining the relationship between demographic variables and role conceptions contributed to socialization and role internalization theories. Additionally, the researcher provided descriptive statistics for each variable, as well as examined interactions between perceived influences and demographics.

For interview data, a first reading of the transcripts helped identify common themes and topics, paving the way for more thorough future analyses (Dey, 1993). During the first read, the researcher made initial annotations, including notes and memos (Charmaz, 2001) that capture sensitizing concepts (Blumer, 1954). A subsequent reading of the data enabled the researcher to further identify emergent categories and conceptually splice, link, and connect categories (Dey, 1993). Coding labels were informed both by theory and participants' exact words (i.e., in vivo coding) and assigned through manual coding along one margin of the transcript, leaving the other margin open for notes on broader themes (Creswell \& Plano Clark, 2011). After evidence was grouped into codes, codes were grouped into larger themes that the researcher applied to the larger research project in context with survey results (Creswell \& Plano Clark, 2011).

Validity. Concerns of validity in mixed methods research is more complex than concerns for qualitative or quantitative studies, precisely because researchers must ensure that both qualitative and quantitative strands are executed in a way that ensures method- 
specific validity, as well as addresses threats specific to mixed methods research (Collins, 2015; Creswell \& Plano Clark, 2011). In the current study, nested sampling - or selecting survey respondents for follow up inquiry - helped limit the threat of inappropriate or inadequate sampling (Creswell \& Plano Clark, 2011). It is also important to time the strands of mixed methods research in a way that makes sense to the research purpose and limits the influence of one strand onto the results of the other strand (Collins, 2015). Due to the nature of this sequential study, following up a quantitative survey with in-depth interviews allows the researcher to discover differences in the lived experiences of the participants in a way that supplements survey data (Hesse-Biber et al., 2015). Another validity concern in mixed methods research is the tendency to conflate meanings across multiple paradigms (Sale et al., 2002). Although the survey is constructed from theoretical conceptualizations and operationalizations of what it means to identify with a "role," the researcher was cognizant of alternative explications of journalistic roles as she transitioned into the interview process. Put another way, since the researcher was exploring the relationship between role conflict and role enactment using qualitative and quantitative methods, and each method carries different philosophical assumptions, then the researcher needed to be clear what the exact phenomenon under study was in each strand of the design (Sale et al., 2002). In this case, qualitative interviews served to go into more depth in the sensemaking process and emotion regulation - difficult concepts to capture using survey methods.

Mixed method studies must also ensure validity in quantitative strands and qualitative strands, independently. Quantitative research requires researchers to be cognizant of threats to internal and external validity (Collins, 2015). External validity 
speaks to the generalizability of the findings and is based on the sampling procedures. Sampling in this study is random and the researcher worked to ensure adequate response rates. Internal validity depends on the ability of the researcher to develop reliable and valid measures and that the findings are accurate (Frey et al., 2000). In order to ensure that the measures in the survey were valid, the researcher grounded operationalizations in theory, ensuring face validity, as well as consolidated previously accepted measures that were established as valid, thus ensuring criterion validity. Finally, confirmatory factor analyses of role conceptions and challenges further contributed to the construct and discriminant validity of those measures. After the initial construction of the questionnaire, a pretest helped uncover issues of validity and problems with the overall construction of the survey (American Association of Public Opinion Research, n.d.).

Threats to internal validity were also accounted for in order to ensure accurate findings. At the level of the research design, measurement validity - as addressed above is just one component. Internal validity of the research experiences threats throughout the design and implementation of survey research. Enabling randomization of the question sequence in particular sections of the survey helped reduce the threat of participant fatigue (Frey et al., 2000). Especially on longer surveys, respondents may experience fatigue, drop out of the survey, or skip certain questions all together. By randomizing the sequence of items, the researcher limited these threats. Additionally, it is important throughout survey construction and implementation to practice "quality checks" (Standards/Ethics). Part of this exercise involved feedback from other scholars prior to pretesting the survey to double check the logistics of the survey's construction. 
The qualitative strand must also ensure validity in its findings (Collins, 2015). Validity in qualitative methods, however, does not mean the same thing as in quantitative research. Rather than focusing on accuracy, qualitative researchers take strides to make sure their findings are trustworthy (Tashakkori \& Teddlie, 1998). In this study, the researcher used peer checks - that is, consulted with colleagues to see if their analyses of interview data converged or diverged - to minimize alternative explanations of the data (Tashakkori \& Teddlie, 1998). Additionally, the researcher relied on member checks to ensure respondent validation (Torrance, 2012). Finally, the researcher provided thick description in the write up of the results (Tashakkori \& Teddlie, 1998).

Limitations. Although mixed methods research offers a more comprehensive approach to understanding complex phenomena (Singer, 2017; Tashakkori \& Teddlie, 1998), this study is not without its limitations. First, this study relied on journalists' perceptions of the influences that inhibit them from fulfilling their ideal roles. What this study did not take into account is the current context of each respondent's choice. For example, if a journalist is having a bad day when they take the survey because they received a harsh critique of their work by an editor, they may hastily indicate that managers and editors inhibit them from doing their job. Research reliant on self-report data must be understood in the context of such limitations (Frey et al., 2000). Similarly, interviewees may have been reluctant to share information that addressed a time or times in which they were unable to fulfill their roles - or, put simply, to do the job they believe they ought to do. Finally, although a point of saturation should be reached in the qualitative strand of the study, the use of variation sampling may not have produced accounts representative of the larger pool of survey respondents. 


\section{Summary}

Overall, this study addressed two underrepresented areas of journalism studies.

First, it focused on the discrepancy between role conception and role enactment. Beyond identifying that a conflict exists between cognitive and practiced roles (Tandoc et al., 2013), this study attempted to pinpoint why that conflict exists and what journalists perceived as the roots of role strain. Second, this study highlighted how journalists made sense of their work in order to understand how role negotiation occurs over time. Not only is a journalist's identity an important factor in role internalization (Tandoc \& Takahashi, 2013), but emotions journalists feel while on the job may influence whether journalists alter their role conceptions. Part of this is building on previous studies (Pantti, 2010; Soronen, 2018; Wahl-Jorgensen, 2013) that have attempted to bring attention to the role of emotion in journalism practice. Insights from this area of research will have significant practical implications for journalism education and training.

In a time when there may be extra stressors in journalistic life (i.e., emerging technologies or challenging political relationships), it seems appropriate to attempt to identify what challenges (old or new) are facing U.S. journalism. The purpose of this exploratory mixed methods study is to provide insight into these complex areas that is more comprehensive than monomethod research could provide. Since journalism in the U.S. has benefited from freedoms provided under the First Amendment, it has adopted normative functions and roles that are designed to facilitate public life and the political process (Christians et al., 2009; Merrill, 1974; Nerone, 2013; Siebert et al., 1963). Such roles include the monitorial, collaborative, facilitative, and radical roles (Christians et al., 2009). Those broad generalizations have been further refined into disseminator, mobilizer 
(Weaver et al., 2007), adversarial (Hanitzsch, 2007), watchdog (Hodges, 1996), and developmental (Pintak \& Setiyono, 2011) roles, among many others, and all speak to various functions of the press (Hanitzsch \& Vos, 2017).

From studies into journalistic role enactment (Carpenter et al., 2016; Tandoc et al., 2013), it is known that journalists practice different roles and that those roles are not always representative of their role conceptions. It is also known that there are several domains of structures that influence journalists, news organizations, and the journalistic institution (Hanitzsch \& Mellado, 2011; Shoemaker \& Reese, 1996; Shoemaker \& Vos, 2009). Whether those structures are perceived factors for the chasm between cognitive and practiced roles is not known. It is also not known how journalists navigate their experiences in the role construction process and negotiate roles over time. To better elucidate this process, it is important to understand how journalists make sense of role conflict and role strain. Applying a sensemaking framework can help researchers discover how individuals make sense of role conflict or unfulfilled roles (Mandler, 1984). Additionally, journalists - as people - are prone to emotion (Kovach \& Rosenstiel, 2014; Pantti, 2010; Soronen, 2018; Wahl-Jorgensen, 2013). When neutrality and objectivity are at the forefront of institutionalized norms (Wahl-Jorgensen, 2013), journalists may experience emotive dissonance (Hochschild, 1983) and seek emotion regulation strategies (Wahl-Jorgensen, 2013) to help them make sense of their work. Thus, three overarching questions guide the study: What are the journalists' cognitive roles, what factors challenge those roles, and how do journalists make sense of emotionality and role strain? As all of these intricate parts come together in the theoretical framework of this study, it is easy to see the complexities of the role internalization, enactment, and 
negotiation processes. As journalism is already a complex institution (Singer, 2017), this only further complicates the phenomena under study. By employing a mixed methods approach, the findings incorporate generalizable survey data with in-depth interview data in order to more thoroughly address the process of journalistic role construction among U.S. political journalists. 


\section{Chapter Five: Findings}

\section{Journalistic Roles}

RQ1 asked about the roles journalists identify as important to their work and why they believe these roles are important to society. To answer this question, survey data provided the generalizable identification of journalistic roles and the hierarchy of those roles, while the qualitative interviews provided a deeper understanding of why those roles are important. In order to identify journalistic roles, the researcher conducted an exploratory factor analysis of the roles items. Previous quantitative studies that analyze journalistic roles assess role items individually (Weaver \& Wilhoit, 1986; 1996) or cluster items into a typology of journalistic roles and study particular segments of journalism (Tandoc, 2014); however, little is known about how political journalists interpret the roles important to their work.

To identify the typology of roles, the researcher conducted a factor analysis using principal axis factoring with oblique (direct oblimin) rotation. Results extracted five factors, explaining $60.34 \%$ of total variance; KMO (Kaiser-Meyer-Olkin Measure of Sampling Adequacy) $=.79$, Bartlett's Test of Sphericity, $\chi^{2}(153)=1327.77, p<.001$. Using a cutoff value of .50 , seven items failed to load on the five extracted factors. These items include: "educate the audience on public problems," "defend the government and its policies," "facilitate in the advancement of social development," "reduce tension in my community," "provide the audience with a forum to express their views," "serve as the mouthpiece of the people," and "investigate official claims." The failure of some of these items to load on any of the factors is not completely unexpected. For instance, journalists indicated that "educate the audience on public problems" $(M=4.67, \mathrm{SD}=.73)$ 
and "investigate official claims" $(M=4.56, \mathrm{SD}=.88)$ were extremely important elements to their work. Rather than measuring a specific role, these items could be representing important features of journalism, regardless of how the journalists perceive their role. Additionally, journalists indicated that "defend the government and its policies" was extremely unimportant to their work $(M=1.59, \mathrm{SD}=.90)$. Consistent with the idea that most journalists in the U.S. would argue that it is not their job to defend the government or its policies, it is not surprising that the item associated with a more collaborative role did not strongly load on any factor. Therefore, these items were omitted from the analysis. The other items that failed to load on any factors included a facilitative item ("facilitate in the advancement of social development," $M=3.18, \mathrm{SD}=1.14$ ), a mediator item ("reduce tension in my community," $M=2.63, \mathrm{SD}=1.09$ ), an access provider item ("provide the audience with a forum to express their views," $M=3.21, \mathrm{SD}=1.25$ ), and an adversary item ("serve as a mouthpiece of the people," $M=2.79, \mathrm{SD}=1.21$ ). These items were included, but analyzed individually.

In order to determine a stronger model of the data, the researcher reparameterized the model excluding the seven items listed above. The new model resulted in a fourfactor solution; $\mathrm{KMO}=.71$, Bartlett's Test of Sphericity, $\chi^{2}(55)=672.84, p<.001$, $67.12 \%$ total variance explained (see Table 2). Structural equation modeling (SEM) using the maximum likelihood (ML) estimation in the package R (Rosseel, 2012) was used to further confirm the factors identified by the exploratory factor analysis. The model fit of the latent variables was adequate, $\operatorname{ML} \chi^{2}(38)=95.40, p<.001, \mathrm{RMSEA}=.08(.06-1.0)$, $\mathrm{CFI}=.91, \mathrm{NNFI} / \mathrm{TLI}=.87, \mathrm{SRMR}=.06($ see model in Appendix F). 
Table 2. Exploratory Factor Analysis of Role Conceptions

\begin{tabular}{|c|c|c|c|c|}
\hline & Factor 1 & Factor 2 & Factor 3 & Factor 4 \\
\hline Provide an analysis of events in the news & .69 & & & \\
\hline Critique political and business leaders & .78 & & & \\
\hline Encourage people to participate in civic activity & & & .86 & \\
\hline Improve communication between officials and citizens & & & .57 & \\
\hline Serve as a critical observer of political conduct & .66 & & & \\
\hline Tell people about issues they should believe in & & & & .53 \\
\hline Advocate for social change & & & & .93 \\
\hline Curate information for my readers & & .40 & & \\
\hline Report things as they are & & .80 & & \\
\hline Provide an explanation of the news & & .58 & & \\
\hline Serve as a mouthpiece for the disadvantaged. & & & & .55 \\
\hline Eigenvalues & 2.93 & 2.06 & 1.35 & 1.04 \\
\hline Variance Explained (\%) & 26.66 & 18.68 & 12.29 & 9.49 \\
\hline Cronbach's $\alpha$ & .74 & .61 & $.49^{\mathrm{a}}$ & .69 \\
\hline
\end{tabular}

The first factor closely resembled a monitorial role (Christians et al., 2009), but also included an item resembling an analyst role (Hanitzsch \& Vos, 2018). This factor included three items: "Provide an analysis of events in the news," "critique political and business leaders," and "serve as a critical observer of political conduct." It is reliable (Cronbach's $\alpha=.74)$.

The second factor was similar to an informational role and included three items: "curate information for my readers," "report things as they are," and "provide an explanation of the news." As evident in Table 2, the curator item did not load highly on 
this factor. However, combining these three tasks is consistent with previous research that argued tasks associated with curator, storyteller, and disseminator roles all address the informational-instructive function of journalism (Hanitzsch \& Vos, 2018). Therefore, the curator item was included in this factor. The reliability of this variable is undesirable, but acceptable (Cronbach's $\alpha=.61)$.

The third factor resembled a participatory role, which calls for a press that facilitates and enables the development of society (Christians et al., 2009). It included two items: "encourage people to participate in civic activity" and "improve communication between officials and citizens." The two items are moderately correlated, $r(248)=.49, p<.001$.

The fourth factor was similar to an advocate-radical role of the press and included three items: "tell people about issues they should believe in," "advocate for social change," and "serve as a mouthpiece for the disadvantaged." This factor is also reliable (Cronbach's $\alpha=.69$ ).

Hierarchy of journalistic roles. Based on an evaluation of the means, political journalists indicated that the informational role was most important to their work $(M=$ $4.45, \mathrm{SD}=.61$ ). It also had the smallest standard deviation, meaning there was little variation in perceptions of its importance. The second most important role was the monitorial role $(M=4.11, \mathrm{SD}=.87)$ followed by the participatory role $(M=3.53, \mathrm{SD}=$ $.96)$. The access provider role $(M=3.21, \mathrm{SD}=1.25)$, facilitative role $(M=3.18, \mathrm{SD}=$ $1.14)$, advocate role $(M=2.87, \mathrm{SD}=1.02)$, and adversarial role $(M=2.79, \mathrm{SD}=1.21)$ were neither important nor unimportant to the journalists work. The mediator role ( $M=$ $2.63, \mathrm{SD}=1.09)$ was viewed as the least important role. 
The survey also asked journalists to assign a rank to 12 role items ( 1 being the most important.) Consistent with the descriptives of each role, journalists ranked the informational role as most important $(M=3.51, \mathrm{SD}=2.09)$, followed by the monitorial role $(M=3.82, \mathrm{SD}=1.91)$, the participatory role $(M=7.68, \mathrm{SD}=3.04)$, and the advocate role $(M=8.23, \mathrm{SD}=2.41)$. The mediator role $(M=9.22, \mathrm{SD}=2.40)$ exhibited the least importance.

Importance of journalistic roles. Although survey data revealed which roles were important to political journalists, interviews with the journalists uncovered two broad themes identifying why those roles are important to society: to enable the democratic process and to provide helpful information. The first and most dominant theme represents the perspective that journalists still firmly accept the vital function they serve in a democratic society. As journalists reflected on their work, they noted the general connection between information dissemination and democracy. As one journalist stated, "In order for a democracy to function, the systems in that democracy need to be informed. So at its most basic level, that's why I think what we do is important" (participant 2). More specifically, journalists pinpointed the importance of getting information to the voters. One journalist expanded on what it means to get information to the public by including the idea that journalists must also explain or clarify what that information means. This journalist believes his role includes:

Writing stories that empower the local populous to make more informed decisions in voting and in knowing what issues are on the table at any given moment ... If I can even clarify a few different areas that people might not understand, I think that is a good public service (participant 6).

Another important aspect of fulfilling this vital democratic function included the ability to serve as a check on power. The journalists interviewed believed that in order for 
democracy to function they should not only disseminate information, but also hold public officials accountable. One interviewee noted:

There is so much that, you know, just being here in Washington that goes on behind closed doors. There's so much that I don't think people realize, or understand, or know about, and so I think it's important to disseminate that information to people all over the country. But I also think it's important to hold lawmakers accountable and make sure that people's elected officials are held to a high standard and actually accomplish everything that needs to get done to have a functioning democracy (participant 3).

However, journalists added that this responsibility to democracy is what distinguishes journalists from other members of the public. As one participant put it, "journalism sets itself apart because there is that drive, or there should be that drive, to hold people accountable and to be, you know, like people say, the watchdogs" (participant 9). Beyond having proper motivation, journalists also indicated that it took a particular skill set to perform the work that they do:

I can't think of any other ways that people would know these things if journalists didn't tell them about it ... And there's no one else who can provide the, sort of, unbiased, unvarnished, this is what's really happening. And more importantly, most importantly, how it will actually affect your lives (participant 7).

A similar perspective was the idea that rather than set itself apart from the public, journalism serves as outsourced labor by the public - a public too busy or disinterested to uncover the truths necessary to make informed voting decisions. Similar to the idea that journalism serves as the Fourth Estate, these journalists believed that if they did not disseminate and explain information to the public or serve as a check on government, who would? From this perspective, political journalism is bound by society to serve as the check on government; researcher of public policy, issues, and events; information disseminator; and analyst. One participant acknowledged that without political journalism, people would overlook a lot of the day-to-day government activities: 
I think about journalism as the fourth estate. We're the fourth branch of government. That if we don't pass along what's going on in plain English, that other people might not be interested or take the time to follow the minutiae of the agendas and the live broadcast of congress. Those kinds of things are just not that interesting to everybody. So it's about helping people eat their broccoli (participant 10).

The second theme that emerged from the interviews was the idea that journalism fulfills a general helpfulness function in society. This includes providing information that readers find helpful for day-to-day decisions, not just voting decisions, and includes a focus on local community. Similar to the previous theme, one participant expressed the importance of explaining complexities surrounding laws; however, this participant grounded her thought under an umbrella concept of helpfulness:

It feels great to share a story that makes a difference in my community, even if maybe it just brightens someone's day. Maybe it's a preview letting people know about this event. Because we wrote it, someone went out and had a great night. That's valuable, and I don't want to diminish the value of those kinds of stories, either. Or even just stories that exlain something that might not be very clear to people, like how this new law's going to impact the city (participant 9).

Another component of this theme included the importance of journalism to serve an educative role to advance professional and personal lives. One participant noted that "knowledge is power" and by educating the public, political journalists are enabling them to better fulfill work, business, or personal goals:

It's just the whole "knowledge-is-power" type argument that the more you know, the better educated you are to do what you need to do, the decisions you need to make, where you line up on things and what you need to do to advance what you need to advance. I guess I feel like good reporting should be used as an educational tool for everybody in just regular life or in work or business or whatever you need it for (participant 15).

Summary. Although results from the survey indicated several roles were associated with political journalism, findings from the survey and interviews emphasize the importance of the informational and monitorial roles. As journalists reflected on their 
work, they communicated the societal importance of an informed public to a functioning democracy. Even though they predominantly related their roles to democracy, some journalists believed that journalism serves a broader function in society. These journalists contended that their goal is to provide content that the public finds useful or helpful, as well.

\section{Identifying and Explaining Factors of Influence}

RQ2 asked how micro-, meso-, and macro-level factors challenge journalists' ability to fulfill their cognitive roles. Results from an exploratory factor analysis illustrate where journalists agree on areas of influence to their work. Findings from the interviews further articulate how journalists encounter micro-, meso-, and macro-level challenges on the job.

Since little is known about how journalists agree on areas of influence to their work, this study employed a factor analysis to see how areas of influence - or items cluster. An exploratory factor analysis using principal axis factoring and direct oblimin rotation found that influences to work could be grouped into six factors, accounting for $61.66 \%$ of total variance; $\mathrm{KMO}=.82$, Bartlett's Test of Sphericity $=\chi^{2}(231)=1170.45$, $p<.001$ (see Table 3). Six items failed to load highly on any factor and were subsequently dropped from the analysis. These items included "the editorial process," "deadlines," "collaboration," "social media obligations," "laws and regulations," and "my religious beliefs."

The first factor represented macro-level influences and accounted for pressure from external parties. It included four items: "pressure from government officials," "pressure from advertisers," "pressure from public relations practitioners," and "pressure 
from interest groups." This scale was reliable (Cronbach's $\alpha=.74)$. The second factor represented the meso-level challenge of a lack of resources. The four items in this factor include "lack of time," "lack of money," "lack of resources (not time or money)," and "personal obligations" (Cronbach's $\alpha=.75)$. Only two items loaded on the third factor: "my own moral compass" and "pressure from my editor." The latter item, "pressure from my editor," also loaded highly on the fourth factor and is indicative of a complex item. However, the fourth factor represented editorial challenges, so for purposes of the analysis "pressure from my editor" was included in the fourth factor and eliminated from factor three. Since factor three had just one item ("my own moral compass"), it was discarded from the analysis.

Factor four represented another meso-level variable and included three items: "my organization's emphasis on profits," "my organization's focus on audience metrics," and "pressure from my editor." The scale was also reliable (Cronbach's $\alpha=.73$ ). The fifth factor reflected another macro-level challenge representing accessibility. It contained two items: "inaccessibility of government officials" and "inaccessibility of business representatives." The two items show a moderate positive correlation $(r(201)=.38, p<$ .001). Finally, the sixth factor represented a micro-level challenge associated with personal pressures and included two items: "pressure from my family" and "pressure from my friends." The two items in this factor were also correlated $(r(198)=.57, p<$ $.001)$. 
Table 3. Exploratory Factor Analysis of Challenges to Role Enactment Process

\begin{tabular}{|c|c|c|c|c|c|c|}
\hline & $\begin{array}{c}\text { Factor } \\
1\end{array}$ & $\begin{array}{c}\text { Factor } \\
2\end{array}$ & $\begin{array}{c}\text { Factor } \\
3\end{array}$ & $\begin{array}{c}\text { Factor } \\
4\end{array}$ & $\begin{array}{c}\text { Factor } \\
5\end{array}$ & $\begin{array}{c}\text { Factor } \\
6\end{array}$ \\
\hline My own moral compass & & & .57 & & & \\
\hline Pressure from my family & & & & & & .63 \\
\hline Pressure from my friends & & & & & & .48 \\
\hline Lack of time & & .64 & & & & \\
\hline Lack of money & & .67 & & & & \\
\hline Lack of resources (not time or money) & & .68 & & & & \\
\hline My organization's emphasis on profit & & & & .62 & & \\
\hline My organization's focus on audience metrics & & & & .72 & & \\
\hline Pressure from my editor & & & & .41 & & \\
\hline Inaccessibility of government officials & & & & & .53 & \\
\hline Inaccessibility of business representatives & & & & & .79 & \\
\hline Pressure from government officials & .43 & & & & & \\
\hline Pressure from advertisers & .80 & & & & & \\
\hline Pressure from public relations practitioners & .62 & & & & & \\
\hline Pressure from interest groups & .62 & & & & & \\
\hline Personal obligations & & .59 & & & & \\
\hline Eigenvalues & 6.01 & 2.45 & 1.54 & 1.29 & 1.23 & 1.05 \\
\hline Variance Explained (\%) & 27.29 & 11.12 & 7.02 & 5.87 & 5.60 & 4.77 \\
\hline Cronbach's $\alpha$ & .74 & .75 & - & .73 & $.38^{\mathrm{a}}$ & $.57^{\mathrm{a}}$ \\
\hline
\end{tabular}

${ }^{\mathrm{a}}$ Correlation coefficient of the two items.

KMO (Kaiser-Meyer-Olkin Measure of Sampling Adequacy) $=.82$; Bartlett's Test of Sphericity, $\chi^{2}(231)$

$=1170.45, p<.001 .54 .65 \%$ total variance explained.

To test construct and discriminant validity, goodness of fit for the five-factor ${ }^{1}$ model was tested using confirmatory factor analysis (CFA) in R (Rosseel, 2012) with the

\footnotetext{
${ }^{1}$ Although results of the exploratory factor analysis revealed a six-factor solution, the third factor ("my own moral compass" and "pressure from my editor") was dropped from the model, resulting in a five-factor solution.
} 
maximum likelihood (ML) estimator. The model fit was adequate, $\operatorname{ML} \chi^{2}(80)=109.27, p$ $<.05$, RMSEA $=.05(.02-.07)$, CFI $=.96$, NNFI $/ \mathrm{TLI}=.94$, SRMR $=.05($ see model in Appendix G). Overall, journalists indicated that a lack of resources was the biggest challenge to their work $(M=3.22, \mathrm{SD}=.98)$, followed by inaccessibility of government and business representatives $(M=3.15, \mathrm{SD}=1.06)$, pressure from editors $(M=2.23, \mathrm{SD}$ $=.95)$, pressure from outsiders $(M=1.70, \mathrm{SD}=.70)$, and personal life influences $(M=$ $1.47, \mathrm{SD}=.63)$.

Micro-level factors. Findings from the survey show that respondents perceived pressure from a personal network to be an occasional challenge in the role enactment process $(M=1.47, \mathrm{SD}=.63)$. Of the two items included in this factor, journalists indicated that "pressure from my family" $(M=1.60, \mathrm{SD}=1.05)$ inhibited work more often than "pressure from my friends" $(M=1.56, \mathrm{SD}=.93)$. However, since these items are measured on a five-point scale, it does not look like these challenges inhibit the journalists from fulfilling their cognitive roles often.

Although these items may not result in a complete derailment of the role enactment process, they do serve as disruptions to the process. Results from the semistructured interviews reveal three areas of influence that journalists identify as challenges to fulfilling their cognitive roles. These themes include: the journalist as a community member, the journalist as a family member, and gender.

The journalist as a community member. The first theme, the journalist as a community member, accounts for the experiences journalist face as a member of a local community, a religion, or a particular culture that challenge the role enactment process. As members of a geographic community, some journalists expressed strong ties to the 
town or state they grew up in - even if it is not where they currently reside. One journalist expressed a strong tie to a state and her struggle to maintain an objective perspective on the issues being covered:

I have a strong sense of identity from where I grew up. And I think at times when certain news stories come out and certain things come out, especially about where I grew up, sometimes I'm like, "It's not like that! I promise!" And then I have to be like, "Okay, it's not personal. They're talking about bigger picture issues and its not a reflection of the people who live there or the people you might know" (participant 3).

Although this journalist mentioned being initially defensive about her home community, the brief challenge subsided and she was able to think rationally about the issues and the events that were part of the "bigger picture."

Other journalists, however, note that there may be an ongoing struggle to separate the tie to a local community and their ability to cover that community objectively. One journalist talked about the risk of covering one neighborhood too closely because of her ties to that area. She found herself asking: "“Am I paying too much attention to this district because I live in this neighborhood and I see these candidates' signs in people's yards and they've knocked on my door?'” (participant 18). Like many journalists, she found herself having to be reflexive in her coverage and made sure not to inflate the coverage of one particular neighborhood community in her coverage of a larger urban center.

Even in small-town publications, journalists have challenges being critical of people they know on a personal level. One journalist who has been in the field for over 20 years said that it's challenging to cover his friends, but it's the job:

You know, I might have to - like all small-town publications, you're writing about your friends sometimes. And that's hard. You don't like putting them in situations, 
but that's one of the unfortuantes of the job ... I mean, my job is not to pick favorites. It's not to cheerlead. It's to report the news (participant 15).

Similar to ties to a local community, religious community pressures have resulted in journalists experiencing role strain. Just as journalists talked about the importance of being reflexive in regards to their coverage of certain geographic communities, some journalists discussed the importance of being reflexive in their coverage of particular issues or topics in terms of their religious perspective. As one journalist put it:

Am I putting words in there, or something about God, or something in there that I wouldn't do if it was another religion, that I wouldn't place in there? Or am I leaving something out, because I'm afraid that I might be having some bias? (participant 14).

Sometimes the struggle to suppress religious ties is not as subtle, though. One journalist reflected on his experiences with sources who were anti-semitic and his struggle to maintain a peaceful relationship with those sources:

Participant: There have been times where the people that I'm interviewing are not aware of my Jewish faith and have made comments about Jews or Judaism that have been uncomfortable. And I've struggled with whether I should approach and let them know of my background. And I chose not to. I chose to simply let it go.

Interviewer: And can I ask you why you chose not to?

Participant: ... I felt that it'd be important that I maintain a relationship with my interviewees, and I felt that confronting would cause unnecessary alienation. Believe me, it was not easy to make that decision" (participant 8).

In this case, the journalist may have been personally conflicted, but rather than defend his faith, he chose to "simply let it go" to further his ability to fulfill his journalistic role.

Although challenges stimulated by geographic community and religious community ties appear to have been overcome by the journalists interviewed, one journalist reflected on a challenge he could not simply overcome to enhance his professional role. This stemmed from his involvement in the LGBTQ community and 
ultimately resulted in role conflict. Unlike the previous journalists who depicted some level of role strain between community ties and their roles as journalists, this journalist did not choose to privilege his journalistic identity. As someone who identifies strongly with the role of journalist as "serving the lesser served," in addition to holding public officials accountable and disseminating information, he stressed that there still needs to be boundaries between personal affiliations and professional conduct:

I have been a long-time advocate of the trans community, and by that I mean well over 30 years. And I made a conscious decision to work within the framework of the activist/advocate and other community fighting first the congress of the United States and then the president of the United States. And as a result, the conflict was I was sitting on some great fucking stories and I couldn't touch them. I couldn't even breathe them ... So I had to make a decision to be a journalist or be an advocate. In this particular instance, I had to not be a journalist (participant 5).

In this instance, his duty as a member of a cultural community outweighed his duty as a journalist. Not only did his strong ties to this facet of his identity result in him favoring it over his journalistic identity, but it also seems to have influenced the role internalization process as well. In other words, by strongly identifying with an underserved community, he interpreted his role as a journalist to also account for serving "the least of these."

The journalist as a family member. The second theme to emerge from the interviews pertaining to micro-level influences was the journalist as a family member. Typically, this theme arose when journalists reflected on their familial obligations and the challenges to balance family and work life. Two sub-themes relate to this larger theme: time away from the family and pressure from the family. The first, time away from the family, accounts for the challenge journalists experience being physically or emotionally unavailable to family members. As one journalist articulated:

It's often frustrating to not be able to spend as much time with my wife as I'd like. During the legislative session - we've been together long enough now and I've 
been in this job long enough now, that she pretty much knows that I disappear for three to four months at the start of each year as the legislature is in session, and my life and my job get a little crazy. Missing some of those things, missing spending time with her is something that comes up, but I think we sort of both adjusted to that and it's gotten easier over time. ... I can think of one case where my wife had a very strong reaction to the election results from November 2016, and it would have been nice to have been with her to help her through that, and obviously that was literally impossible (participant 7).

Other journalists agreed that the job detracts from time spent with the family and "it's hard to be away from the family" (participant 8). However, just like participant 7, many attributed years of experience as one way to alleviate the stress associated with that challenge. The longer the journalists were in the field, the more they adjusted to a skewed work/family relationship.

In addition to journalists feeling the pull of wanting to spend more time with their family, they also addressed times when they felt pressure from family members to fulfill their role a certain way. For example, one journalist reflected on the pressure she received from family members after the spike in fake-news allegations surrounding the 2016 presidential election:

I guess after the last election, it was so emotional and divisive, the presidential election in 2016. I had family members who were conservatives and friends who had a hard time with me being part of the media, family members who are very liberal who wished that I took a different approach to my job, and a lot of my friends in the industry felt the same way, that there was a lot of pressure from our personal lives to be better or we were just a sounding board for all media criticism at that time (participant 10).

This journalist found herself having to defend her approach to journalism by emphasizing to critics that she must maintain a "barrier" between "the main issues of the day and myself."

Gender. The final theme associated with micro-level influences to the role enactment process was the least observed, but it accounted for the idea that the 
journalists' gender challenged their ability to fulfill their role. Primarily, this theme was related to issues of accessibility of government officials and offensive content. For instance, one female journalist found that her experience as a woman covering Washington D.C. was much more difficult than her male counterparts, because of her sources' preference to deal with other men:

I covered congress, and it is easier to be a man covering that building than it is to be a woman. And so I do think that can be a struggle ... You're dealing with 535 members of congress, and they're overwhelmingly men, and many of them feel more comfortable talking to other men. And so I think that's a sourcing issue that I have had at times, where I thought that it made it harder to be a political journalist for that reason (participant 13).

This same participant also reflected on her discomfort covering offensive material. As a journalist covering a politician's inappropriate remarks in an Access Hollywood video, she remembered feeling uncomfortable having to not only listen to the content, but also report on the event itself:

As a woman, you're like, "Oh, God." You wanna be angry. You wanna be like, "This is awful." You wanna be like, "This is terrible." But you can't, right? You have to sort of put that in a little box and be like, "I'm not gonna let that affect the way I do my job today" (participant 13).

Another journalist alluded to the idea that her identity as a woman influenced her ability to fulfill her role as a journalist. Although not blatantly stated, she implies that a struggle exists between her gender and her ability to cover policy: "I mean, I'm pretty acutely aware of how many of my rights are being taken away as a woman at any given time reporting on policies, but that pretty much just encourages me to write about it more" (participant 20). In this case, she alludes to the idea that she covers topics that she may have a personal conflict covering, but - ultimately - she finds that her gender enables her to better fulfill her role. 
Although only a few journalists reported gender as a challenge to the role enactment process, more participants did note that gender was an influencer in the role enactment process. As discussed in RQ3, some female journalists (much like participant 20 above), actually found their identity as a woman to be beneficial to their journalistic work. Therefore, gender appears to be a complicated factor of influence on the role enactment process.

Meso-level factors. Survey results show that journalists viewed a lack of time as the biggest meso-level inhibitor to their work $(M=3.84, \mathrm{SD}=1.18)$, followed by a lack of resources (not time or money, $M=3.34, \mathrm{SD}=1.29)$, a lack of money $(M=3.17, \mathrm{SD}=$ 1.53), personal obligations (further supporting lack of time, $M=2.64, \mathrm{SD}=1.29$ ), the organization's emphasis focus on audience metrics $(M=2.49, \mathrm{SD}=1.30)$, the organizations' emphasis on profits $(M=2.18, \mathrm{SD}=1.3)$, and pressure from editors $(M$ $=2.15, \mathrm{SD}=1.11)$. Based on the descriptives, it appears that access to resources (both monetary and otherwise) represent more consistent challenges to the role enactment process than influences in the editorial process.

Findings from the follow-up interviews provided more depth and context into the meso-level challenges affecting the journalistic process. As journalists reflected on their work, three broad themes emerged that each represent an area of influence to the journalists' routines: lack of resources, editorial decisions, and colleagues.

Lack of resources. The first theme was most dominant and supports the quantitative findings that demonstrate a concern for lack of time, money, and other resources. From a big-picture perspective, journalists viewed their role as altruistic and ideal, implying that there was never enough time or money to fulfill their role to the best 
of their ability. In their view, the nature of corporate media and concern for the bottom line was always going to be a limitation of their job. As one journalist put it:

In its purest form, the kind of journalism that is going to make you feel the most complete and the most intellectually satisfied is super expensive. And so you don't have-very few newsrooms have the ability to operate without concern for the bottom line (participant 2).

Another journalist even went as far as to call corporate journalism "inherently evil at its inception" (participant 5) because of its focus on the bottom line. He viewed this challenge as a battle between "the God-all-great dollar ... versus the journalist trying to tell the truth in the story."

Similarly, journalists expressed that organization size and structure often had implications for accessibility to resources. Many journalists who worked within smaller news organizations expressed both time and money limitations due to the availability of resources within their organization. For example, when it came down to time, one journalist said, "I'm currently one person covering all the state government politics, so that means I don't get to everything” (participant 12). Another journalist expressed:

I think for me, the bigger problem or challenge in getting done what I wanna get done is just a matter of time. You know, I'm the chief political reporter for the entire network across the state. So nine stations. I'm one person. I shoot all of my own material with a camera. I do almost all my own interviewing. I have to download that video; I've gotta edit it; I've gotta write the story, write the script, write the web story. And that's a lotta work for one person. And so the amount of stuff you can do is greatly reduced (participant 16).

Particularly as newsrooms are cutting staff due to bottom-line concerns, news workers are finding it hard to continue to produce the same amount of work while juggling multiple responsibilities - such as video editing, reporting, and writing for multiple stations. Although on its face this appears as a time-centric concern, it may be stemming 
from monetary decisions that lead to a consolidation of responsibilities onto fewer people.

Additionally, journalists working for smaller news organizations may not have the financial resources necessary to get access to certain records. In reflecting on challenges to her role, one journalist noted that her biggest challenge is records requests because of the associated costs:

Say I wanna look at the emails from this public official for the past year, and then they come back and say, "Well, it's gonna take us two hours, three hours, five hours, whatever, to go through that. We need \$100, \$300, whatever, for the staff time," and that's - they're able to do that if it's a reasonable fee. And then sometimes it's just too much money for us. We're a small paper and we have to make the decisions that - that's my editor's call. Is it worth the money to look into this or not? So money is a big factor (participant 14).

As this journalist illustrates, the limited financial resources of a smaller newspaper made it impractical for her to access particular records that she viewed as important to public knowledge. This is just one of many examples of how journalists are finding themselves negotiating the realities of their roles in light of monetary restrictions.

Even at larger organizations, journalists, editors, and publishers must make decisions about allocating resources interdepartmentally or inter-organizationally. For example, one journalist who oversees his own media company reflected on the struggles of running his primary news outlet along with its sister organizations. Although those sister organizations had since folded, he highlighted that there was always a competition for resources:

Obviously there's always a competition for resources and there's a competition for legitimacy of publications and what not. That happens from time to time. I mean, [company name] is one of the oldest black news sites in the world. So obviously the resources are going to go in the direction of that property (participant 4). 
Finally, even freelance journalists expressed challenges associated with resources that inihibited them from fulfilling their cognitive roles. One journalist described his monetary struggle as a freelancer, stating that as the freelance market becomes more saturated, news organizations are able to lower their asking price for stories. Once organizations begin to offer smaller reimbursement packages for freelancers, covering the cost of reporting for freelancers becomes tricky:

And at a certain point, you just no longer suggest stories because you're ending up subsidizing the reporting out of your own pocket for a major publication. ... But you have to kind of pull together various funding sources. So that's a completely different way of doing honest, professional journalism (participant 19).

Not only is the reduced compensation affecting how freelancers cover the cost of production, but - according to this journalist - it is also making it more challenging for those journalists to produce quality work.

Editorial decisions. The second theme in this section relates to editorial decisions and accounts for the relationship between the journalists interviewed and their supervisors. The biggest challenge associated with this theme revolves around story selection and assignment. The two other related areas include the inexperience of the editor and the editor's/organization's focus on innovation.

When it comes to story selection and assignment, journalists viewed editorial policies and decisions as limitations to their work. One journalist addressed an editorial policy that dictates the appropriateness of political stories: "I can tell you when we cover our local elections, a policy we sort of have is to not really focus on anything that would completely tip the balance of the race. Not to publish anything overly salacious" (participant 6). Although this policy may have had merit on the local elections, he 
believed that based on what was happening on a national level, "that approach might not be that tenable."

Beyond restrictive policies, other journalists expressed concerns about the power editors have in the newsroom of assigning stories. Although journalists may have an idea of how to best fulfill their role by covering certain stories, editors often assign them to unrelated tasks or can't justify putting the journalist on the story. For example, one journalist recalled when she was assigned to cover a different story than the one she believed she ought to be covering. Because she didn't have the time to cover both, she felt frustrated:

My editor will assign me to that story and the whole time I'm kind of frustrated that I have to spend my time and resources to reporting what I may think is a superficial story when I know that I'm working on other stories that could hopefully have an impact on people (participant 18).

Journalists also acknowledged the struggle of having to work under an inexperienced or bad editor. These editors may not completely understand the subject matter or are too easily persuaded by outside influences, such as politicians or advertisers. As those in more powerful positions (such as editors) push subordinates to cover stories in ways contradictory to how the journalist feels they should be covered, that can breed conflict. One journalist who has struggled with bad editors in the past compared a bad editor to a bad general: "There's nothing worse than a bad editor. That's like going to war with a bad general. Everybody gets killed, you know?” (participant 1).

Regardless of experience, editors who succumb to pressure to innovate sometimes risk negatively impacting the workflow of their journalists. Especially in an increasingly digital-first environment, more and more newsrooms are looking for new ways of delivering content to news consumers. This constant pressure to innovate has led 
journalists to focus more on keeping up with new technologies or reporting processes and less on their role in society. One journalist noted:

I mean, because we're digital first, we do a lot of experimentation. And so it feels like, too, we have kind of flavor of the month technology tools or approaches to reporting that we're strongly encouraged to do and try out, and we do them and we try them out and fumble with them ... So that's extremely distracting (participant 21).

In her case, she found that the time she spent navigating the new technology was time away from fulfilling her other duties, such as social media management. She also believed that this time away from her other responsibilities meant that she did not feel as if she was giving " 100 percent" to her role.

Colleagues. The final and smallest meso-level theme to emerge from the interviews pertained to the journalists' experiences with coworkers and colleagues. Similar to the editorial challenges faced by the journalist, challenges by colleagues often related to the approach the journalists should take to a story (e.g., angle, focus, or sourcing). One journalist expressed frustration when he believed his coworker was focused too closely on only one small part of a story, rather than looking at the big picture issues:

There was one instance where a series of officials in town sent out some newsletters about a ballot referendum that people would vote on to potentially raise taxes a little bit to cover expanded emergency ambulance services in that town that was taking maybe 20-30 minutes to get to people with cardiac arrest. That sort of thing. And for a time, one of my colleagues was under the impression that they were violating a relatively arcane part of the state law saying, "You can't voice an opinion on an issue if you hold these positions in office." That was going to be a big focus of the story, rather than the issue at hand itself of whether the taxes should be raised to cover this or not (participant 6). 
In this journalist's opinion, his coworker lost sight of the agenda-setting role of journalism, resulting in his coworker's overemphasis on something unimportant in comparison to the bigger issue - the issue that would have a bigger impact on voters.

However, not all challenges in this theme come from within the organization. Some journalists expressed challenges stemming from relationships with other journalists they must work with on set or in the field. For example, one television host explained that he has faced challenges with colleagues on set who try to "out" him as a member of a political party. Having been active in Democratic politics more than 20 years prior, he believed that his political affilliations that far in the past should have little bearing on his current position in the newsroom:

I have had colleagues recount that affiliation in front of politicians, which is not what I'd - I'd rather that not be. Because, again, for all they know I've become a Republican. You know, who knows? ... And so I have found that when my colleagues try to - excusive my French - out me as a Democrat or a member of the Democratic party, I do think that it has made it difficult to do what I want to do, which is come at my work from a neutral viewpoint (participant 8).

He recalled that the hostility he has faced surrounding these experiences changed the dynamic of the relationship he has with his sources and challenged his ability to fulfill his role as a journalist.

\section{H1: Staff journalists will experience more meso-level challenges than}

freelance journalists. The first hypothesis stated that staff journalists, opposed to journalists who are primarily freelancers, will experience more meso-level challenges to their work. An independent samples $t$-test assessed group differences for each meso-level variable: lack of resources and editorial pressure. For the first variable, lack of resources, no group differences existed between staff journalists $(M=3.24, \mathrm{SD}=.91)$ and freelancers $(M=3.06, \mathrm{SD}=1.35), t(27.61)=-.66,95 \% \mathrm{CI}[-.76, .39]$. In testing whether 
group differences existed in perceptions of editorial challenges, it appeared that freelancers $(M=1.80, \mathrm{SD}=.82)$ may have viewed this challenge as less inhibitive of their work than staff journalists $(M=2.30, \mathrm{SD}=.95)$. An independent samples $t$-test showed that the differences were significant, $t(188)=-2.64, p<.01$, two-tailed, $95 \% \mathrm{CI}$ $[-.88,-.13]$. However, after controlling for age, gender, and years of experience, being a staff journalist was not a significant predictor of perceptions of editorial challenges, $(\beta=-$ $.15, p=.07), F(4,181)=2.27, p=.06, \mathrm{R}^{2}=.05$. Therefore, this hypothesis is not supported.

Macro-level factors. Results from the survey show that journalists viewed "inaccessibility of government officials" as the biggest macro-level challenge to their work $(M=3.50$, SD 1.31$)$. This was followed by "inaccessibility of business representatives" $(M=2.83,1.24)$, "pressure from government officials" $(M=1.76, \mathrm{SD}=$ $.92)$, "pressure from public relations practitioners" $(M=1.73, \mathrm{SD}=.98)$, "pressure from interest groups," $(M=1.72, \mathrm{SD}=.91)$, and "pressure from advertisers" $(M=1.61, \mathrm{SD}=$ .96). Findings from the follow-up interviews support the survey results that indicate pressure from outside groups and inaccessibility are popular macro-level challenges to the role enactment process. Other themes to emerge from the qualitative analysis include challenges pertaining to technology and a general distrust in journalism.

External pressures and accessibility. Although descriptives from the quantitative results indicate that pressure from outside parties do not often inhibit journalists from fulfilling their role, journalists did describe that this pressure occurs frequently in their work. As the biggest theme in this section, external pressure accounts for pressure from politicians and public relations practitioners. Consistent with the low means for the 
related items from the survey, journalists did not believe that the challenge presented by this pressure resulted in role strain. In fact, one journalist noted that "outside influences as a political reporter come with the job" (participant 5). Another journalist described the type of pressure and his mindset in handling that pressure from a government official:

I remember that there was an attorney general who admitted he had an extramarital affair and made a big show about it at a press conference and the whole bit. Well, he ran for governor about two years later, and any time I mentioned that as a political pitfall, I got pressured and bullied and given a lotta crap about whether that was relevant or not. I thought it was. And continued to defend the position ... But to be pressured and bullied into taking a different position, I'm not gonna succumb to that (participant 15).

Although journalists reflected on times where they received direct pressure from a government representative, journalists also described receiving that pressure second-hand through their editor or publisher. As one journalist recalled:

You know, a local politician - president of the senate here - one time I was writing stuff about him, what he was doing. He didn't like it, he called the publisher. The publisher was his buddy. The publisher called me in and said, "You know, you're being kinda rough on this guy. Maybe you should back off and so on and so forth." And I said, "I won't back off because this is necessary. This has to be written about. This has to get into the paper. If you don't want me to do this, then, you know, I'll leave." So you have those types of conflict and in that case there, I prevailed, but sometimes you don't win. And that can lead to problems (participant 1).

In the context of this case, although the journalist felt direct pressure from his editor, the root of the pressure stemmed back to the local politician. By including the publisher into the conversation, this particular pressure heightened the challenge faced by the journalist and almost resulted in his resignation. In this instance, the expectation of the publisher clashed with the expectation of the journalist, resulting in role strain. Even though this is an instance of editorial pressure (a meso-level challenge), the cause of that pressure is grounded in the motivations of a government official (a macro-level challenge). 
In addition to the challenges posed by government officials, journalists indicated the struggles associated with dealing with public relations practitioners as well. Acknowledging that public relations plays a particular role in government or politics, the journalists tended to have an understanding of the nature of the relationship between journalism and public relations. Like one journalist said, "I think there's an understanding for the most part of, 'You play your role, I play mine'” (participant 7). Another journalist who had only been on the job for two years noted that her inexperience on the job and personality may have put her in a position susceptible to manipulation by people in public relations:

You get these people who are just very charismatic. They're very good at being pleasant. And they're very good at, some people try to say, like buttering you up, right? ... I think that that's something that can be taken advantage of, especialy by people who are very good at being able to manipulate people ... Even a compliment can make you feel bad about writing something bad about someone (participant 9).

Journalists described that they faced challenges not only from pressure of these external parties, but also from having sometimes limited access to external representatives or events. This included journalists not being able to sit in on public meetings due to space constraints, as well as journalists not being able to reach government officials as sources of information. Although journalists usually reflected on this challenge as a byproduct of an official's busy schedule, one journalist viewed her relationship with a local representative a bit differently. She noted that her source only "tends to talk to us when it's something he wants to talk about, and if it's something he doesn't want to talk about, he doesn't return the call" (participant 10). But even for her, she acknowledged the difficulty of accessing the official just by nature of his job: 
I'm trying to build a relationship with [our congressman] by doing some of those stories about the things he does want to talk about, but he's in Washington most of the time. His local office is not in our city. Yeah, it's just hard to build a lot of rapport across that distance (participant 10).

Culture and technology. The other macro-level challenge to emerge from the interviews included challenges inherent in technological advancements in the field and general shifts in sentiment toward media. As journalists reflected on the growth of consumer generated content on social media and personal websites/blogs, they noted the challenges they faced in getting their content to certain audiences. In other words, this was a "filter bubble" concern:

Social media organizations make money by keeping people on the site longer so they can show them more ads. And the way that they do that is to show them content that they would like to see and the proxy for that is likes and shares, so people are served a stream of self-reinforcing, or content that reinforces a person's already-held beliefs as a way to entice them to stay on the platform longer. So, given that, you have sort of this exacerbating or vicious cycle, circle, of not being able to reach critical masses of audiences or maybe audiences who would disagree with the nature or tenor of a piece of information or story you're trying to report on (participant 2 ).

Even if journalists are able to break through the filter bubble, they still expressed the concern about a general distrust in the media. Based on the interviews, it appears the more troublesome challenge for journalists rests in the declining trust audiences have in journalism. One journalist notes that this distrust is one part of a longer-term trend: "If you think back just the last fifteen years, all of the institutions in the United States, in its government, in its businesses, in its other sections of society that have failed, you can see why trust in institutions is very low" (participant 2). Most journalist viewed the distrust challenge as related to misperceptions of what it means to be a journalist:

And now that we have social media and everyone's got the soapbox and can say these are what I think the facts are and that's what I think about it and they're 
right, I think the assumption is that's what journalists do, too, and it's not (participant 21).

Journalists also noted that these misperceptions stem from direct attacks and animosity toward media - a relatively new phenomenon in recent years. Especially in the wake of the "fake news" frenzy, journalists must now spend more time explaining to audiences why they can trust their work, which detracts from their ability to focus on producing quality journalism. Not only is this a time concern, but it is also ultimately a concern for their identity as a journalist, which will be elaborated on in the next section.

\section{Making Sense of Role Strain}

RQ3 examined how journalists made sense of role strain on the job. Sensemaking is ongoing, retroactive, and occurs when there is an interruption to routine or disruption in the system. As journalists reflected on the challenges to their role, they identified the cues that served as triggers to the sensemaking process. Even during the course of the interview, participants were still attempting to understand and rationalize those challenges. Although the challenges addressed in the previous section highlight the more common disruptions to routine, not all challenges resulted in role strain. When disruptions occur that stymie journalists' ability to fulfill cognitive roles (i.e., disruptions to the role enactment process), journalists must make sense of those challenges and make decisions about how they will respond to those challenges both in the moment and in the future. Four primary themes emerged from the data that illustrate how journalists interpreted the disruptive cues: reinforcing the real-self/fake-self dichotomy, reinforcing their cognitive role, adjusting to new tasks, and accepting (or not) the limitations of the job. 
Reinforcing the real-self/fake-self dichotomy. The first theme to emerge in the analysis accounts for the journalists' tendency to distinguish between a work life and a personal life and occurred when micro-level challenges inhibited their ability to fulfill their role. As the following sub-themes illustrate, journalists who were interviewed demonstrate a strong and emotional tie to their identity as a journalist. When journalists faced role strain at work, they often looked to rationalize their decisions by compartmentalizing their life. In most cases, the journalists' passion for their work dictated their behavior. However, some individuals found that areas of their personal life - although distinct from their professional life - could serve to enable their professional goals.

Establishing boundaries. The first way journalists reinforced the dichotomy between real and fake selves was by establishing boundaries between work and personal life to avoid conflicts of interest. This occurred both proactively and reactively. Proactive compartmentalization meant that journalists intentionally sought to distinguish between their personal life and professional life. One journalist described this separation as “ensuring the professional ethics and standards of my profession" (participant 5). Other journalists noted that it was important to keep an arm's-length distance away from work that could challenge personal beliefs or stimulate emotional reactions.

Even though journalists proactively tried to mitigate conflicts of interest on the job, they still had to cover controversial topics or topics in which they were opinionated. In order to objectively report on these areas, journalists continuously reminded themselves that personal opinions had no place in their work. As one journalist put it:

I cover things like abortion and the death penalty, and just kind of those hot button issues, or immigration and so forth. And so I don't know. I just don't think 
it's personally my job to put my opinions on the various very hot button social issues into my reporting. So I have personal opinions on these issues, but, like, I don't - I try to keep that very separate from my work (participant 12).

When journalists feel strongly about an issue they are covering, they reactively employ reflexive strategies that help remind them about the distinction between their personal connection to the topic and professional obligations. This strategy enables them to provide balance in a story and, as another journalist stated, put on a "let's-be-fair hat" (participant 13).

Other journalists, however, admitted that while reflexivity is important to understanding those boundaries, they may tend to overcompensate for their personal opinion. As one journalist reflected on her experience being personally conflicted on the job, she recalled representing the side least similar to her personal viewpoint more in her coverage than the side more similar to her personal opinion:

I'm probably hyper-aware of my biases and sometimes will be too critical of them and try to cover the other side more, the one I don't align with. Which is interesting. So then I've had to reign my criticism of that side back, or my own side back (participant 9).

Another journalist noted a similar experience overcompensating for her political ideology in reporting, but explains experience as crucial in managing this tendency:

In the effort of not looking biased, [I] was too lenient in my reporting and writing when I spoke with people who were more conservative and maybe didn't push back as much, and that I pushed back more against people who were more liberal, I guess, because I didn't want to give the appearance of going easier on people who might have been Democrats. I think I've gotten over that as I've been in the business longer, where I'm able to push back against people evenly know (participant 11).

As these journalists acknowledged, it was important to ensure that personal experience, opinions, or beliefs did not bleed over into reporting. However, sometimes the fear of 
infusing reporting with personal bias led journalists to over-correct and instead favor a different perspective.

A hierarchy of roles. Although journalists sought to compartmentalize their life, they also demonstrated a strong tie to their identity as a journalist. Several interviewees described journalism as a large part of who they are and had a passion for their job, even if it affected their ability to find fulfillment in other areas of their life. By grounding journalism as an essential element to democracy, the journalists idolized the idea that they were making a difference in their community. Therefore, other facets of their identity - such as their role as a father, husband, wife, mother, citizen - took second-class positions to their identity as a journalist (with few exceptions.) One married journalist who has been in the field for nine years noted, "People know, for the most part, that my job comes first" (participant 7). He also mentioned that an exception to this rule occurred a few years ago when his mother fell ill during the legislative session, at which point he claimed "family took precedent." But many journalists corroborated the idea that being a political journalist meant time away from family - a loss they were able to live with if it meant they were able fulfill their role in society.

However, not all journalists privileged their journalistic role over other obligations. One journalist, who sees a component of his role as a journalist as serving the underrepresented in society, is an advocate for the LGBTQ community. He views these roles, however, as mutually exclusive. In one instance, he decided to hang up his press credentials and chose not to cover an issue, instead focusing on his duty as an advocate for the LGBTQ community: "I had to make a decision to be a journalist or be an advocate. In this particular instance, I had to not be a journalist” (participant 5). 
Role collaboration. Finally, journalists tended to reinforce the dichotomy between professional selves and personal selves by acknowledging the different set of responsibilities inherent in different facets of their identity, but leveraging one area of their identity to maximize their ability to fulfill the other area. In times of role strain, their prioritization of their journalistic role led them to make decisions based on the opportunity(ies) presented by other areas of their identity. For example, although journalists viewed journalism as invaluable to democratic society, they were able to forego repsonsibilities associated with other democratic traditions, such as voting or free speech. Many journalists acknowledged the importance of censoring their speech in order to avoid expressing personal opinions on topics they may cover. While no journalist interviewed expressed giving up the right to vote, one journalist did confess that his participation in the voting process is merely to benefit his role as a journalist. For him, voting in an election was not so much about his voice as a citizen, but rather how he could meet his journalistic objectives:

And when I do vote, nine times outta ten I know the people on the ballot. I know 'em well. And the reason I vote for people has nothing to do with policy. It has everything to do with how much access I think I'm gonna get out of 'em. Which is extremely selfish. And I understand that. But it goes to my point that I feel so strongly about not taking positions, not feeling like I need to advance an agenda, that I personally don't take - there are very few positions that I personally care about (participant 15).

By leveraging his role in other areas of his life to maximize his ability to fulfill his journalistic role, this participant played the position of a "role collaborator." In this instance, he avoids having a conflict of interest because of his ability to ground decisions in his journalistic role. Although his was an extreme case, other journalists also noted that various facets of their identity further enabled them to perform their journalistic role. 
Even if challenges to the role enactment process did not necessarily result in role strain, journalists acknowledged the possibility of finding strength in their job through their personal life - even as they tried to compartmentalize their life. One journalist, for example, noted that her experience as a woman and a mother has helped inform her work: "You know, since having children, I feel like I'm more aware of educational issues, education policy, because those things might directly affect me" (participant 21). But she also notes: "I feel like it's really important in my role that I don't let my own personal experiences, I guess, influence my work so much that, you know, the reader is disadvantaged."

Reinforcing their cognitive role. The second theme illustrated the journalists' tendency to reinforce their journalistic identity and confirm their cognitive role. Although journalists would often initially interpret the disruptions that resulted in role strain as frustrating, they ultimately found that those challenges reinforced their work expectations and fueled their determination to fulfill their cognitive role. Referring back to the journalist who said she was "acutely aware of how many of my rights are being taken away as a woman at any given time reporting on policies" (participant 20), she also said that strain actually encourages her to keep going and "write about it more." One interviewee who works for a black press publication said that when he faced pressure from politicians, it only further validated his work: "It speaks volumes to our credibility and our ability to keep going as a result of forces who would not like for us to" (participant 4). Although journalists may be pressured by editors, publishers, or external sources to cover topics differently, this pressure can serve as a cue that they are doing something right in their job. One journalist claimed that recent challenges posed by the 
"fake news" rhetoric made him feel like his role was more important than ever: "If nothing else, it's just emboldened me and made me grind down and just try and focus more on doing what I feel like I've always been doing" (participant 15).

Similarly, journalists felt the need to emphasize a long-held journalistic principle: transparency. Although transparency has been considered an integral element in journalism for decades, the interviewees stressed the importance of staying committed to the notion of transparency in reporting when facing criticism. One journalist who identified struggles with skepticism from sources and the rhetoric around "fake news" said:

I have the same approach as always. And that is to be totally upfront about what I'm doing, about what story I'm writing, how I'm approaching it, who I've talked to. Totally open book. And I find that disarms people a bit (participant 16).

Particularly when faced with pressure to perform their role differently, journalists often found themselves defending their decisions and their role in society. Rather than reconceptualizing their cognitive roles, these journalists reinstated and doubled-down on their role conceptions by standing by their behavior and convinctions. When journalists believed that their editors or colleagues were approaching a story in the wrong manner, or if they perceived pressure from their editor to cover a story in a particular way, the journalists often defended their position and rationalized their decision as part of the larger picture. For example, one journalist stated that if his editor was wrong, "you have to stand your ground, because the most important thing is the story. That's more important than anything" (participant 1). However, not all pressure comes from within the newsroom. Especially in a time of increased skepticism of media, journalists found 
themselves having to defend their role to audiences and media critics. This brings us to the next theme: adjusting to new tasks.

Adjusting to new tasks. As journalists reflect on the challenges inherent in increased public skepticism of the media, they articulated the need to adjust tasks to better fulfill their role. One new task was the need to convince the public that what they report is valid. As one journalist stated:

So, it's a lot of things you have to jump over, I would say, to convince people if you have a story that's, like, factually true that it is factually true, and that is important for their life in some way. I would say that's definitely a new thing from when I started to now, where that's the conversation now as opposed to just like what is in the news, what is happening, what should we be saying about it (participant 20).

In addition to attempting to re-build trust with the public, journalists also expressed concern about the difficulty of reaching certain audiences. As illustrated in RQ2, journalists acknowledge that audiences are becoming increasingly segmented as they create custom information silos around their specific interests. The filter bubble problem has resulted in journalists trying to find a way to reach new audiences or even disseminate different content to their audiences. For example, one journalist said that recognizing who his audiences are and where they are accessing his content is key to understanding how to work around information silos:

We knew where we were in the filter bubble, so what we did was we used our spot in the filter bubble as a safe space to present challenging viewpoints ... So that was an opportunity to try to use the societal changes to let me take advantage of almost, to be a Trojan Horse in a way (participant 2).

This "Trojan Horse" journalism represented a new approach to audience viewership. As a journalist working in audio/podcasting, he acknowledged the fact that audiences gravitate toward information they are comfortable with or that reinforces their viewpoint. Instead 
of trying to reach a broader audience, he believed it is more important to disseminate a broader message to his pre-existing audience in hopes of delivering more diverse perspectives on political issues.

Accepting (or not) limitations. Finally, journalists expressed a sense of acceptance of the challenges they face while on the job. Even though they felt conflicted or experienced competing expectations at work, they wrote those challenges off as part of the job. As journalists face the same challenges over and over, they were able to better anticipate some of those challenges resulting in fewer instances of role strain. One interviewee, for example, recalled that when she first started as a journalist, she had to find a way to work around a position she felt put her in an unsafe situation:

We were a series of community newspapers across three different counties, and one of the editors ... wanted me to go and knock on the door of a sex offender and ask them how they felt about it. I remember not at all being comfortable with that and ending up doing a reverse phone look-up and finding someone that I could just talk to on the phone instead. ... Over time, I guess I just got used to the idea of potentially putting myself in harm's way to be there to tell the story (participant $11)$.

Other journalists explained that experience was key to overcoming the struggle between work/life or managing pressure from editors and external parties. Over time, the journalists either adjusted their practices to work around conflicts - successfully navigating around potential conflicts of interest or expected challenges - or did not.

The journalists who could not find workarounds or accept the challenges to their work looked to quit their current position. Especially in cases where the journalist's expectations clashed with their editor's or publisher's expectations, journalists usually threatened to quit with the intent of working as a political journalist elsewhere. In one case, however, the journalist viewed the current political landscape as an existential threat 
to journalism: "It is very challenging to cover a president who lives in a world where facts are not objective, but subjective. And covering that in a neutral fashion is quite a challenge" (participant 8). This journalist decided his best option was to forego his role as a political journalist since he believed this challenge made him fall short of ever being able to fulfill that role.

Summary. Based on responses to RQ1, it is evident that journalists had a strong tie to their role as a journalist. Therefore, it is not surprising that these journalists also expressed the need to prioritize their journalistic role when faced with challenges at work. As journalists reflected on those challenges, they consistently described the distinction between their personal life (e.g., personal opinions or personal obligations) and their professional life. Additionally, they demonstrated that they view certain roles as a priority over others, including roles that they play outside of work. For many journalists, their journalistic role was prioritized over other facets of their life. As changes occur in society, such as changes in technology or culture, journalists indicated the need to adapt to new tasks in order to fulfill their role. Finally, journalists had to assimilate to newsroom practices and adapt to the challenges to their work, or adjust their cognitive role altogether.

\section{Making Sense of Emotion}

RQ4 asked how journalists made sense of emotion associated with role strain. This section dissects findings from this question into three parts: first, it will address how often journalist experience emotional labor at work; next, this section will provide a brief overview of the types of emotion journalists associate with role strain; finally, it will cover how journalists regulate or manage emotion associated with role strain. 
Practicing emotional labor. RQ4a asks to what extent do journalist practice deep acting and surface acting at work. Findings from the survey revealed that, on average, journalists rarely-to-sometimes experience deep acting $(M=2.56, \mathrm{SD}=.92)$ and surface $(M=2.74, \mathrm{SD}=.87)$ acting, but are more likely to experience surface acting than deep acting. In other words, it is more routine for journalist to mask emotions at work than to try to actually feel the emotions they believe they need to feel in order to do their job.

\section{H2: Compared to freelance journalists, staff journalists will experience more}

surface acting and deep acting at work. The second hypothesis states that staff journalists will experience more emotional labor than freelance journalists. On average, freelance journalists $(M=2.45, \mathrm{SD}=.87, n=28)$ were less likely to experience surface acting than staff journalists $(M=2.79, \mathrm{SD}=.87, n=176)$. However, a multivariate regression analysis controlling for gender, years of experience, and age showed that the nature of the journalists' work is not a significant predictor of surface acting $(\beta=-.11, p$ $=.14$; see Table 4). Additionally, freelance journalists $(M=2.56, \mathrm{SD}=1.08)$ and staff journalists $(M=2.56, \mathrm{SD}=.89)$ indicated experiencing the same amount of deep acting. Therefore, the regression model did not did not find a significant relationship between freelance work and deep acting $(\beta=-.07, p=.33)$. This hypothesis is not supported.

H3: The longer journalists have been on the job, the less they will experience deep acting and surface acting at work. The third hypothesis states that as journalists gain experience, the amount of emotional labor they experience on the job will decline. Results from the regression suggest no significant correlation exists between years of experience and surface acting, $(\beta=.21, p=.09)$. However, the longer journalists have been in the field, the less they experience deep acting at work, $(\beta=-.28, p<.05)$. Since 
years of experience was measured in 5-year increments, every five years they experience $.14(2.5 \%)$ less deep acting at work. Overall, the third hypothesis is partially supported. Table 4. Regression Coefficients for the Prediction of Surface and Deep Acting

\begin{tabular}{lcccc}
\hline & \multicolumn{2}{c}{ Surface acting } & \multicolumn{2}{c}{ Deep acting } \\
\hline Freelance & $\underline{\mathrm{B}(\mathrm{SE})}$ & $\underline{\beta}$ & $\underline{\mathrm{B} E})$ & $\underline{-}$ \\
Years of experience & $-.29(.19)$ & -.11 & $-.19(.20)$ & -.07 \\
Female & $.10(.06)$ & .21 & $-.14(.06)$ & $-.28^{*}$ \\
Age & $.02(.14)$ & .01 & $.44(.15)$ & $.22^{* *}$ \\
& $-.16(.07)$ & $-.27^{*}$ & $.13(.08)$ & .21 \\
\hline
\end{tabular}

Note: * $p<.05$; ** $p<.01$

Surface acting: $F(4,195)=2.36, p=.06, \mathrm{R}^{2}=.05$; deep acting: $F(4,195)=4.12, p<.01, \mathrm{R}^{2}=.08$

\section{H4: Female journalists will experience more surface and deep acting than}

male journalists. The fourth hypothesis posits that journalists who are women will experience more emotional labor than those who are men. Women $(M=2.78, \mathrm{SD}=.75)$ indicated having experienced slightly more surface acting than men $(M=2.74, \mathrm{SD}=.92)$. However, results from the regression show that being female is not an indicator of surface acting $(\beta=.01, p=.91)$. Women $(M=2.90, \mathrm{SD}=.95)$ also indicated having experienced more deep acting than men $(M=2.42, \mathrm{SD}=.87)$. Results show being female is a moderate predictor of deep acting $(\beta=.44, p<.01)$, such that being female could result in $8.8 \%$ more deep acting. This means women try to internalize emotions and match how they truly feel with how they believe they should feel more often than men. This hypothesis is partially supported.

Emotions and role strain. Although journalists experience emotion in multiple facets of their work, this question focuses on emotion stemming from challenges at work. Perhaps it is not surprising to report that the responses from interviewees indicated predominantly negative emotions. As with most jobs, when workers are faced with 
challenges or disruptions at work, they experience frustration - regardless of the cause of the disruption. Journalists indicated feeling frustrated regularly with time limitations to their work. For example, one journalist said, "I guess when stories pop up or things break and you aren't expecting it. You know, you haven't, like, allotted that amount of time into your day. That's frustrating" (participant 12). Other journalists also expressed frustration, particularly in dealing with access to sources or covering political officials. One journalist noted: “It's also hard for me when I hear misinformation spread or a politician repeats the same lie that, you know, myself and my colleagues have sometimes repeatedly pointed out in our stories as incorrect" (participant 21).

In addition to the frustration that journalists experienced surrounding those challenges, they also expressed deeper emotions such as anger and rage. The stronger the journalists' connection to their cognitive roles, the more enraged they were when they felt they were unable to fulfill their role. As one journalist stated:

I got into journalism because I believe in a mission of what journalism is and the role it plays in democracy. So I feel a connection to the idea that facts matter and that people need news and information and facts in order to make decisions. So when I see those things under attack or facing those challenges, it can lead to a sense of anger sometimes (participant 2).

Another journalist, who expressed a deep commitment to serving the underrepresented in society, said that he experienced rage and disappointment when editors required changes to a story he was passionate about telling from a certain perspective:

Rage from when you've got a story that you know deep in your heart has to be told, that it is truly about the least of these and your corporate bosses or management is not listening. Disappointment because maybe they didn't see things the way you did. They ran it anyway, but they edited out what you thought was critical, or important, or they watered it down (participant 5). 
One journalist, however, expressed feeling satisfaction with one particular challenge. In his case, he enjoyed when sources made assumptions about his political ideology, especially if those assumptions were wrong: "I enjoyed it, because in a lot of ways it showed that I was doing my job, because they didn't know" (participant 8). But this participant noted that in the current cultural landscape, his emotions toward the same situation has changed:

Under the current administration, it's a lot harder. Because, you know, a lot of us in the press, despite whether we happen to be Democrats, Republicans, liberals, conservatives, whatever it is, we do feel that there is an existential threat to the First Amendment and to journalism. And so when people started making assumptions about your political leanings, it's more charged because we feel so under threat (participant 8).

These journalists all expressed having negative emotional experiences when interruptions inhibited or challenged them from fulfilling their cognitive roles. This finding is not surprising, especially given that these journalists strongly identify with and value what their work contributes to society. Believing that journalism carries a heavy burden in democracy, these journalists got annoyed, frustrated, angry, and disappointed when faced with the lack of resources necessary to do their job, when they could not get in contact with important sources, or when they faced the challenges associated with dealing with public skepticism.

Emotion regulation strategies. In order to manage the strong negative emotions these journalists associated with role strain, they employed certain strategies that they believed ultimately enabled them to fulfill their journalistic roles. Two broad themes emerged from the interviews pertaining to how journalists regulate emotion: proactive strategies and reactive strategies. Both approaches to emotion regulation support the 
tendency for journalists to separate negative emotion from their work, thus reducing the chances of their frustration or anger from affecting their output.

Proactive strategies. Through training, socialization, and experience, journalists have an idea of when and how influences may challenge their work. By understanding when those challenges could arise, these journalists were able to employ preemptive strategies that helped them prevent experiencing negative emotion. These strategies included: avoiding conflicts of interest, compartmentalizing negative emotions from work, defining rules regarding the appropriateness of emotion at work, and adapting to experiences at work.

Avoiding conflicts of interest. In day-to-day routines, journalists discussed the importance of avoiding covering issues in which they have personal connections. For example, one journalist who is an active member of her church chose not to cover the Governor's visit because it was hosted by her church. She recalled:

I didn't want there to be any implications of impropriety. It's a fairly large church and they get involved on things like immigration orthe opiate problem in Ohio. So they were just having panel discussions there, but I didn't think it was worth the potential repercussions, I suppose, to cover it (participant 12).

Although the long-standing ethical tenet of journalism pertaining to avoiding conflicts of interest commonly pertains to a journalists' affiliation with sources, organizations, or associations, another journalist talked about keeping a distance from the issues he covered altogether. He noted that, for the most part, he tries not to even have personal opinions on the topics he covers:

There are very few positions that I personally care about. I care about cars driving too closely when I'm biking down the road. I mean, yeah, I care about that. But do I care about abortion? No. Do I care about - I don't know. Pick a topic. Do I care about it? I let others care about it. I just write about it (participant 15). 
By avoiding the potential for personal conflictions, these journalists were able to also avoid experiencing potential emotionality or perceived bias.

Compartmentalizing. Avoiding conflictions on the job is not always possible, though, so these journalists also crafted emotional boundaries to help them compartmentalize their lives into professional and personal lives. Similar to findings from RQ3, these journalists established boundaries at work to help them make sense of emotion. By understanding when they have personal opinions about the topics they cover, the journalists were able to acknowledge their personal emotions about a topic and segment that from their reporting duties. As one journalist noted: "It's not okay for me to share how I feel about things. I've gotta keep a psychological distance between the main issues of the day and myself" (participant 10). Another journalist recalled having a strong, averse reaction to a topic she was covering, but circumvented her personal reaction in order to do her job. She described putting her feelings about a topic "in a little box" (participant 13) so as not to affect the way she carried out her journalistic tasks. Additionally, journalists expressed approaching issues from a neutral viewpoint or “trying to keep an arm's length from the stuff that I cover, even if it is something that would personally affect me or my family or friends" (participant 21).

A time and a place. Additionally, journalists developed rules that dictated when emotion was appropriate in the workplace. For example, negative emotions affiliated with challenges to their job were deemed inappropriate for the workplace. For these journalists, there was a time and a place for emotion: "I let my focus on my job be the complete priority for me and then I would deal with everything else when I got back to my apartment and let it all soak in" (participant 6). As another journalist claimed: "If 
you're in the newsroom, you [hide emotion] everyday because it's an office" (participant 20). For these journalists, the nature of the work does not matter, it is the idea that showing certain emotions in the workplace is unprofessional. A female journalist added, "I also think that just being a woman in the workplace - and this is journalism everywhere - we are hypersensitive to being depicted as emotional" (participant 13). Although this was just one journalist's perspective, it is an interesting understanding of how female journalists may feel a stronger urge to curb or manage emotion at work for fear of being conveyed as "hypersensitive."

Other journalists indicated that it can be appropriate to show emotion in the newsroom, but not in public. Several journalists explained the importance of putting on a "poker face" or their "public face" when in the field reporting or working with sources. Especially as journalists form emotional relationships with coworkers or supervisors, the idea of expressing emotion in a private space with those they work with appeared to be appropriate to some. For example, one journalist said, "I have no problem sharing my emotion with my colleagues or with my boss, but yeah, I try to keep it in as much as possible when I'm around people who could be seeing me" (participant 9).

While journalists viewed certain emotions as inappropriate for the workplace or for public viewing, they also believed that certain emotions were appropriate - even encouraged - at work. This predominantly involved emotion that was unrelated to role strain; however, journalists did justify expressing negative emotion - such as sadness, anger, or frustration - in the newsroom in situations ranging from national tragedies to being scooped, or beaten to a story, by other news outlets. What was more common was 
the tendency for journalists to value the ability to empathize with subjects and sources in their coverage and showing a human side to their work. As a few journalists noted:

The most important part of being able to do my job is to be human (participant 5).

I think that emotion is also helpful as a reporter because it distinguishes you from, like I said, not being human (participant 9).

Ijust think empathy can be really important in telling the stories of real people (participant 11).

One editor said that emotion is vital to his role, because a large part of what he does is motivate his employees:

Being an editor is like being a coach, I think, sometimes on the football field, you know? You gotta push - everybody's got different ways to motivate, you know? I tend to, like, to just encourage people ... I unleash some passion. I feel sometimes passion is contagioius. If folks feel like their editor cares, then they should care, too, and they do care (participant 15).

But even though they embrace the idea that emotion is essential in relating to their sources, subjects, or coworkers, these journalists still emphasized the importance of not letting that emotion get in the way of reporting. Although these examples of emotion represent the appropriate instances of emotion in the workplace, the journalists note that they still need to produce content that is not swayed by that emotion. As one journalist put it:

It's really kind of a balancing act of being able to connect as a human to another human while reporting on a story, but also being removed enough to be able to accurately report on what's playing out (participant 18).

Another journalist said that even if they are empathetic with their sources in the reporting process, it is important to take a "critical eye" to the story "when you're actually in the process of putting the pieces together" (participant 20). In other words, while it was acceptable to be empathetic while dealing with sources, journalists believed that it was 
essential to detach themselves from emotion while writing and editing their content.

Ultimately, by understanding the rules dictating when and how emotion should be handled in the newsroom, these journalists primed themselves to better manage different types of emotions that they face on the job.

Cognitive adjustments. The emotion regulation strategies thus far have encompassed proactive strategies that journalists intentionally employ in order to prevent emotion from hindering their work. However, journalists also experienced a cognitive change over time that reduced the strength of an emotion associated with role strain. For example, one journalist noted: "If someone wants to give me a rough time - I used to get riled up about it, but I guess I've just gotten more numb to it now and just it's the way that it goes" (participant 15). Other journalists explained that experience helps almost every facet of the job, including their ability to manage and mitigate inappropriate emotions at work:

I mean, I can think of a couple cases very early on. I mean, literally like my first year of this job where I had to leave a room for a couple minutes just to let off some steam, because I was so frustrated by what I was hearing. And now it's - it barely gets a raised eyebrow and a roll of the eyes for the most part. Because you just sort of-you develop a thicker skin when it comes to that sort of thing (participant 7).

Reactive strategies. Though journalists employed proactive strategies that helped protect them from experiencing negative emotion at work, they were still prone to experiencing emotionality at work. When these situations arose, journalists relied on reactive strategies to manage their emotions. These included: venting to colleagues, friends, or family; using journalistic tasks to mask emotion; physical activity; practicing quality checks; and reframing the situation. 
Venting. The most common method used by the journalists was emotional ventilation. By expressing emotions to colleagues, friends, or family members, the journalists were able to better understand the emotional experience, receive feedback, and mitigate the initial affect of negative emotion. Sometimes it was just the mere ability of venting that helped journalists control emotions, as expressed by a couple journalists who explained that they would rant to themselves. As one journalist noted: "Sometimes when I'm in the car I have rants, and that's a good place to have them, because usually people can't hear what you're saying" (participant 14). Just as important as the act of venting is the intended target of that ventilation. The journalists also said that they relied on emotional venting to a person who could understand or empathize with their experience, whether that person may be an editor, coworker, another journalist outside of their organization, friend, spouse, or parent. Journalists indicated that they would choose specific outlets for emotional ventilation based on the root cause of the frustration. For example, one journalist explained that for issues regarding coworkers, she would rely on venting to friends or people in the "industry" who could understand her frustration: "So de-stressing with friends, too, or people who are also in the journalism industry. Just kind of talking about, you know, things that may frustrate you related to your coworkers or whatever. That can help" (participant 9).

Using work to mask emotion. In addition to venting, journalists also relied on their work as an outlet for emotion. These journalists believed that the nature of the work writing, asking questions, note taking - served as an emotion regulation strategy. One journalist even compared the act of reporting to the experiences faced by cops, but noted 
that the benefit of being a journalist is that they can write about events as a form of

ventilation. In his example, writing about emotional experiences was therapeutic:

It's not a normal profession. It's not 9-5. You go to work and whatever you doyou're an accountant, or an auditor, or a mechanic, or a plumber-it's different because you tend to cover some very basic and dramatic things in your career. And they stay with you. It's like being a cop on many occasions. You get these cops out there, doing these very important things in your life, and it tends to stay with them, and then one day they explode. Unlike a cop, a reporter writes about it. And gets it out of your system that way, and then you move on to something else (participant 1).

Another journalist mentioned the benefit of burying her head in her notes if she feels emotion creeping in at an event or during an interview:

Especially if I do start to feel like I am losing a little bit of control over my emotions, it's helpful to sort of put your head down to your notebook for just like a second and take notes and compose yourself and then start to re-engage again (participant 18).

In her case, this journalist relied on an essential task of journalism - note taking - to help her mask emotion and gain composure. Another journalist said that at certain events, she alleviated the affect frustration or anger may have had on her work through the use of follow-up questions:

I'm not afraid to say, "Hey, you said this thing, I've been told that's wrong." You know? "Can you expand on that, can you explain what your critics say? Explain why your critics are wrong?" Or something, like, along those lines. It usually comes out in the form of a question, and it is extremely relieving to do that (participant 21).

As these journalists expressed, they were able to channel negative emotions through specific journalistic taks. This channeling enabled the journalist to deflect the risk of appearing emotional into the benefit of appearing more professional by doubling down on a task. 
Exercise. Additionally, journalists talked about the importance of physical exercise to help reduce stress associated with workplace frustration. Whether it was stepping outside the office to take a walk or practicing yoga after a long day, these journalists looked to physical activity to help them manage instances of negative emotionality. For example, one journalist relied on exercise along with other emotion regulation strategies, such as venting and compartmentalization, to help manage emotion: "I also practice yoga regularly, so being active that way also helps. So in my down time I really try to be active and do things that I enjoy that are not reading the news and that sort of thing" (participant 18). Another journalist explained that just taking a break to walk around the block allowed her the space she needed to "tackle the task at hand:" "So, I was like really upset. And I expressed it to an editor that was here, and then - my frustrations - and then I left work for like 30 minutes and just went on a walk around the block and then, yea, came back here" (participant 3). Whether the exercise served as a quick-fix to emotion, such as in the case of participant 3, or a strategy to manage the ongoing emotion toll of stress, such as in the case of participant 18 , the journalists indicated that emotion was an important tool in their emotion regulation toolbox. One journalist emphasized the importance of self-care in general and noted that it took her time to really understand the importance of self-care and exercise: "So that comes down to personal self-care and taking care of myself in my free time, and exercising, and that kind of thing. So that's taken some time to learn how to do" (participant 10).

Quality checks. When journalists acknowledge that they have had an emotional tie to a topic, issue, or event they cover, some journalists indicated the importance of double checking their stories to make sure certain biases did not manifest in their work. This was 
usually accomplished by the journalists reviewing their own work. As one journalist put it, "I always try to read my story from a couple different ways" (participant 21). Another journalist noted that he makes sure everything he writes "is thoroughly backed-up in evidence" (participant 17). Sometimes this involved the reporter ensuring that the reporting process accounted for diverse perspectives. For example, one journalist noted that despite his personal opinions on a topic, he still needed to seek balance in reporting: A few months ago, I was covering a human trafficking panel ... So when I'm writing a story like that, for example, I want the advocates to succeed on a personal level. I want them to get their ideas out there. I want them to persuade lawmakers at the state level to pass the bill to combat a pretty heinous crime. But at the same time, I do - I acknowledge any hardship that might be in the way of the bill, or - you know - that certain provisions may or may not be best to include, that they might be bogging down the central premise. Stuff along that nature (participant 6).

This type of quality check "on-the-go" enabled the journalist to table his emotional investment in a cause in order to adequately portray differing perspectives. These quality checks were predominantly conducted at the individual level, meaning that journalists relied on their own evaluations of their stories to ensure their material illustrated minimal bias.

Reframing the situation. Finally, a few journalists indicated the importance of acknowledging emotional reactions to events, issues, or topics in coverage, but reframing their perspective to focus on their work. Contrary to the idea that journalists successfully banish emotion at work, these journalists briefly acknowledge their emotions, but shift their interpretation of events toward a more "journalistic outlook." One journalist described this as "recognizing frustration and then taking a second to pivot and focus on the task at hand and meeting your deadlines and everything like that" (participant 3). Although this journalist expressed a feeling of frustration, her perspective of the situation 
changed when she was reminded of her work obligations. Another journalist recalled feeling offended as a woman having to cover demeaning language. She recalled:

Okay, this is upsetting, but I can't let it upset me. And this is - this type of language is horrific, bit I can't let it affect the way that I cover a candidate and subsequently a president, because that would be doing a disservice to my readers (participant 13).

This journalist's outlook on her work was compelling enough for her to put aside her personal detestation of the situation and focus on reporting the story to her audience. She said that, ultimately:

You have to have a moment where you have to say, "These are my emotions and they're totally legitimate, and I am entitled to feel them. Now, how am I going to use them? And like I said before, you have to learn how to use them in a way that informs what you do and not influecnes what you do (participant 13).

For her, it was important to be cognizant of her emotions and personal bias affiliated with her coverage in order for her to control it in her work. By reframing her perspective to align with her journalistic role, she was able to suppress and regulate her corresponding emotion.

Summary. Although survey results indicated that journalists only sometimes experience emotional labor - either deep or surface acting - on the job, follow-up interviews revealed ways in which journalists proactively and reactively mitigated the affect of inappropriate emotions on their work. While journalists acknowledged feelings of frustration, anger, sadness, and disappointment when faced with challenges, they did embrace other emotions in order to fulfill their role. To better make sense of emotion, journalists had predetermined rules that dictated which emotions had legitimacy in their work. By establishing that there was a time and a place for emotion, they understood when and where it was appropriate to express themselves. Additionally, journalists tried 
to prevent negative emotions from affecting their work by establishing emotional boundaries, avoiding covering issues they had strong opinions on or avoiding holding strong opinions in the first place, and by making cognitive adjustments over time. When journalists did experience emotion at work, they relied on reactive strategies to help them keep negative emotion from influencing work. These strategies included venting to friends, family, or colleagues; using work to hide emotion; exercise; quality checks; and reframing the situation. 


\section{Chapter Six: Discussion}

The purpose of this study was to understand how journalists made sense of the role enactment process. This included gaining insight into the roles political journalists viewed as important to their work; understanding the micro-, meso-, and macro-level factors of influence that pose challenges to the role enactment process; and exploring how journalists made sense of role strain and emotionality associated with those challenges. Using a qualitatively-driven mixed methods design, this study employed survey and interview methods to identify generalizable role conceptions, factors of influence, and prevalence of emotionality, as well as explore the sensemaking processes associated with role strain and emotionality at work. While scholars have noted the prevalence of certain influences in the news production process (Shoemaker \& Reese, 1996; Shoemaker \& Vos, 2009; Shoemaker et al., 2009), only a few studies have explored how these factors affect the role enactment process (Carpenter et al., 2016; Tandoc et al., 2013; Tandoc \& Peters, 2015). This research aimed to help close that gap by understanding not ony the challenges journalists face in fulfilling their ideal role, but also how they make sense of those challenges.

\section{Summary of Major Findings}

RQ1 asked which roles journalists identify as important to their work and why they consider those roles important to society. Based on the survey results, this study revealed four broad roles that were important to their work: an informative role, a monitorial role, a participatory role, and an advocate role. Interestingly, items that represented educative, detective, and collaborative roles did not load on any factors. However, journalists indicated that educative and detective items were extremely 
important to their role, regardless of their cognitive role. Additionally, they believed the collaborative item was extremely unimportant, regardless of their cognitive role. The implication is that educating the public and investigating official claims are functions of political journalism, rather than addressing any one role specifically. Similarly, defending the government and its policies has an inverse relationship and does not describe a role or function affiliated with political journalism in the U.S.

Results from the survey also indicate that the informational role was most important to their work, followed by the monitorial role. This is consistent with the qualitative findings in which interviewees expressed the importance of both informing the public and covering officials closely in order to ensure the democratic process. In many ways, the journalists' conceived roles aligned closely with the broader conception of a monitorial role as defined by Christians and his colleagues (2009).

Findings show that the primary function of political journalism, according to journalists, is to serve as a safeguard to democracy. Beyond democracy-based reasons, journalists also indicated an importance of their work in being genuinely helpful to the public. This implies that political journalism is not only inherently tied to democratic means in the U.S., but also associated with a general public helpfulness in society. Consistent with previous research that contends "helpfulness" should serve as journalism's normative anchor (Thomas, 2017), these journalists believed that their roles were important in society for expanding opportunities for others. Rather than viewing this function as contradictory to the first function - enabling the democratic process - it builds upon a broader normative framework for journalism that rejects the notion that journalism is explicitly tied to democracy. 
Although journalists described having a passion for their work and strong sense of identity as journalists, they also identified micro-level, meso-level, and macro-level factors of influence that challenged their ability to fulfill their roles. Survey results indicated one micro-level factor that represented pressure from friends and family. Even though this factor exhibited as the lowest challenge to their work, findings from the qualitative data supported this factor. However, the follow-up interviews also identified other micro-level influences that were not accounted for in the survey. More specifically, qualitiative findings suggested that while the journalists faced challenges associated with their family life, they also faced challenges as a member of the community they covered and indicated that gender could also manifest itself as a challenge.

At the meso-level, results from the survey found two challenges: lack of resources and editorial pressure. Interviews supported these quantitative findings, especially in regards to the magnitude of the challenges associated with a lack of resources. Journalists overwhelmingly identified a lack of time and a lack of money as inhibitors to fulfilling their idealized roles. Although survey data indicated a "lack or resources" variable and an "editorial pressure" variable, journalists in the interviews often conflated the two, expressing that it was often an editor's or publisher's emphasis on the bottom line that cut funding opportunities for the journalists. Additionally, journalists noted that when it came to challenges associated with an editor or supervisor, it could include factors such as years of experience of the editor, story selection and assignment, or an emphasis on innovation. Perhaps not surprising, both freelance journalists and staff journalists indicated experiencing challenges associated with a lack of resources. However, survey results indicated that freelance journalist may not perceive editorial pressures as 
inhibitive to their work as much as staff journalists found it to be. Although the relationship between freelancers and editorial pressure was not supported, the regression coefficient was nearing significance. Additionally, the sample only accounted for a handful of freelance reporters, so future studies should further test this relationship. However, the findings still lend credibility to the argument that freelancers could perceive editorial pressures as less ihibitive to their work than staff journalists. Even though the freelance model requires journalists to produce content that is desirable to editors and publishers, this finding supports previous research that found that freelancers perceive greater autonomy in their work (Jenkins, 2017; Ryan, 2009).

Survey results also identified two macro-level factors: inaccessibility to political/corporate representatives and external pressure. The biggest challenge of the two was inaccessibility of government and business representatives. Perhaps consistent with meso-level findings, the root of this challenge may have more to do with time limitations. Journalists who operate on tight deadlines may face more challenges getting sources to return a call or email, or in scheduling times for interviews. Although survey results showed that pressure from external parties rarely inhibited the journalists' role enactment process, journalists did indicate in the interviews that they are frequently faced with this type of pressure. However, findings from RQ3 illustrated that the journalists' prioritization of their journalistic role enabled them to overcome that direct pressure from politicians, public relations, or the public.

Other macro-level challenges that emerged from interviews included those affiliated with technology and culture. These challenges were harder to overcome because they were affiliated with broader societal shifts, including the increase in "fake 
news" rhetoric. Although the concept of "fake news" has long existed, it has grown in importance since the 2016 U.S. presidential election (Allcott \& Gentzkow, 2017), both in the proliferation of blatantly false news reports on social media and in the misnomer assigned by then President-Elect Donald Trump to news networks (Sutton, 2017). It was the latter instance that journalists described in the interviews as discouraging to their work. The subsequent lack of public trust in journalism created new challenges for journalists, who now had to consider how to rebuild that trust while continuining to cover government and its officials through a critical lens.

As journalists reflected on their experiences with these challenges to their work, they provided insight into how they made sense of instances of role strain. The sensemaking process is retroactive, meaning that even though the circumstances of role strain had already occurred, the journalists were still cognitively processing those experiences. Although journalists firmly embraced their cognitive roles, there were still conditions in which micro-, meso-, and macro-level challenges resulted in the journalist experiencing role strain. This strain would have been between the journalistic cognitive role and the journalist's role as a parent, spouse, employee, community member, or friend. When journalists feel a pull between roles, this strain affects their role enactment process, or the process of a cognitive role becoming a practiced role. This disruption served as a trigger for the sensemaking process.

Through the in-depth interviews in this study, four themes emerged pertaining to this sensemaking process. First, the journalists tended to compartmentalize their lives, particularly when confronted with micro-level challenges. Usually, this required journalists to be reflexive in their process and acknowledge if and when personal bias 
may be apparent in their work. Whether intentionally or not, the journalists described a methodology to their work that was reminiscent of the method of objectivity (Kovach \& Rosenstiel, 2014) in which they seek balance and try to approach their work with limited bias. Second, journalists sometimes viewed challenges as a reminder as to why their role was so important to society, thus validating and reinforcing their cognitive roles. Even as journalists confirmed their cognitive roles, they acknowledged the need to adopt additional responsibilities in order to fulfill their roles. This included finding ways to both rebuild trust with news consumers and break through the filter bubble. Third, as journalists made sense of the challenges to the role enactment process, they ultimately had to either learn to accept the fact that these challenges existed and find ways to work around them, or change their cognitive role. Although no one in the sample indicated quitting journalism altogether, one journalist did say that he was transitioning his position from a political journalist to a position more focused on history and less on current politics. As he made sense of the challenges to his role, he altered his role conception in a way that he believed would alleviate those challenges.

This study demonstrated that after the disruption to the journalists' cognitive roles, they form interpretations of the role strain that inform role negotiation (see Figure 2). While the disruptions may stem from any of the micro-, meso-, or macro-level factors identified in this study, the interpretations are similar. As journalists interpret the role strain, they predominantly attempt to compartmentalize facets of their identity and ground interpretations in their journalistic identity. This demonstrates a prioritization of their journalistic cognitive role. Finally, journalists use their interpretations of role strain to negotiate their cognitive role. Similar to previous research, journalists assimilated to 
newsroom challenges and accepted the limitations of their cognitive roles, or they exited their cognitive role and negotiated an entirely new identity as a journalist (Hanitzsch \& Vos, 2017). However, this study also found that journalists felt empowered by certain limitations to their role, resulting in a reinforcement of their cognitive role. Rather than be deterred by limitations or alter the idealism of their role conception, some journalists found limitations as a source of determination or as confirmation that they were properly enacting their cognitive role.

Perhaps not surpringly, when journalists experienced role strain they indicated feeling an array of negative emotion. Overall, however, survey results showed that the journalists only sometimes practiced emotional labor at work. Findings revealed that the journalists experienced surface acting more than deep acting at work, meaning that they are more likely to mask emotion at work than try to feel the way they believe they should be feeling. While no differences were found between freelancers and staff journalists in frequency of emotional labor, men did indicate experiencing deep acting less than

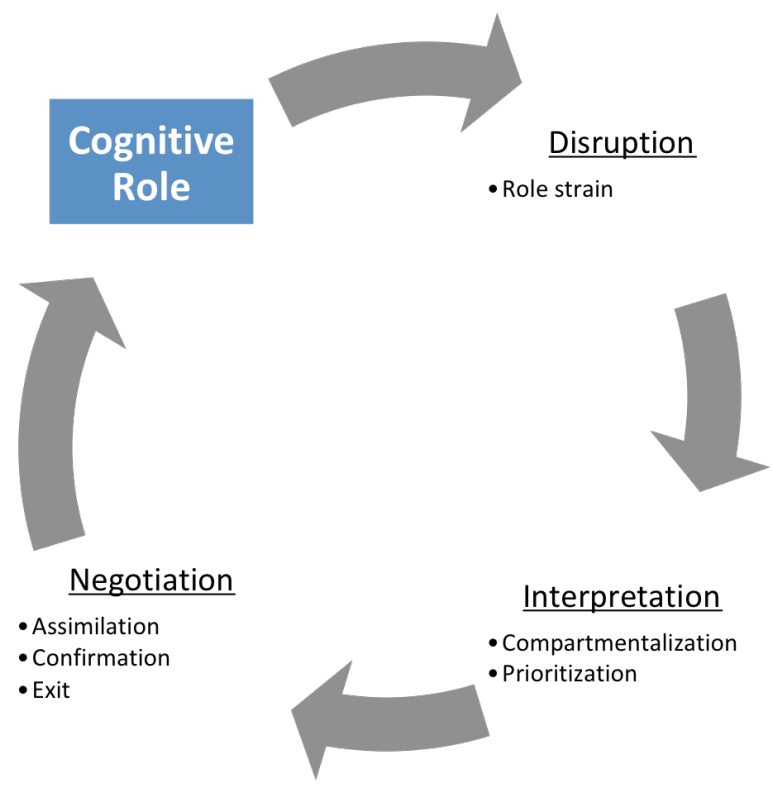

Figure 2. Journalists' Sensemaking Process of Role Strain. 
women. Consistent with the qualitative findings that indicated women may be "hypersensitive" to their emotionality at work, female journalists in the survey showed a greater tendency to try to internalize the emotions they believed they needed to show at work.

Findings did show that the longer journalists have been in the field, the less they experienced deep acting. This finding could be representative of socialization theory, where exposure to certain messages over a long period of time could influence a person's decision-making process (Van Maanen \& Schein, 1979). Rather than exposure to formal or informal messages, exposure to deep acting over time could result in the person to change the way they feel toward their job. Gibson and Papa (2000) outlined the concept of "organizational osmosis" as a socialization process in which people learn to adopt the rules and values of an organization through long-term exposure to the organization. Similarly, journalists in the interview revealed that after being initially frustrated when confronted with a challenge to their role, this frustration dissipated in subsequent affiliations with the same challenge. Perhaps this demonstrates "emotional osmosis" where, over time, journalists have internalized "appropriate" emotions at work.

When it came to regulating the emotions the journalists experienced at work, they employed both proactive and reactive strategies. The former included strategies that the journalists used to preemptively mitigate or avoid anticipated emotions. This included avoiding conflicts of interest, compartmentalizing, establishing a time and a place for emotion, and making cognitive adjustments. In instances where the journalists could not avoid experiencing emotion at work, they employed reactive strategies that helped them maintain a barrier between negative emotion and work (see Table 5). These included: 
emotional ventilation, hiding emotion through work, engaging in physical activity, practicing quality checks, and reframing the situation.

The most common proactive strategy used by the journalists was establishing a time and a place for emotion. For the most part, political journalists believed that emotions were an essential part of their role, but needed to be managed so as not to affect their final product. However, journalists noted that there were also inappropriate emotions in the newsroom, including the negative emotion stemming from workplace challenges. This segmentation of appropriate and inappropriate emotion implies challenges for the dominant emotionality/rationality tradition. Where emotionality in the newsroom or workplace has been considered relatively taboo (Kovach \& Rosenstiel, 2014; Mumby \& Putnam, 1993), these journalists leverage emotionality to fulfill their cognitive roles - that is, when the emotion is considered appropriate.

The most common reactive strategy used by the journalists was emotional venting. Consistent with research on "emotionships" (Cheung, Gardner, \& Anderson, 2015), the journalists in this study not only accessed their social network to regulate emotion, but also segmented their social network to better identify who they needed to go to depending on the context of the emotion. This network diversity helped broaden the "pool of emotion-regulation resources to draw from" (Cheung et al., 2015, p. 412). When journalists needed to vent about frustrations within the field, such as sourcing issues or inaccessibility, they turned to colleagues or other journalists who could better empathize with the journalists' situation. Most journalists, however, also indicated having a resource outside of journalism who they could access when they needed to vent frustrations. Being 
able to target different resources depending on the experienced emotion enhances the quality of the venting strategy in a way that benefits well-being (Cheung et al., 2015).

Table 5. Emotion Regulation Strategies of U.S. Political Journalists

\begin{tabular}{|c|c|}
\hline Strategy & Description \\
\hline Proactive & $\begin{array}{l}\text { Emotion regulation strategies that journalists employ in } \\
\text { anticipation of emotion at work. }\end{array}$ \\
\hline Avoid conflicts of interest & Not covering issues they personally care about. \\
\hline Compartmentalizing & Developing emotional boundaries at work. \\
\hline A time and a place & $\begin{array}{l}\text { Establishing rules for which emotions were appropriate at } \\
\text { work and when those emotions were appropriate. }\end{array}$ \\
\hline Cognitive adjustments & $\begin{array}{l}\text { Adjusting the degree to which they experienced emotion } \\
\text { related to certain stimuli over time. }\end{array}$ \\
\hline$\underline{\text { Reactive }}$ & Emotion regulation strategies that journalists employ after \\
\hline & experiencing emotion. \\
\hline Venting & $\begin{array}{l}\text { Selectively targeting members of their social network for } \\
\text { emotional ventilation. }\end{array}$ \\
\hline Using work to mask emotion & $\begin{array}{l}\text { Deferring emotions to work tasks in order to mask or hide } \\
\text { emotions. }\end{array}$ \\
\hline Exercise & $\begin{array}{l}\text { Managing emotions through physical activity, such as } \\
\text { walks, yoga, or running. }\end{array}$ \\
\hline Quality checks & $\begin{array}{l}\text { Evaluating content to manage the manifestation of } \\
\text { emotions in work. }\end{array}$ \\
\hline Reframing the situation & $\begin{array}{l}\text { Acknowledging emotions, but shifting the focus of the } \\
\text { situation to rational ends. }\end{array}$ \\
\hline
\end{tabular}

Overall, findings tell the story of how political journalists navigate and manage the role enactment process. Findings from RQ1 illustrated the roles that they idealized in their work, as well as why they believed those roles were important to society. As they identified and explained the challenges that they face in fulfilling their cognitive roles, the journalists provided insight into their sensemaking process that ultimately showed how important their professional roles are to their identity. Additionally, they discussed 
ways that they have had to adjust reporting practices to overcome or work around the challenges that appear more frequently in their work. Finally, journalists expressed dissatisfaction when faced with those challenges, but employed both proactive and reactive emotion regulation strategies to help identify and separate inappropriate emotions from work.

\section{Theoretical Implications}

This study reinforces the notion that journalists strongly identify with a criticalmonitorial role (Christians et al., 2009; Glasser \& Gunther, 2005). However, rather than differentiate between an analytical and a monitorial role (Hanitzsch \& Vos, 2018;

Weaver \& Wilhoit, 1986, 1996), the political journalists in this study converged on their conception that offering analysis is one component of a critical-monitorial role. Additionally, they very much believed that an informative role was most important to their work. Consistent with Hanitzsch and Vos (2018), this study illustrated that curator, storyteller, and disseminator items provide a good measurement for this informative role. Interestingly, educative and detective survey items represented very important features of journalism, regardless of the journalists' role conception.

Where previous research has attempted to delineate various functions of journalism (Hanitzsch \& Vos, 2018; Schudson, 2008), this study illustrated that political journalists in the U.S. favor a general helpfulness function, which includes their commitment to the democratic process. Even though enabling democracy was important to their work, these journalists also wanted to provide a public service that could enable others to lead a fulfilling life. This study posits, then, that perhaps more attention is warranted to the idea of helpfulness as a normative concept (Thomas, 2017), rather than 
rooting journalistic normativity solely in conceptions of democratic needs. This study found that while journalists function to be helpful in society, they overwhelmingly adopted the idea that they must also serve the educative and investigative roles. Results from the survey indicate that educating the public and investigating official claims were very important roles to journalists, regardless of their other role conceptions. Rather than operationalizing an educative role and an investigative role as distinct from other roles of the press, perhaps they should be understood as meta-roles indicative of the institution. Meta-roles, unlike more narrowly defined roles, reflect broader role conceptions that journalists across specialties may embrace (Vos, 2017). Just as the gatekeeping role became conceptually linked to journalism practice (Vos, 2017), journalists across specialties may also emphasize the importance of investigating or verifying claims and educating the public to some degree.

This study also built on previous research that identified factors of influence to journalists' work routines (Shoemaker \& Reese, 1996; Shoemaker \& Vos, 2009). Findings show that journalists view a lack of resources (i.e., time and money) and inaccessibility of sources as the biggest challenges to their work, but also indicated that the consistent pressure they experience from external parties presents additional challenges. The micro-level factors of influence, including religion and pressure from one's social network, presented as the weakest inhibitor to their work. On a macro-level, journalists were still making sense of and adjusting to cultural changes, such as new technology and shifts in the media-audience relationship. While gatekeeping theory accounts for the influence culture has on the news production process (Shoemaker \& Vos, 2009), cultural changes - such as the heightened "fake news" rhetoric - serve as an 
external shock to the journalistic institution. This shock to the system results in an institutional sensemaking process in which journalists are still findings ways to navigate around this challenge.

Particularly in handling micro-level challenges, journalists seek to compartmentalize their personal life and professional responsibilities. Findings suggest that although journalists privileged the idea of segmenting their real-self from their professional identity, the distinction is not always so clean cut. There are still some journalists who believed their personal attributes or experiences further enabled them to fulfill their role. This is particularly true in marginalized journalists, such as women, black, and/or gay journalists. This supports the theory of "crystallized" selves, where people refer to certain aspects of one multi-faceted identity depending on the context of a situation (Tracy \& Trethewey, 2005). As journalists perceived that their work could be informed by their personal experiences, the barrier between real-self and fake-self deteriorates - albeit, temporarily.

Although journalists indicated that roles associated with other facets of their identity (e.g., roles affiliated with parenthood, marriage, or membership in a particular community) were usually distinct from their journalistic roles, on occasion these journalists were able to tap into the capital associated with other aspects of their identity to better fulfill their journalistic role. Thus, prioritizing one aspect of their identity - their journalistic role - over others. The findings support observations made by Tandoc and Peters (2015) in which journalists leveraged their collaborative role to better enable their monitorial role. This study illustrated that journalists also use roles they play in their personal lives as resources to fufill their journalistic roles. These "role collaborators" find 
ways to leverage one role in order to enable or inform their journalistic role. For example, one journalist issued his vote for a candidate based on how accessible he perceived that candidate to be in office. Thus, this journalist used his duty as a citizen as a means to fulfill his role as a journalist.

In reflecting on the larger process of the discursive construction of journalistic roles, this study also expands on the process model constructed by Hanitzsch and Vos (2017). While their model accounts for normative roles, cognitive roles, practiced roles, and narrated roles, as well as the processes that lead a journalist to internalize, enact, reflect, and negotiate those roles, the focus of the current study was only on a fraction of that model. More specifically, this study investigated the cognitive roles of the journalists and influences to the role enactment process. Although the preconceived model indicates that journalists engage in a sensemaking process as they reflect on their practiced roles (the end product of role enactment), this study demonstrates that the journalists' also make sense of the role enactment process as well. Journalists not only engage in sensemaking as they reflect on the roles exhibited in their work (like the original model suggests), but they also continuously make sense of role strain and challenges to their work throughout the role enactment process. While Figure 2 illustrates what this latter sensemaking process looks like, Figure 3 shows where this specific sensemaking process occurs in the model of the discursive construction of journalistic roles.

Additionally, this study found that this sensemaking process also accounts for role negotiation. In previous research, role negotiation has accounted for journalists' ability to assimilate to newsroom routines, appropriate their cognitive role to accommodate limitations to their job, or exit their role (Hanitzsch \& Vos, 2017). Similarly, journalists 


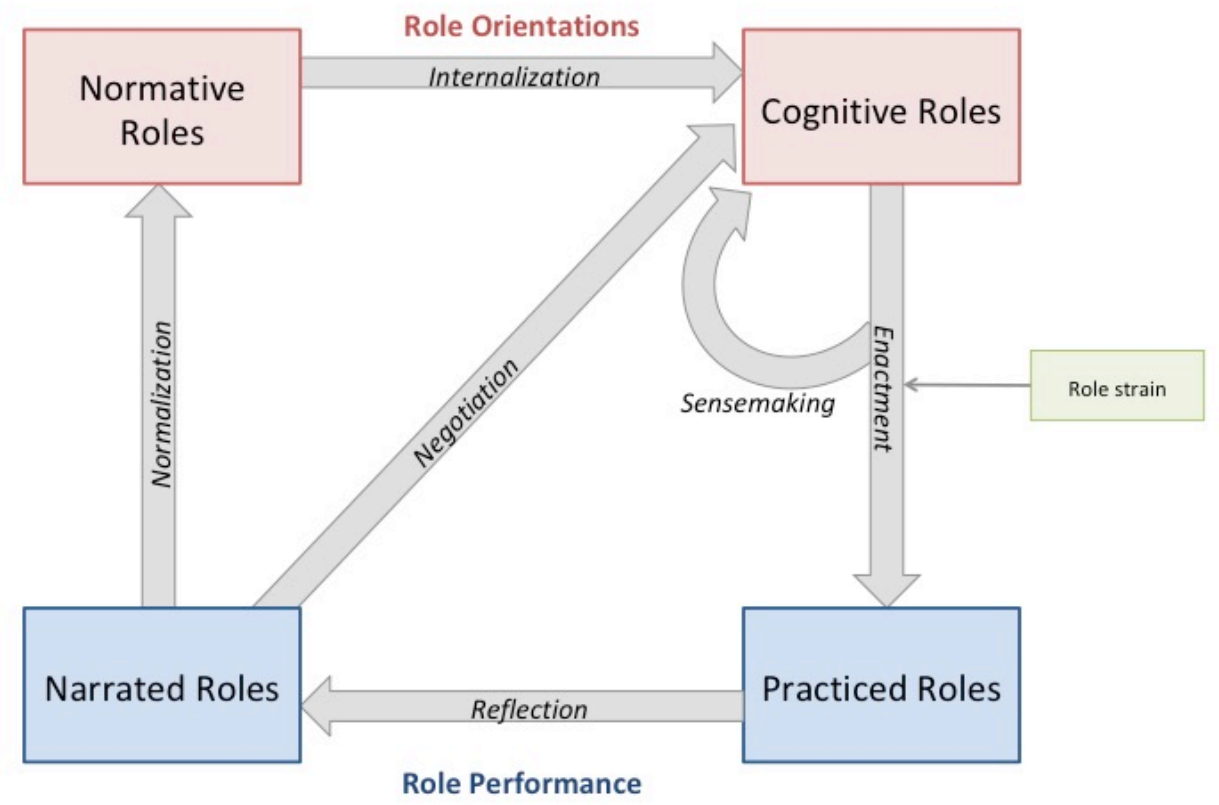

Figure 3. Discursive Construction of Journalistic Roles (Adapted from Hanitzsch \& Vos, 2017).

in this study indicated assimilating to the newsroom and adjusting their cognitive role in light of certain challenges, as well as exiting their cognitive role in cases where they cannot overcome certain challenges. However, this study also showed that journalists found certain challenges as confirmations of their cognitive roles, thus reinforcing and strengthening their role conception. Rather than making concessions in light of certain challenges, journalists found ways to work around anticipated challenges in the role enactment process to better fulfill their cognitive roles.

In fulfilling those day-to-day tasks associated with their cognitive roles, journalists indicated that they occasionally experience surface and deep level acting. However, the follow-up interviews revealed that journalists routinely used empathy or hid particular emotions in order to better fulfill their role. Similar to Hochschild's (1983) foundational work on emotional labor, these journalists often put on a face to present themselves as professional and make their sources feel at ease. While some of these 
journalists reflected on this experience as simply being human, their attempt to strip emotion from the final product of their work illustrates their tendency to rationalize this emotionality.

Consistent with Fineman's (1996) outlook on the relationship between emotionality and rationality in organizational studies, journalists ultimately believed that emotions could be leveraged to fulfill an end goal of rationality, further subjugating emotionality to rationality. This dichotomy is prevalent in employee training manuals that emphasize the importance of employees to show concern for customers and mask any frustration or impatience they may be feeling while dealing with customers (Sutton and Rafaeli, 1988). Police officers and debt collectors are also asked by management to adopt certain emotional display rules to match social interactions to orgnanizational goals (Rafaeli and Sutton, 1991). Similar to the findings of this study, the way workers' feel inside is often masked and regulated to maintain an organizationally-approved façade.

This study demonstrated that journalists regulate their emotions using certain strategies, which can be proactive or reactive in nature. Just as Dougherty and Drumheller (2006) found that full-time workers in various organizations regulated emotions in a way that privileged rationality, this study found that journalists also practiced some of the same strategies, including establishing a time and a place for emotion and reframing the situation. However, journalists also attempted to keep an emotional distance from events and issues they covered, compartmentalized their lives, and relied on venting and exercise to help manage emotions. Additionally, they underwent cognitive adjustments over time. After years in journalism, journalists experienced an "emotional osmosis" where they no longer practice deep acting, but have 
finally internalized the appropriate emotions - or lack thereof - in certain situations. Many journalists expressed this as "becoming numb" to particular challenges, such as pressure from an editor or government representative.

Although journalists subjugated emotionality to rationality, they still believed that emotion was important to the reporting process. Even political journalists who indicated a prioritization of informational and monitorial roles, indicated an importance of empathy and being human in the news production process. Contradictory to the idea that emotionality only has a place in certain journalistic roles (Wahl-Jorgensen, 2013), these findings suggest that emotionality may play a larger part in journalism across many roles. However, the role of emotion may vary based on the cognitive roles of the journalists. For example, one participant in the interviews identified strongly with the advocateradical role of the press. For him, it was imperative that his reporting came from a place of emotion. Similarly, some of the journalists in the interviews identified with the monitorial role and believed it was essential for them to be passionate about their job, driven, and not deterred by instances of role strain.

Differences in emotionality can also be closely linked with experiences of role strain affiliated with certain cognitive roles. While journalists who identified with the monitorial role indicated challenges associated with a decline in trust in the media and pressure from external sources, the journalist who identified himself as an advocateradical journalist was not concerned with either of those challenges. In fact, although he addressed experiencing pressure directly from a previous presidential administration, he expressed joy over that situation because it resulted in increased exposure to his brand and credibility to his cause. The emotion he associated with particular pressures or 
challenges, then, was quite different than the more common sentiments of frustration or anger.

Although there was the one journalist who indicated the importance of emotionally-laden work, the journalists in the interviews predominantly relied on emotionality as an instrument to their work. Overall, this study supports Pantti's (2010) work that showed that journalists do not feel that their emotion should be represented in their work. By privileging rationality and objectivity, journalists are able to use emotion or empathize with sources as a means to an end, but have the ability to practice quality checks of their work to ensure their content is free from personal bias. This emphasis on sripping emotionality from work, however, places extra stress on the journalist when they are faced with emotionally-laden situations. Journalism is a social endeavor in which journalists must engage in social interactions with sources, editors, colleagues, subjects, and audiences on a routine basis. Emotions are an inescapable occurrence inherent in human interaction. When emotional display rules and emotional labor are institutionalized, employees risk feeling greater tension between "felt and feigned emotions" (Putnam \& Mumby, 1993, p. 50). By consistently reinforcing an unrealistic emotionality/rationality dichotomy, organizations and social institutions place greater stress on workers to regulate the way they truly feel.

Although reason and rationality have an important place in journalism, this study suggests that journalism can also benefit from emotional roles. As the journalists in this study reflected on the importance of fulfilling traditional elements of journalism, such as transparency and objectivity, they indicated that emotion plays a complex role. Just as journalists try to manage negative emotions that may be detrimental to the reporting 
process, they acknowledge the importance of emotion that emerges from human interaction. They also expressed the value in being determined or committed in their work, passionate, and even able to motivate other journalists. These are all instances in which genuine emotion is key to fulfilling their cognitive roles, rather than inhibitive of objective methods and transparent reporting practices.

Finally, this study not only supports the notion that objectivity is still a widely practiced tradition (Tuchman, 1972; Kaplan, 2006), but also supports research that suggests journalists are making attempts to increase their levels of transparency (Hellmueller, Vos, \& Poepsel, 2013). While employing objectivity as a method in their reporting process, journalists must now be more transparent than ever with their sources and audiences in an effort to rebuild trust in the institution. Based on this study, it seems that in the wake of the "fake news" controversy, journalists are increasingly emphasizing the importance of both transparency and objectivity. Although recent research has indicated that audiences may not necessarily associate transparency with credibility (Tandoc \& Thomas, 2017), these journalists believed that being open and honest with sources about the reporting process was a crucial element in establishing a trusting relationship between journalists and news consumers.

\section{Practical Implications}

Journalism educators and newsroom supervisors should discuss the challenges political journalists may face in their work. As younger journalists are training for a career in journalism, early exposure to some of those challenges could jump-start their socialization into the field in a way that prepares their cognitive toolkit to better handle instances of role strain. Findings show that the more often journalists are exposed to 
challenges and emotion at work, the sooner they could become numb or apathetic in certain contexts.

However, journalists are still attempting to make sense of some of the newer, more macro-level challenges. As demonstrated in the interviews, journalists are still navigating the escalating "fake news" rhetoric and general decline in trust in the media, but must also grapple with a new journalistic function: rebuilding trust. Journalists now, more than ever, are finding themselves practicing with objectivity and transparency, employing additional quality checks on their work, and taking the time to reduce implicit bias, as found in previous research (Hellmueller et al., 2013; Kovach \& Rosenstiel, 2014; Schudson, 2011) and confirmed in this study.

In order to fulfill their function in society, political journalists are also trying to adjust to the challenges posed by the filter bubble problem. While larger newsrooms may already have the resources to offer a more diverse range of perspectives, journalists who work for more niche publications are finding ways to bring more diverse - even competing - perspectives into their programming or coverage. Journalists who have an understanding of where they fall in the filter bubble can employ this "Trojan Horse" journalism tactic to help diversify the information being consumed by their audiences.

Finally, this study revealed several ways journalists navigate through challenges to work and regulate emotion. While findings revealed the prioritization of rationality at work, journalism educators and newsroom editors should acknowledge the benefit emotionality plays in the journalists' work. The ability to be human, empathetic, and passionate about their work was necessary in order for them to fulfill their role. When journalists experienced emotion that hindered their ability to perform, they turned to 
emotional venting and physical exercise - even if it was just stepping outside during work hours for a quick walk. Taking the time to invest in self-care can not only help journalists manage negative emotion at work, but also enable them to better fulfill their role. For example, the Dart Center for Journalism and Trauma at Columbia Journalism School is dedicated to educating journalists on strategies related to reporting on conflict, violence, and tragedy. It provides practical recommendations and tips to journalists, such as debriefing after traumatic experiences and maintaining a regular routine, that enable "healthier newsrooms and better journalism" (Dart Center for Journalism \& Trauma, 2009). Similarly, the Center for Health Journalism at USC Annenberg also acknowledges the importance of self-care for journalists who are under stress and offer similar tips for journalists in managing that stress (Stifter, 2014). Although these sites offer useful strategies for managing extraordinarily emotional situations or compassion fatigue, this study illustrated that journalists must also manage more routine instances of stress and emotion in order to sustain well-being. Newsrooms and media companies should be prepared to not only acknowledge and accept the nature of emotionality, but also offer mental health services that can better facilitate the journalists in maintaining a healthy balance of emotion, stress, life, and work.

\section{Limitations and Directions for Future Research}

Though this research contributes to theoretical understandings of journalistic roles, gatekeeping, emotion, and the sensemaking process, it is not without its limitations. First, political journalism - and journalism in general - is becoming an increasingly nebulous term with the rise of independent blogger sites and social media. In order to provide a specific scope to this study, a narrow definition of "political journalist" was 
used. By using this limited definition to guide sampling procedures, people who contribute to political discourse, but who may not consider themselves a political journalist, were not included in the study. Additionally, this studied relied on databases of registered journalists for participant recruitment. Even though these databases are constantly monitored and updated, the listings do not serve as a complete list of the population of U.S. journalists.

Second, timing posed restrictions in two ways. Participant recruitment began shortly after Project Veritas' failed attempts to manipulate journalists into abandoning their journalistic ethics. In November 2017, The Washington Post revealed that a source had falsely claimed that Roy Moore, the Republican U.S. Senate candidate from Alabama, had impregnated her as a teenager in 1992. The Post discovered that this woman worked " with an organization that uses deceptive tactics to secretly record conversations with journalists in an effort to embarrass them" (Boburg, Davis, \& Crites, 2017). After connecting this source to Project Veritas (an organization that practices "sting" operations that target the news media and liberal interest groups), the newspaper concluded that the failed operation was an attempt to discredit media outlets that had been covering the Moore allegations (Boburg, Davis, \& Crites, 2017). In the wake of this scandal, several journalists became skeptical of requests for participation in research and declined to participate. Additionally, in the wake of an unexpected presidential election and direct, verbal attacks on the news media by public officials, the timing of this study may have resulted in narratives stemming from those recent events. However, insight into how journalists made sense of those challenges and experienced emotion related to those 
challenges provides timely consideration into the current lived experiences of the journalists in this study.

The second time concern was much more common in qualitative interviews and pertained to the length of the interviews. Although interviews lasted between 25-40 minutes, that amount of time only enabled the researcher to scratch the surface of the journalists' sensemaking processes and experiences with emotionality. Future research could explore in more depth the experiences journalists have when faced with particular challenges to their work. Perhaps longer interviews or observational studies could better explore the intricate nature of journalists' sensemaking processes.

Third, results from the interviews unveiled several potential factors of influence that were not accounted for in the survey. For example, "pressure from my family" was the only item that quantitatively measured familial role pressure. However, findings from the interviews revealed that participants experienced several family-related influences to work, such as pressure from family members to practice differently and the struggle to balance work with familial obligations. Future studies could further examine journalists' work/life balance to better address micro-level challenges to the role enactment process. Additionally, it seems as though years of experience has helped journalists better navigate around several areas of role strain. Further research could provide the field with a better understanding of how journalists who are in the field have found success managing work with life.

Fourth, this study had substantially more staff journalist participants than freelance participants. Again, this could be a result of using databases that best identify journalists based on their involvement with news organizations and publications. Even 
with the relatively small sample of freelance journalists, this study hinted at differences in perceptions of challenges to journalistic work. Future research could further explore the differences in challenges and role perceptions between the two groups.

Additionally, political journalism represents one small facet of the larger U.S. media landscape. Journalism, as a social institution, is comprised of several supplementary beats or genres of reporting and relies on its relationship with peripheral agents, such as public relations representatives and advertisers. Future research into challenges to the role enactment process should address how journalists operating in those other supplementary areas of journalism make sense of role strain and emotion. In order to evaluate both sides of the coin, research should also account for the role conceptions, practiced roles, and challenges faced by peripheral agents. This line of inquiry could provide valuable insight into the complexities of the journalism-public relations-advertising relationship and may even better inform mass communications and media educators.

While this study presented exploratory insight into the nature of emotionality and journalism, future studies should seek to explain the complex relationship between emotion and journalistic roles. Research that further illuminates the lived experiences and emotional life histories of journalists can help explain the nature of journalistic work in the context of new and emerging institutional challenges (Wahl-Jorgensen, 2018). Additionally, more research clarifying instances of emotional labor in journalism could contribute to a greater understanding of institutionalized display rules and role strain. While the current study relied on previous scales used to measure surface and deep level acting (Kruml \& Geddes, 2000; Naqvi, 2014), this study shows that modifications can be 
made to the scale that better tailor the indices to the journalistic institution. More specifically, future research should account for items that better measure deep acting in journalism, such as: "I believe it is important to genuinely empathize with sources" and "I try to match the way I truly feel with the emotions I want my sources and audiences to believe I'm feeling." In order to customize surface acting scales for journalism practice, items could include: "I make sure to show a poker face when I am reporting in public" and 'I try to appear empathetic to sources, even though I don't try to truly match how they feel."

\section{Conclusion}

Political journalists in the U.S. identify strongly with an informational role that includes curating information, disseminating that information, and providing an explanation of the news. The second most important role to these journalists was a more monitorial role, which included providing an analysis of events in the news, critiquing political and business leaders, and serving as a critical observer of political conduct. Regardless of their role conception, journalists believed that their job also included investigating official claims. This is not surprising, given the importance of verification in journalism and the emphasis it receives by journalism educators.

In fulfilling these roles, the journalists believed they enabled people to seek opportunities, as well as fulfilled a vital role in democracy. Additionally, these roles were deeply embedded in the journalists' identities. So much so that the journalists rarely faced challenges to their work stemming from other facets of their identity. Even though these journalists privileged their journalistic roles and had certain expectations of how they should perform those roles, they still faced challenges enacting those roles. When editors, 
government representatives, advertisers, publishers, or other journalists imposed conflicting expectations on the journalists, they experienced an instance of role strain.

This study demonstrated that in the face of these challenges, journalists prioritize their journalistic identitiy. More often than not, journalists actually reinforced their cognitive role in light of these challenges, but may have had to appropriate those challenges to their work. In the context of larger social system challenges, journalists are still finding ways to alleviate the threat those challenges pose to their role. For example, niche publications could be resorting to "Trojan Horse" journalism to present contradictory and diverse viewpoints to audiences who may not necessarily be expecting it to address the filter bubble problem.

Finally, this study illustrated that experience helps journalists better nagivate role strain and emotion at work. While some emotion is appropriate, even desirable, in the newsroom, some emotion - particularly negative emotion - could hinder their work. As journalists gained experience interacting with challenges at work, over time they practiced "emotional osmosis" in which they ultimately became numb to certain challenges. In other words, after long-term exposure to one challenge, the journalists no longer experienced an emotional reaction (depending on the severity of the challenge.)

Overall, understanding the interconnectivity among journalism, challenges to work, sensemaking, and emotion presents worthwhile insight that benefits journalism and mass communication practice and education. Future research should further investigate not only the effect of challenges on journalistic work, but also how journalists make sense of those challenges beyond the political journalism landscape. Additionally, research into emotionality in journalism is underrepresented, even though the 
phenomenon is pervasive. This study attempted to fill this gap and serves as a foundation for future studies into emotion regulation and sensemaking in the journalistic institution. 


\section{References}

Adam, G. S. (2009). Freedom of expression and the liberal democratic tradition. In L. Wilkins \& C. G. Christians (Eds.), The handbook of mass media ethics (pp. 317-327). New York, NY: Routledge.

Allcott, H., \& Gentzkow, M. (2017). Social media and fake news in the 2016 election. Journal of Economic Perspectives, 31(2), 211-236. doi:10.1257/jep.31.2.211.

Allen, D. S., \& Hindman, E. B. (2014). The media and democracy: Using democratic theory in journalism ethics. In W. N. Wyatt (Ed.), The ethics of journalism: Individual, institutional, and cultural influences (pp. 185-203). London, UK: I. B. Tauris.

American Association for Public Opinion Research. (n.d.) Standards/Ethics. Retrieved on Sept. 15, 2017, from: https://www.aapor.org/Standards-Ethics.aspx.

Andersson, L. (2012). There is no alternative: The critical potential of alternative media in the face of neoliberalism. Communication, Capitalism, \& Critique, 10(2), 752-764.

Atton, C. (2002). News cultures and new social movements: Radical journalism and the mainstream media. Journalism Studies, 3(4), 491-505.

doi:10.1080/1461670022000019209.

Baker, C. E. (2002). Media, markets, and democracy. New York, NY: Cambridge University Press.

Baran, M. L. (2016). It is all in the design: Creating the foundations of a mixed methods research study. In M. L. Baran \& J. E. Jones (Eds.), Mixed methods research for improved scientific study (pp. 66-78). Hershey, PA: IGI Global.

Barnett, R. C., \& Baruch, G. K. (1985). Women's involvement in multiple roles and psychological distress. Journal of Personality and Social Psychology, 49(1), 135-145. doi:10.1037/0022-3514.49.1.135.

Bas, O., \& Grabe, M. E. (2015). Emotion-provoking personalization of news: Informing citizens and closing the knowledge gap? Communication Research, 42(2), 159-185. doi:10.1177/0093650313514602.

Bell, M. (1998). The journalism of attachment. In M. Kieran (Ed.), Media ethics (pp. 1522). London, UK: Routledge.

Bennett, W. L., \& Serrin, W. (2005). The watchdog role. In G. Overholser \& K. H. Jamieson (Eds.), The press (pp. 169-188). New York, NY: Oxford University Press. 
Blumler, H. (1954). What is wrong with social theory? American Sociological Review, 19(1), 3-10. Retrieved from: http://www.jstor.org/stable/2088165.

Boburg, S., Davis, A. C., Crites, A. (2017, November 27). A woman approached The Post with dramatic - and false - tale about Roy Moore. She appears to be part of undercover sting operation. The Washington Post. Retrieved (March 28, 2018) from https://www.washingtonpost.com/investigations/a-woman-approached-the-post-withdramatic--and-false--tale-about-roy-moore-sje-appears-to-be-part-of-undercoversting-operation/2017/11/27/0c2e335a-cfb6-11e7-9d3abcbe2af58c3a_story.html?utm_term $=.7715 \mathrm{f} 8 \mathrm{~d} 3 \mathrm{e} 312$.

Boczkowski, P. J. (2010). News at work: Imitation in an age of information abundance. Chicago, IL: University of Chicago Press.

Borden, S. L. (2014). Communitarian journalism and the common good: Lessons from the Catholic Worker. Journalism, 15(3), 273-288. doi:10.117/1464884913477283.

Bourdieu, P. (1998). On television. New York, NY: New Press.

Brotheridge, C. M., \& Grandey, A. A. (2002). Emotional labor and burnout: Comparing two perspectives of "people work." Journal of Vocational Behavior, 60(1), 17-39. doi:10.1006/jvbe.2001.1815.

Brownlee, B. J., \& Beam, R. A. (2012). U.S. journalists in the tumultuous early years of the $21^{\text {st }}$ Century. In D. H. Weaver \& L. Willnat (Eds.), The global journalist in the $21^{\text {st }}$ Century (pp. 348-362). New York, NY: Routledge.

Campbell, V. (2004). Information age journalism: Journalism in an international context. London, UK: Arnold.

Carey, J. W. (1989). Communication as culture: Essays on media and society. New York, NY: Routledge.

Carlson, M. (2016). Metajournalistic discourse and the meanings of journalism: Definitional control, boundary work, and legitimation. Communication Theory, 26(4), 349-368. doi:10.1111/comt.12088.

Carpenter, S., Boehmer, J., \& Fico, F. (2016). The measurement of journalistic role enactments: A study of organizational constraints and support in for-profit and nonprofit journalism. Journalism \& Mass Communication Quarterly, 93(3), 587-608. doi:10.1177/1077699015607335.

Cassidy, W. P. (2006). Gatekeeping similar for online, print journalists. Newspaper Research Journal, 27(2), 6-23. doi:10.1177/073953290602700201. 
Charmaz, K. (2001). Grounded theory: Methodology and theory construction. In N. J. Smelser \& P. B. Baltes (Eds.), International encyclopedia of the social and behavioral sciences (pp. 6396-6399). Amsterdam: Elsevier.

Cheung, E. O., Gardner, W. L., \& Anderson, J. F. (2015). Emotionships: Examining people's emotion-regulation relationships and their consequences for well-being. Social Psychological and Personality Science, 6(4), 407-414. doi:10.1177/1948550614564223.

Christians, C. G., Glasser, T. L., McQuail, D., Nordenstreng, K., \& White, R. A. (2009). Normative theories of the media: Journalism in democratic societies. Urbana, IL: University of Illinois Press.

Cohen, B. C. (1963). The press and foreign policy. Princeton, NJ: Princeton University Press.

Collins, K. M. T. (2015). Validity in multimethod and mixed research. In S. Hesse-Biber \& R. B. Johnson (Eds.), The Oxford handbook of multimethod and mixed methods research inquiry (pp. 240-256). New York, NY: Oxford University Press.

Commission on Freedom of the Press. (1947). A free and responsible press. Chicago, IL: University of Chicago Press.

Cook, T. E. (1998). Governing with the news: The news media as a political institution. Chicago, IL: University of Chicago Press.

Coser, R. L. (1975). The complexity of roles as a seedbed of individual autonomy. In L. A. Coser (Ed.), The idea of social structure: Papers in honor of Robert K. Merton (pp. 237-263). New York, NY: Harcourt Brace Jovanovich.

Côté, S., \& Morgan, L. M. (2002). A longitudinal analysis of the association between emotion regulation, job satisfaction, and intentions to quit. Journal of Organizational Behavior, 23(8), 947-962. doi:10.1002/job.174.

Coverman, S. (1989). Role overload, role conflict, and stress: Addressing consequences of multiple role demands. Social Forces, 67(4), 965-982. doi:10.1093/sf/67.4.965.

Creswell, J. W. (2015). Revisiting mixed methods and advancing scientific practices. In S. Hesse-Biber \& R. B. Johnson (Eds.), The Oxford handbook of multimethod and mixed methods research inquiry (pp. 57-71). New York, NY: Oxford University Press.

Creswell, J. W., \& Plano Clark, V. L. (2011). Designing and conducting mixed methods research. Thousand Oaks, CA: Sage. 
Dart Center for Journalism and Trauma. (2009, April 30). Self care tips for news media. Dart Center for Journalism \& Trauma. Retrieved (March 29, 2018) from https://dartcenter.org/content/self-care-tips-for-news-media-personnel-exposed-totraumatic-events.

Delli Carpini, M. X. (2013). Breaking boundaries: Can we bridge the quantitative versus qualitative divide through the study of entertainment and politics? International Journal of Communication, 7, 531-551. Retrieved from: http://ijoc.org/index.php/ijoc/article/view/1972.

Dey, I. (1993). Qualitative data analysis: A user-friendly guide for social scientists. London, UK: Routledge.

DiMaggio, P. J., \& Powell, W. W. (1991). Introduction. In W. W. Powell \& P. J. DiMaggio (Eds.), The new institutionalism in organizational analysis (pp. 1-38). Chicago, IL: The University of Chicago Press.

Donohue, G. A., Tichenor, P. J., \& Olien, C. N. (1995). A guard dog perspective on the role of media. Journal of Communication, 45(2), 115-132. doi:10.1111/j.14602466.1995.tb00732.x.

Donsbach, W. (2008). Journalists' role perception. In W. Donsbach (Ed.), The international encyclopedia of communication (pp. 2605-2610). Oxford, UK: WileyBlackwell.

Donsbach, W., \& Patterson, T. E. (2004). Political news journalists: Partisanship, professionalism, and political roles in five countries. In F. Esser \& B. Pfetsch (Eds.), Comparing political communication: Theories, cases, and challenges (pp. 251-270). New York, NY: Cambridge University Press.

Dougherty, D. S., \& Drumheller, K. (2006). Sensemaking and emotions in organizations: Accounting for emotions in a rational(ized) context. Communication Studies, 57(2), 215-238. doi:10.1080/10510970600667030.

Eide, M. (2017). Normative theories and journalistic role performance. In C. Mellado, L. Hellmueller, \& W. Donsbach (Eds.), Journalistic role performance: Concepts, models, and measures (pp. 90-105). New York, NY: Routledge.

Ferrucci, P., \& Vos, T. P. (2017). Who's in, who's out? Constructing the identity of digital journalists. Digital Journalism, 5(7), 868-883.

doi:10.1080/21670811.2016.1208054.

Fineman, S. (1996). Emotion and organizing. In S. R. Clegg, C. Hardy, \& W. R. Nord (Eds.), Handbook of organization studies (pp. 289-310). London, UK: Sage. 
Frey, L. R., Botan, C. H., \& Kreps, G. L. (2000). Investigating communication: An introduction to research methods ( $2^{\text {nd }}$ ed.). Boston, MA: Allyn \& Bacon.

Gans, H. J. (1972). The famine in American mass-communications research: Comments on Hirsch, Tuchman, and Gecas. American Journal of Sociology, 77(4), 697-705. doi:10.1086/225195.

George, C. (2013). Diversity around a democratic core: The universal and the particular in journalism. Journalism, 14(4), 490-503. doi:10.1177/1464884912464169.

Gibson, M. K., \& Papa, M. J. (2000). The mud, the blood, and the beer guys: Organizational osmosis in blue-collar work groups. Journal of Applied Communication Research, 28(1), 68-88. doi:10.1080/00909880009365554.

Glasser, T. L., \& Ettema, J. S. (1989). Investigative journalism and the moral order. Critical Studies in Mass Communication, 6(1), 1-20. doi:10.1080/15295038909366728.

Glasser, T. L., \& Gunther, M. (2005). The legacy of autonomy in American journalism. In G. Overholser \& K. H. Jamieson (Eds.), The press (pp. 384-399). New York, NY: Oxford University Press.

Glasser, T. L., \& Lee, F. L. F. (2002). Repositioning the newsroom: The American experience with "public journalism." In E. Neveu \& R. Kuhn (Eds.), Political journalism: New challenges, new practices (pp. 203-224). London, UK: Routledge.

Goode, W. J. (1960). A theory of role strain. American Sociological Review, 25(4), 483496. Retrieved from: http://www.jstor.org/stable/2092933.

Grandey, A. A. (2000). Emotion regulation in the workplace: A new way to conceptualize emotional labor. Journal of Occupational Health Psychology, 5(1), 95110. doi:10.1037/1076-8998.5.1.95.

Gross, J. J., Richards, J. M., \& John, O. P. (2006). Emotion regulation in everyday life. In D. K. Snyder, J. A. Simpson, \& J. N. Hughes (Eds.), Emotion regulation in couples and families: Pathways to dysfunction and health (pp. 13-35). Washington, D. C.: American Psychological Association.

Guba, E. G., \& Lincoln, Y. S. (1994). Competing paradigms in qualitative research. In N. Denzin \& Y. S. Lincoln (Eds.), Handbook of qualitative research (pp. 163-194). Thousand Oaks, CA: Sage.

Habermas, J. (1989). The structural transformation of the public sphere. (T. McCarthy \& F. Lawrence, Trans.). Cambridge, MA: MIT Press. 
Hanitzsch, T. (2007). Deconstruction journalism culture: Toward a universal theory. Communication Theory, 17(4), 367-385. doi:10.1111/j.1468-2885.2007.00303.x.

Hanitzsch, T., \& Hanusch, F. (2012). Does gender determine journalists' professional views? A reassessment based on cross-national evidence. European Journal of Communication, 27(3), 257-277. doi:10.1177/0267323112454804.

Hanitzsch, T., \& Mellado, C. (2011). What shapes the news around the world? How journalists in eighteen countries perceive influences on their work. International Journal of Press/Politics, 16(3), 404-426. doi:10.1177/1940161211407334.

Hanitzsch, T., \& Vos, T. P. (2018). Journalism beyond democracy: A new look into journalistic roles in political and everyday life. Journalism, 19(2), 146-164. doi:10.1177/1464884916673386.

Hanitzsch, T., \& Vos, T. P. (2017). Journalistic roles and the struggle over institutional identity: The discursive construction of journalism. Communication Theory, 27(2), 115-135. doi:10.1111/comt.12112.

Held, D. (1987). Models of democracy. Stanford, CA: Stanford University Press.

Hellmueller, L., \& Mellado, C. (2015). Professional roles and news construction: A media sociology conceptualization of journalists' role conception and performance. Communication \& Society, 28(3), 1-11. doi:10.15581/003.28.3.1-11.

Hellmueller, L., Vos, T. P., \& Poepsel, M. A. (2013). Shifting journalistic capital? Transparency and objectivity in the twenty-first century. Journalism Studies, 14(3), 287-304. doi:10.1080/1461670X.2012.697686

Hesse-Biber, S., Rodriguez, D., \& Frost, N. A. (2015). A qualitatively driven approach to multimethod and mixed methods research. In S. Hesse-Biber \& R. B. Johnson (Eds.), The Oxford handbook of multimethod and mixed methods research inquiry (pp. 3-20). New York, NY: Oxford University Press.

Hindman, E. B. (1997). Rights vs. responsibilities: The Supreme Court and the media. Westport, CT: Greenwood Press.

Hindman, E. B. (1998). "Spectacles of the poor": Conventions of alternative news. Journalism \& Mass Communication Quarterly, 75(1), 177-193. doi:10.1177/107769909807500117.

Hochschild, A. R. (1983). The managed heart: Commercialization of human feelings. Berkeley, CA: University of California Press.

Hodges, L. (1986). Defining press responsibility: A functional approach. In D. Elliot (Ed.), Responsible journalism (pp. 13-31). Newbury Park, CA: Sage. 
Hoyle, R. H. (2000). Confirmatory factor analysis. In H. E. A. Tinsley \& S. D. Brown (Eds.), Handbook of applied multivariate statistics \& mathematical modeling (pp. 465-497). San Diego, CA: Academic Press.

Jenkins, J. (2017). Low-stakes decisions and high-stakes delimmas: Considering the ethics decision-making of freelance magazine journalists. Journal of Media Ethics, 32(4), 188-201. doi:10.1080/23736992.2017.1359609.

Jepperson, R. L. (1991). Institutions, institutional effects, and institutionalism. In W. W. Powell \& P. J. DiMaggio (Eds.), The new institutionalism in organizational analysis (pp. 143-163). Chicago, IL: The University of Chicago Press.

Johnstone, J. W. C., Slawski, E. J., \& Bowman, W. W. (1972). The professional values of American newsmen. Public Opinion Quarterly, 36(4), 522-540. doi:10.1086/268036.

Jones, G. R. (1986). Socialization tactics, self-efficacy, and newcomers' adjustments to organizations. Academy of Management Journal, 29(2), 262-279. doi:10.2307/256188.

Josephi, B. (2013). How much democracy does journalism need? Journalism, 14(4), 474489. doi:10.1177/1464884912464172.

Kaplan, R. L. (2006). The news about new institutionalism: Journalism's ethic of objectivity and its political origins. Political Communication, 23(2), 173-185. doi:10.1080/10584600600629737.

Karppinen, K. (2013). Uses of democratic theory in media and communication studies. Observatorio, 7(3). Retrieved from: http://www.scielo.mec.pt/scielo.php?pid=S1646$59542013000300001 \&$ script $=$ sci_arttext\&tlng=pt.

Kovach, B., \& Rosenstiel, T. (2014). The elements of journalism ( $3^{\text {rd }}$ ed.). New York, NY: Three Rivers Press.

Kramer, M. W., \& Hess, J. A. (2002). Communication rules for the display of emotion in organizational settings. Management Communication Quarterly, 16(1), 6-80. doi:10.1177/0893318902161003.

Kramer, M. W., \& Miller, V. D. (1999). A response to criticisms of organizational socialization research: In support of contemporary conceptualizations of organizational assimilation. Communication Monographs, 66(4), 358-367. doi:10.1080/03637759909376485.

Kruml, S. M., \& Geddes, D. (2000). Exploring the dimensions of emotional labor: The heart of Hochschild's work. Management Communcation Quarterly, 14(1), 8-49. doi:10.1177/0893318900141002. 
Kvale, S. (1996). InterViews: An introduction to qualitative research interviewing. Thousand Oaks, CA: Sage.

Lambeth, E. B. (1998). Public journalism as a democratic practice. In E. B. Lambeth, P. E. Meyer, \& E. Thorson (Eds.), Assessing public journalism (pp. 15-35). Columbia, MO: University of Missouri Press.

Lowrey, W. (2011). Institutionalism, news organizations and innovation. Journalism Studies, 12(1), 64-79. doi:10.1080/1461670X.2010.511954.

Lynch, J., \& McGoldrick, A. (2005). Peace journalism. Gloucestershire, UK: Hawthorn Press.

Lynch, K. D. (2007). Modeling role enactment: Linking role theory and social cognition. Journal for the Theory of Social Behavior, 37(4), 379-400. doi:10.1111/j.14685914.2007.00349.x.

Maitlis, S., Vogus, T. J., \& Lawrence, T. B. (2013). Sensemaking and emotion in organizations. Organizational Psychology Review, 3(3), 222-247. doi:10.1177/2041386613489062.

Mandler, G. (1984). Mind and body: Psychology of emotion and stress. New York, NY: Norton.

Marshall, C., \& Rossman, G. B. (1995). Designing quality research. Thousand Oaks, CA: Sage.

McCracken, G. (1988). The long interview. Newbury Park, CA: Sage.

McChesney, R. W. (2013). Digital disconnect: How capitalism is turning the Internet against democracy. New York, NY: The New Press.

McGoldrick, A. (2011). Empathy and ethics: journalistic representation and its consequences. In I. S. Shaw, J. Lynch, \& R. A. Hackett (Eds.), Expanding peace journalism: Comparative and critical approaches (pp. 122-144). Sydney, Australia: Sydney University Press.

Mellado, C. (2015). Professional roles in news content: Six dimensions of journalistic role performance. Journalism Studies, 16(4), 596-614. doi:10.1080/1461670X.2014.922276.

Merrill, J. C. (1974). The imperative of freedom: A philosophy of journalistic autonomy. New York, NY: Hastings House.

Mill, J. S. (1859). On liberty. London, UK: Longman. 
Milton, J. (1644). Areopagitica. Retrived from:

https://www.dartmouth.edu/ milton/reading_room/areopagitica/text.html.

Moeller, S. D. (1999). Compassion fatigue: How the media sell disease, famine, war, and death. New York, NY: Routledge.

Morse, J. M. (2015). Issues in qualitatively-driven mixed-method designs: Walking through a mixed-method project. In S. Hesse-Biber \& R. B. Johnson (Eds), The Oxford handbook of multimethod and mixed methods research inquiry (pp. 206-222). New York, NY: Oxford University Press.

Murphy, A. (2013). Discursive frictions: Power, identity, and culture in an international working partnership. Journal of International and Intercultural Communication, 6(1), 1-20. doi:10.1080/17513057.2012.740683.

Myers, K. K., Jahn, J. L. S., Gailliard, B. M., \& Stoltzfus, K. (2011). Vocational anticipatory socialization (VAS): A communicative model of adolescents' interest in STEM. Management Communication Quarterly, 25(1), 87-120. doi:10.1177/0893318910377068.

Naqvi, F. (2014). Development and validation of emotional labour scale for teachers. IPE Journal of Management, 4(1), 1-20. Retrieved from http://proxy.mul.missouri.edu/login?url=https://search.proquest.com/docview/155960 4466 ? accountid $=14576$.

Nerone, J. (1995). Last rights: Revisiting four theories of the press. Urbana, IL: University of Illinois Press.

Nerone, J. (2013). The historical roots of the normative model of journalism. Journalism, 14(4), 446-458. doi:10.1177/1464884912464177.

Nicotera, A. M., \& Clinkscales, M. J. (2010). Nurses at the nexus: A case study in structurational divergence. Health Communication, 25(1), 32-49. doi:10.1080/10410230903473516.

O’Brien, H. L., \& Lebow, M. (2013). Mixed-methods approach to measuring user experience in online news interactions. Journal of the American Society for Information Science and Technology, 64(8), 1543-1556. doi:10.1002/asi.22871.

Pantti, M. (2010). The value of emotion: An examination of television journalists' notions on emotionality. European Journal of Communication, 25(2), 168-181. doi:10.1177/0267323110363653.

Pierson, P. (2004). Politics in time. Princeton, NJ: Princeton University Press. 
Pintak, L., \& Setiyono, B. (2011). The mission of Indonesian journalism: Balancing democracy, development, and Islamic values. The International Journal of Press/Politics, 16(2), 185-209. doi:10.1177/1940161210391784.

Preissle, J., Glover-Kudon, R., Rohan, E. A., Boehm, J. E., \& DeGroff, A. (2015). Putting ethics on the mixed methods map. In S. Hesse-Biber \& R. B. Johnson (Eds.), The Oxford handbook of multimethod and mixed methods research inquiry (pp. 144166). New York, NY: Oxford University Press.

Putnam, L. L., \& Mumby, D. K. (1993). Organizations, emotion and the myth of rationality. In S. Fineman (Ed.), Emotion in organizations ( $2^{\text {nd }}$ ed., pp. 36-57). Newbury Park, CA: Sage.

Rafaeli, A., \& Sutton, R. I. (1991). Emotional contrast strategies as means of social influence: Lessons from criminal interrogators and bill collectors. Academy of Management Journal, 34(4), 749-775. doi: 10.2307/256388.

Rosseel, Y. (2012). Lavaan: An R package for structural equation modeling. Journal of Statistical Software, 48(2), 1-36. URL: https://www.jstatsoft.org/article/view/v048i02

Roulston, K. (2010). Considering quality in qualitative interviewing. Qualitative Research, 10(2), 199-228. doi:10.1177/1468794109356739.

Ryan, K. M. (2009). The performative journalist: Job satisfaction, temporary workers and American television news. Journalism, 10(5), 647-664. doi:10.1177/1464884909106537.

Ryfe, D. (2006). The nature of news rules. Political Communication, 23(2), 203-214. doi:10.1080/10584600600629810.

Ryfe, D. (2012). Can journalism survive? An inside look at American newsrooms. Malden, MA: Polity Press.

Ryfe, D. (2016). News institutions. In T. Witschge, C. W. Anderson, D. Domingo, \& A. Hermida (Eds.), The Sage handbook of digital journalism (pp. 370-382). Thousand Oaks, CA: Sage .

Sale, J. E. M., Lohfeld, L. H., \& Brazil, K. (2002). Revisiting the quantitative-qualitative debate: Implications for mixed-methods research. Quality and Quantity, 36(1), 43-53. doi:10.1023/A:1014301607.

Schudson, M. (2008). Why democracies need an unlovable press. Malden, MA: Polity Press.

Schudson, M. (2011). The sociology of news ( $2^{\text {nd }}$ ed.). New York, NY: W. W. Norton \& Company. 
Schultz, T. (2002). Does education matter? Characteristics of journalists who went to graduation school. Journalism, 3(2), 223-238. doi:10.1177/146488490200300204.

Sewell, W. H. (1992). A theory of structure: Duality, agency, and transformation. American Journal of Sociology, 98(1), 1-29. doi:10.1086/229967.

Shannon-Baker, P. (2016). Making paradigms meaningful in mixed methods research. Journal of Mixed Methods Research, 10(4), 319-334. doi:10.1177/1558689815575861.

Shoemaker, P. J., \& Reese, S. D (1996). Mediating the message: Theories of influence on mass media content ( $2^{\text {nd }}$ ed.). White Plains, NY: Longman.

Shoemaker, P. J., \& Vos, T. P. (2009). Gatekeeping theory. New York, NY: Routledge.

Shoemaker, P. J., Vos, T. P., \& Reese, S. D. (2009). Journalists as Gatekeepers. In K. Wahl-Jorgensen \& T. Hanitzsch (Eds.), Handbook of Journalism Studies (pp.73-87). New York, NY: Routledge.

Siebert, F. S., Peterson, T., \& Schramm, W. (1963). Four theories of the press. Urbana, IL: University of Illinois Press.

Siegelbaum, S., \& Thomas, R. J. (2016). Putting the work (back) into newswork: Searching for the sources of normative failure. Journalism Practice, 10(3), 387-404. doi:10.1080/17512786.2015.1025415.

Singer, J. B. (2004). The resocialization of print journalists in converged newsrooms. Journalism \& Mass Communication Quarterly, 81(4), 838-856. doi:10.1177/107769900408100498.

Singer, J. B. (2017). Triangulating methods in the study of journalistic role performance. In C. Mellado, L. Hellmueller, \& W. Donsbach (Eds.), Journalistic role performance: Concepts, models, and measures (pp. 206-220). New York, NY: Routledge.

Small, M. L. (2011). How to conduct a mixed methods study: Recent trends in a rapidly growing literature. Annual Review of Sociology, 37, 57-86. doi:10.1146/annurev.soc.012809.102657.

Soronen, A. (2018). Emotional labour in magazine work: Suppressing and evoking emotions as part of project-based teamwork. Journalism Practice, 12(3), 290-307. doi:10.1080/17512786.2017.1297685.

Sparrow, B. H. (1999). Uncertain guardians: The news media as a political institution. London, UK: Johns Hopkins University Press. 
Spector, P. E., \& Jex, S. M. (1991). Relations of job characteristics from multiple data sources with employee affect, absence, turnover intentions, and health. Journal of Applied Psychology, 76(1), 46-53. doi:10.1037/0021-9010.76.1.46.

Stifter, C. (2014, July 1). For reporters covering stressful assignments, self-care is crucial. USC Annenberg Center for Health Journalism. Retrieved (March 29, 2018) from https://www.centerforhealthjournalism.org/resources/lessons/reporters-coveringstressful-assignments-self-care-crucial.

Sutton, K. (2017, January 11). Trump calls CNN "fake news," as channel defends its reporting on intelligence briefing. Politico. Retrieved (March 29, 2018) from https://www.politico.com/blogs/on-media/2017/01/trump-refusing-to-answerquestion-from-cnn-reporter-you-are-fake-news-233485.

Sutton, R. I., \& Rafaeli, A. (1988). Untangling the relationship between displayed emotions and organizational sales: The case of convenience stores. Academy of Management Journal, 31(3), 461-487. doi: 10.2307/256456.

Szpunar, P. S. (2012). Western journalism's “other": The legacy of the Cold War in the comparative study of journalism. Journalism, 16(3), 324-340. doi:10.1177/1464884911400845.

Tandoc, E. C. (2014). The roles of the game: The influence of news consumption patterns on the role conceptions of journalism students. Journalism \& Mass Communication Educator, 69(3), 256-270. doi:10.1177/1077695813520314.

Tandoc, E. C., Hellmueller, L., \& Vos, T. P. (2013). Mind the gap: Between journalistic role conception and role enactment. Journalism Practice, 7(5), 539-554. doi:10.1080/17512786.2012.726503.

Tandoc, E. C., \& Peters, J. (2015). One journalist, two roles: What happens when journalists also work as media coordinators? Journalism, 16(3), 324-340. doi:10.1177/1464884913520199.

Tandoc, E. C., \& Takahashi, B. (2013). Playing a crusader role or just playing by the rules? Role conceptions and role inconsistencies among environmental journalists. Journalism, 15(7), 889-907. doi:10.1177/1464884913501836.

Tandoc, E. C., \& Thomas, R. J. (2017). Readers value objectivity over transparency. Newspaper Research Journal, 38(1), 32-45. doi:10.1177/0739532917698446.

Tashakkori, A., \& Teddlie, C. (1998). Mixed methodology: Combining qualitative and quantitative approaches. London, UK: Sage. 
Tedlock, B. (2003). Ethnography and ethnographic representation. In N. K. Denzin \& Y. S. Lincoln (Eds.), Strategies of qualitative inquiry ( $2^{\text {nd }}$ ed., pp. 165-213). Thousand Oaks, CA: Sage.

Thomas, R. J. (2017). Helpfulness as journalism's normative anchor: Addressing blind spots and going back to basics. Journalism Studies. doi:10.1080/1461670X.2017.1377103.

Torrance, H. (2012). Triangulation, respondent validation, and democratic participation in mixed methods research. Journal of Mixed Methods Research, 6(2), 111-123. doi:10.1177/1558689812437185.

Tracy, S. J., Myers, K. K., \& Scott, C. (2006). Cracking jokes and crafting selves: Sensemaking and identity management among human service workers. Communication Monographs, 73(3), 283-308. doi:10.1080/03637750600889500.

Tracy, S. J., \& Trethewey, A. (2005). Fracturing the real-self $\leftarrow \rightarrow$ fake-self dichotomy: Moving toward "crystallized" organizational discourses and identities. Communication Theory, 15(2), 168-195. doi:10.1111/j.1468-2885.2005.tb00331.x.

Tuchman, G. (1972). Objectivity as strategic ritual: An examination of newsmen's notion of objectivity. American Journal of Sociology, 77(4), 660-679. doi:10.1086/225193.

Tunguz, S. (2016). In the eye of the beholder: Emotional labor in academia varies with tenure and gender. Studies in Higher Education, 41(1), 3-20.

doi:10.1080/03075079.2014.914919.

Van Damme, K., Courtois, C., Verbrugge, K., \& De Marez, L. (2015). What's APPening to news? A mixed-method audience-centred study on mobile news consumption. Mobile Media \& Communication, 3(2), 196-213. doi:10.1177/2050157914557691.

Van Maanen, J., \& Schein, E. H. (1979). Towards a theory of organizational socialization. In B. M. Staw (Ed.), Research in organizational behavior (pp. 209264). Greenwich, CT: JAI Press.

Vos, T. P., \& Wolfgang, J. D. (2016). Journalists' normative constructions of political viewpoint diversity. Journalism Studies. doi:10.1080/1461670X.2016.1240015.

Vos, T. P. (2017). Historical perspectives on journalistic roles. In C. Mellado, L. Hellmueller, \& W. Donsbach (Eds.), Journalistic role performance: Concepts, models, and measures (pp. 41-59). New York, NY: Routledge.

Wahl-Jorgensen, K. (2013). The strategic ritual of emotionality: A case study of Pulitzer Prize-winning articles. Journalism, 14(1), 129-145. doi:10.1177/1464884912448918. 
Wahl-Jorgensen, K. (2016). Emotion and journalism. In T. Witschge, C. W. Anderson, D. Domingo, \& A. Hermida (Eds.), The Sage handbook of digital journalism (pp. 128143). Thousand Oaks, CA: Sage.

Wahl-Jorgensen, K. (2018). Challenging presentism in journalism studies: An emotional life history approach to understanding the lived experience of journalists. Journalism. doi: $10.1177 / 1464884918760670$.

Waisbord, S. R. (2000). Watchdog journalism in South America. New York, NY: Columbia University Press.

Waisbord, S. R. (2013). Democracy, journalism, and Latin American populism. Journalism, 14(4), 504-521. doi:10.1177/1464884912464178.

Weaver, D. H., \& Wilhoit, G. C. (1986). The American journalist. A portrait of U.S. news people and their work. Bloomington, IN: Indiana University Press.

Weaver, D. H., \& Wilhoit, G. C. (1996). The American journalist in the 1990s: U.S. news people at the end of an era. Mahwah, NJ: Lawrence Erlbaum.

Weaver, D. H., Beam, R. A., Brownlee, B. J., Voakes, P. S., \& Wilhoit, G. C. (2007). The American journalist in the $21^{\text {st }}$ Century: U.S. news people at the dawn of a new millennium. Mahwah, NJ: Lawrence Erlbaum.

Weick, K. E. (1995). Sensemaking in organizations. Thousand Oaks, CA: Sage.

Welbers, K., Van Atteveldt, W., Kleinnijenhuis, J., Ruigrok, N., \& Schaper, J. (2016). News selection criteria in the digital age: Professional norms versus online audience metrics. Journalism, 17(8), 1037-1053. doi:10.1177/1464884915595474.

White, D. M. (1950). The "gate keeper" : A case study in the selection process. Journalism Bulletin, 27(4), 383-390. doi:10.1177/107769905002700403.

Wieland, S. M. B. (2010). Ideal selves as resources for the situated practice of identity. Management Communication Quarterly, 24(4), 503-528. doi:10.1177/089331890374938.

Wiik, J. (2015). Internal boundaries: The stratification of the journalistic collective. In M. Carlson \& S. C. Lewis (Eds.), Boundaries of journalism: Professionalism, practices and participation (pp. 118-134). New York, NY: Routledge.

Yin, R. (2006). Mixed methods research: Are the methods genuinely integrated or merely parallel. Research in the Schools, 13(1), 41-47.

Yin, R. (2011). Qualitative research from start to finish ( $2^{\text {nd }}$ ed.). New York, NY: The Guilford Press. 
Zelizer, B. (2013). On the shelf life of democracy in journalism scholarship. Journalism, 14(4), 459-473. doi:10.1177/1464884912464179.

Zeller, F., O'Kane, J., Godo, E., \& Goodrum, A. (2014). A subjective user-typology of online news consumption. Digital Journalism, 2(2), 214-231. doi:10.1080/21670811.2013.801686. 


\section{Appendices}

\section{Appendix A - Survey Items}

A. Journalistic role conceptions - "Please tell me, on a scale of 1 to 5, how much do you agree with the following items as they pertain to your role as a political journalist. One means you strongly disagree with the item, 2 means you moderately disagree, 3 means you neither agree nor disagree, 4 means you moderately agree and 5 means you strongly agree."

1. Investigate official claims

2. Provide an analysis of events in the news

3. Critique political and business leaders

4. Facilitate in the advancement of social development, even if this means collaborating with government.

5. Defend the government and its policies

6. Encourage people to participate in civic activity

7. Educate the audience on public problems

8. Improve communication between officials and citizens

9. Reduce social tension in my community

10. Provide the audience with a forum to express their views

11. Serve as the mouthpiece of the people

12. Serve as a critical observer of political conduct

13. Tell people about issues they should believe in

14. Advocate for social change

15. Curate information for my readers

16. Report things as they are

17. Provide an explanation of the news

18. Serve as a mouthpiece for the socially disadvantaged.

B. Micro-Level Factors - "Please tell me, on a scale of 1 to 5, how much do you agree with the following items as they pertain to your role as a political journalist. One means you strongly disagree with the item, 2 means you moderately disagree, 3 means you neither agree nor disagree, 4 means you moderately agree and 5 means you strongly agree. Please, read the statement below and assess each item individually as if it were filling in the blank in the statement. If the item does not pertain to your work experiences, select N/A."

Statement: Sometimes___ [fill in the blank]__ inhibit(s) me from performing my role as a political journalist.

1. my own moral compass

2. my religion

3. personal obligations

4. pressure from family

5. pressure from friends 
C. Meso-Level Factors - "Please tell me, on a scale of 1 to 5, how much do you agree with the following items as they pertain to your role as a political journalist. One means you strongly disagree with the item, 2 means you moderately disagree, 3 means you neither agree nor disagree, 4 means you moderately agree and 5 means you strongly agree. Please, read the statement below and assess each item individually as if it were filling in the blank in the statement. If the item does not pertain to your work experiences, select N/A."

Statement: Sometimes__fill in the blank]_ inhibit(s) me from performing my role as a political journalist.

1. pressure from colleagues

2. the editorial process

3. a lack of time

4. a lack of money

5. a lack of resources (not time or money)

6. deadlines

7. collaboration

8. social media obligations

9. my organization's emphasis on profits

10. pressure from my editor

11. my organization's focus on audience metrics

D. Macro-Level Factors - "Please tell me, on a scale of 1 to 5, how much do you agree with the following items as they pertain to your role as a political journalist. One means you strongly disagree with the item, 2 means you moderately disagree, 3 means you neither agree nor disagree, 4 means you moderately agree and 5 means you strongly agree. Please, read the statement below and assess each item individually as if it were filling in the blank in the statement. If the item does not pertain to your work experiences, select N/A."

Statement: Sometimes [fill in the blank] inhibit(s) me from performing my role as a political journalist.

12. laws and regulations

13. inaccessibility of government officials

14. inaccessibility of business representatives

15. pressure from government officials

16. pressure from advertisers

17. pressure from business representatives

18. pressure from public relations practitioners

19. pressure from interest groups 
D. Emotional Labor - "Please tell me on a scale of 1 to 5, how often do you experience each of the items below. One means you never experience an item, 2 means you rarely experience the item, 3 means you sometimes experience the item, 4 means you often experience the item and 5 means you always experience the item."

Deep Acting:

1. On a personal level, I make an effort to actually feel the emotions that I need to display to others

2. I really try to feel the emotions I have to show as part of my job

3. When getting ready for work, I tell myself that I am going to have a good day

Surface Acting:

4. I put on a mask in order to express the right emotions for the job

5. The emotions I show match what I truly feel ${ }^{2}$

6. I hide my true feelings about a situation

2 This item is reverse coded 


\section{Appendix B - Interview Protocol}

\section{A. Introduction}

1. To start off the conversation, please briefly tell me about yourself.

\section{B. Normative and Cognitive Roles}

2. How would you describe your role as a political journalist?

3. What are the most important tasks you complete as part of this role?

4. Why do you consider this role to be important?

\section{Factors of Influence and Role Conflict}

5. What roles do you play outside of your work as a journalist?

6. Can you tell me about a time when you felt that any of those other roles were at odds with your role as a journalist?

7. How did you manage that conflict?

8. Can you think of a time when someone or something else within your organization challenged your ability to practice your role as a journalist? What happened?

9. Tell me about a time when you felt like your role as a political journalist was threatened because of someone or something else outside of journalism.

10. Can you tell me about a situation where you felt pressure to carryout tasks that are contradictory or different than what you felt you should be doing?

11. Have these challenges ever stopped you from doing your job the way you wanted to do it? How so?

\section{Sensemaking and Emotion}

12. Knowing that these challenges influence the way you perform, how well do you believe your work matches the role you play?

13. As you reflect on the challenges to your work, what emotions come to mind?

14. How do you manage those emotions?

15. Do you believe they have influenced the way you think about your role? How so?

16. Tell me about a time you had to hide your emotions at work.

17. Do you believe that emotion helps or hinders your ability to fulfill your role as a political journalist? Why?

\section{E. Ending Remarks}

18. Is there anything we haven't covered that you would like to add? 


\section{Appendix C - Survey Recruitment Letter}

Dear [recipient first name],

My name is Kimberly Kelling, and I am a doctoral candidate at the Missouri School of Journalism. I am conducting research on role conceptions, democracy and workplace influences within political reporting for my dissertation. I am inviting you to participate in a brief survey because of your position as a political journalist. Your participation in this survey will be incredibly valuable in developing an understanding of the factors that, perhaps, inhibit you from fulfilling your journalistic role.

The survey asks about how you conceive of your job as a political journalist and information on work and life influences that may impact your work, in addition to some basic demographic questions. The survey should take no more than 30 minutes to complete. If you agree to participate, you will have the option to opt in to a follow-up interview. Findings from the survey and interviews will provide invaluable insights that can enhance journalism education and training. Please be assured that your survey and interview responses will both be kept completely confidential throughout the research and reporting process.

If you have any questions about this study, you can reach me at kaf7bf@mail.missouri.edu.

Follow this link to the survey:

[Survey link]

Kimberly Kelling, Doctoral Candidate

Missouri School of Journalism 


\section{Appendix D - Survey Consent Form}

\section{CONSENT FOR PARTICIPATION IN RESEARCH}

Project Title: "Conceptions of democracy and roles in U.S. political journalism" Principal Investigator: Kimberly Kelling, Doctoral Candidate, Missouri School of Journalism

You are invited to take part in a research survey about roles of political journalists in the United States. Your participation will require approximately 30 minutes and is completed online at your computer. There are no known risks or discomforts associated with this survey, but your participation will help advance our understanding of how political journalists view their role in society and what factors, if any, inhibit them from fulfilling those roles.

At the end of the survey, you will have the opportunity to opt-in to follow-up interviews. Interviews will take place between 1/2/18-3/1/18 and should last no longer than 45 minutes. All interviews will be conducted on phone or video platforms. Interviews will further inform our understanding of how journalists manage conflict and emotion while on the job. Findings from the survey and interviews will have practical implications for journalism education and training.

Please be assured that your responses will be kept completely confidential. Taking part in this survey is completely voluntary. If you choose to be in the study, you can withdraw at any time, for any reason, and without any prejudice. If you have any questions regarding the research, please contact the Principal Investigator, Kimberly Kelling, at kaf7bf@mail.missouri.edu, or Dr. Ryan J. Thomas, advisor, at thomasrj@missouri.edu.

You may contact the Campus Institutional Review Board if you have questions about your rights, concerns, complaints or comments as a research participant. You can contact the Campus Institutional Review Board directly by telephone or email to voice or solicit any concerns, questions, input or complaints about the research study at (573) 882-9585, email: umcresearchcirb@missouri.edu.

By clicking on the button below, you acknowledge that your participation in the study is voluntary, you are at least 18 years of age, and that you are aware that you may choose to terminate your participation in the study at any time and for any reason.

Please note, this survey will be best displayed on a laptop or desktop computer. Some features may be less compatible for use on a mobile device.

- I consent, begin the study

- I do not wish to participate 


\section{Appendix E}

Description of Interview Participants

\begin{tabular}{|c|c|c|c|}
\hline Participant & Title & Medium & $\begin{array}{c}\text { Years in } \\
\text { Journalism }\end{array}$ \\
\hline 1 & Political columnist & Newspaper & +25 \\
\hline 2 & Executive producer & Audio/podcasting & 19 \\
\hline 3 & Production assistant & Broadcast/TV & 4 \\
\hline 4 & Host and publisher & Online/broadcast & 20 \\
\hline 5 & Chief political correspondent & Wire service and print & +25 \\
\hline 6 & Municipal government reporter & Newspaper & 3 \\
\hline 7 & Statehouse bureau chief & Radio & 9 \\
\hline 8 & Host & Broadcast/TV & 20 \\
\hline 9 & Staff writer & Newspaper & 2 \\
\hline 10 & Government watchdog reporter & Newspaper & 5 \\
\hline 11 & Statehouse reporter & Newspaper & 11 \\
\hline 12 & Reporter & Newspaper & 8 \\
\hline 13 & Election correspondent & Wire service & 9 \\
\hline 14 & Reporter & Newspaper & 6 \\
\hline 15 & Editor & Online newspaper & 22 \\
\hline 16 & Chief political reporter & Broadcast/TV & +25 \\
\hline 17 & Staff writer & Online & 4 \\
\hline 18 & City/county government reporter & Newspaper & 2 \\
\hline 19 & Freelancer & Newspaper and magazine & +25 \\
\hline 20 & Editor & Online & 10 \\
\hline 21 & Reporter & Online & 9 \\
\hline
\end{tabular}




\section{Appendix F - CFA Model of Journalistic Role Conceptions}

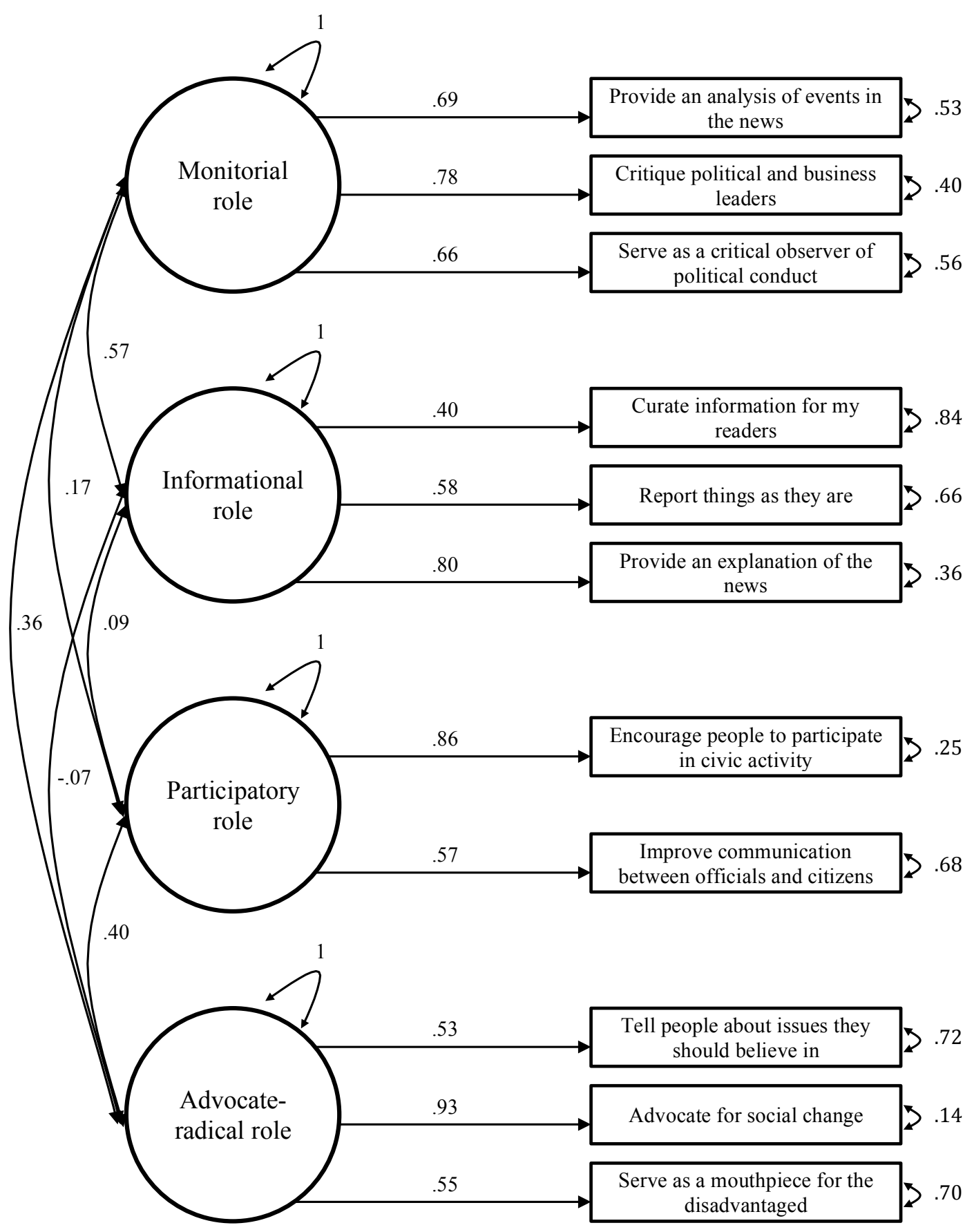




\section{Appendix G - CFA Model of Challenges to the Role Enactment Process}

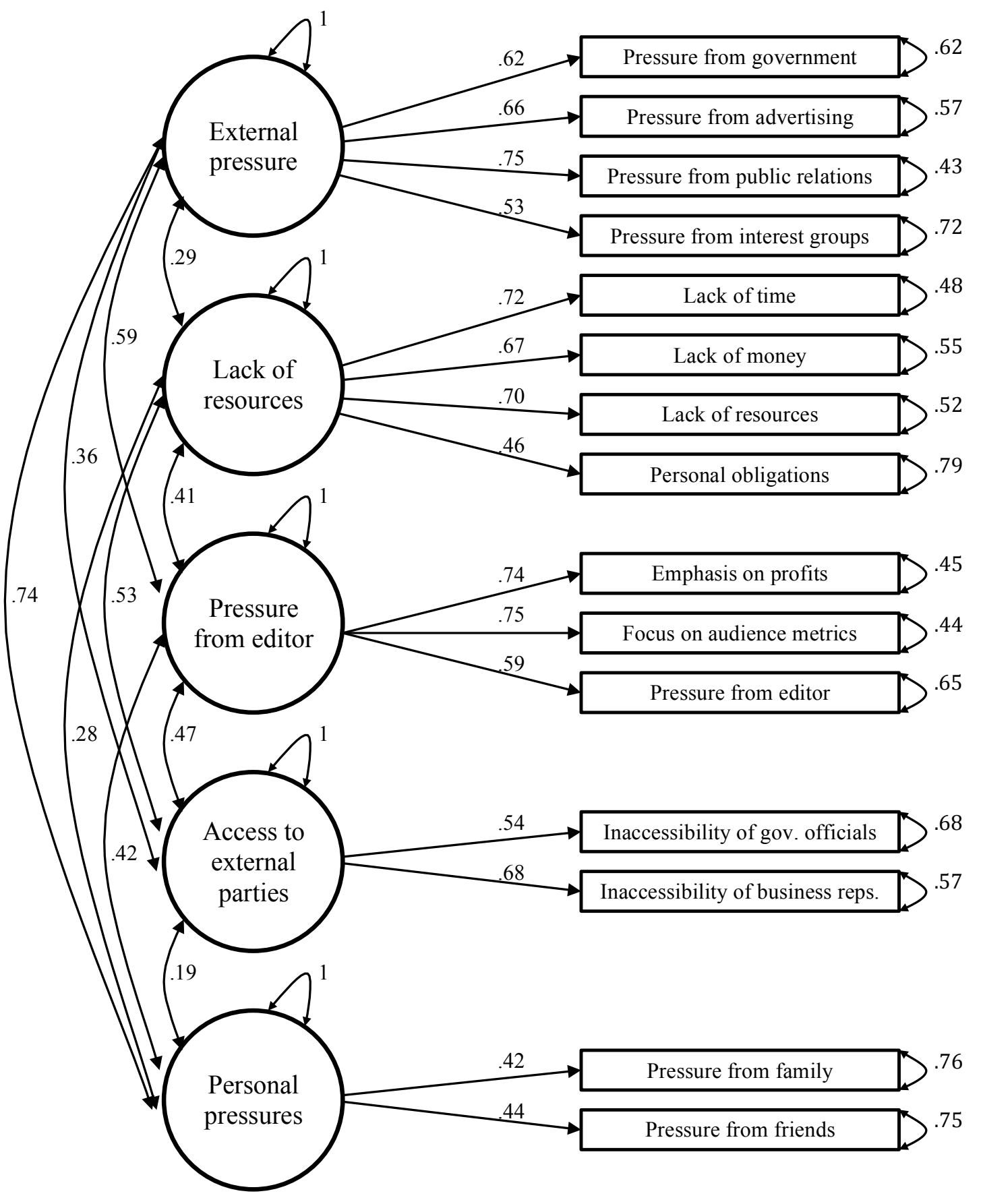


Kimberly Kelling will be an assistant professor of journalism in the College of Letters and Science at the University of Wisconsin Oshkosh. In Fall 2018, she will teach Principles of Public Relations; Principles of Advertising; and Ad Copy, Layout, and Production. Her research focuses on organizational and sociological processes that affect the construction of news. She hopes to expand her research agenda to explore role conceptions of strategic communicators, as well as how public relations and advertising professionals make sense of role conflict in the workplace.

Before working on her doctorate at the University of Missouri, Kelling worked as a marketing director for a financial company outside of Chicago. She oversaw all marketing operations for the company, which included anything from creative branding and logo generation, to leading training sessions for managers on internal communication and change management best practices. Kelling also worked as a freelance marketing and management consultant, providing creative solutions for small, mid-size, and non-profit organizations.

In 2011, she received her bachelor's of journalism and bachelor's of science in business administration from the University of Missouri. During her undergraduate, she served as the public relations coordinator for a local non-profit entertainment company that brings live music to Columbia, Missouri. She received her master's degree in communication from Northwestern University in 2012. 